Universidad de Lima

Facultad de Ingeniería y Arquitectura

Carrera de Ingeniería Industrial

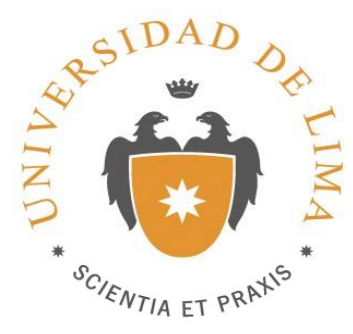

\title{
MEJORA DE LA GESTIÓN DE ABASTECIMIENTO DE LA TIENDA MAYORISTA PROVEEDORES DE ABARROTES SANTA ANA S.R.L. EN LA CIUDAD DE CHICLAYO
}

Trabajo de investigación para optar el título profesional de Ingeniero Industrial

Ana Stephany Montenegro Campos

Código 20100738

Oscar Álvaro Camacho Holguín

Código 20101395

\author{
Asesor \\ José Antonio Táquia Gutiérrez
}

Lima-Perú

Noviembre de 2017 


\section{MEJORA DE LA GESTIÓN DE ABASTECIMIENTO DE LA TIENDA MAYORISTA PROVEEDORES DE ABARROTES SANTA ANA S.R.L. EN LA CIUDAD DE CHICLAYO}




\section{TABLA DE CONTENIDO}

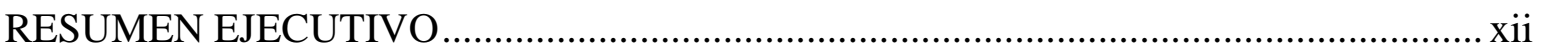

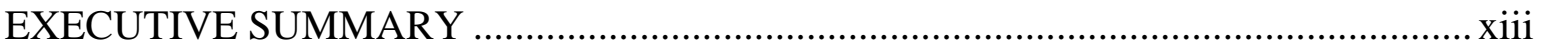

CAPÍTULO I : CONSIDERACIONES GENERALES DE LA INVESTIGACIÓN ............ 1

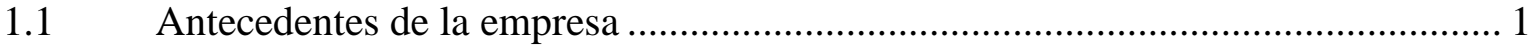

1.1.1. Breve descripción de la empresa y reseña histórica ...................................... 1

1.1.2. Descripción de los productos o servicios ofrecidos .................................... 3

1.1.3. Descripción del mercado objetivo de la empresa ..................................... 4

1.1.4. Estrategia general de la empresa............................................................ 4

$1.2 \quad$ Objetivos de la investigación. ................................................................. 5

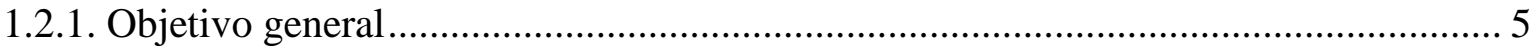

1.2.2. Objetivos Específicos ...................................................................... 5

1.3 Alcance y limitaciones de la investigación ................................................. 6

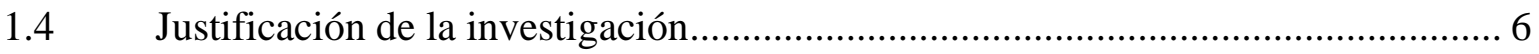

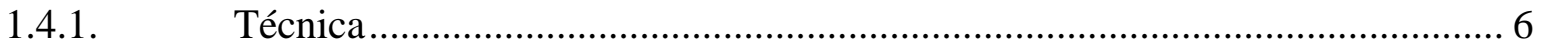

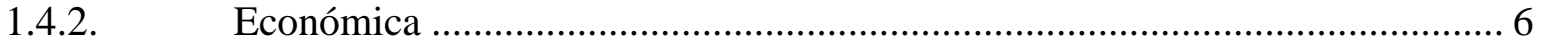

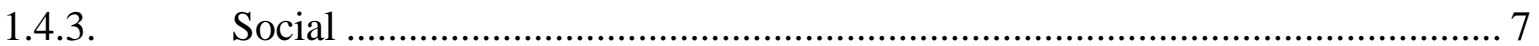

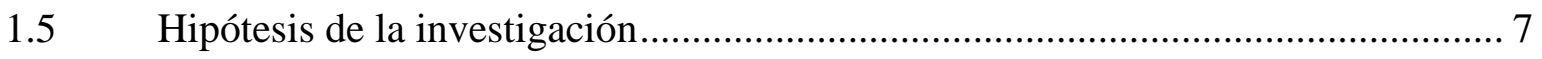

1.6 Marco referencial de la investigación. .......................................................... 7

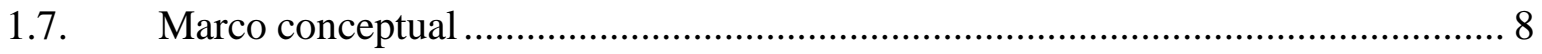

CAPITULO II: ANÁLISIS SITUACIONAL DE LA EMPRESA Y SELECCIÓN DEL

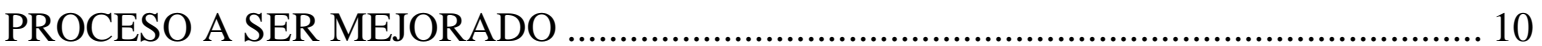

2.1 Análisis externo de la empresa.................................................................. 10

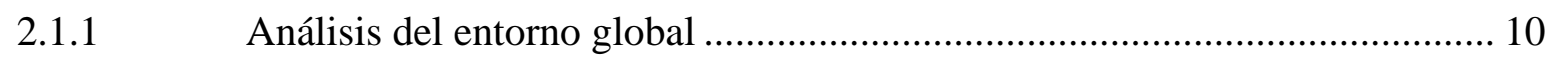

2.1.2 Análisis del entorno competitivo y del mercado ..................................... 12

2.1.3. Identificación y evaluación de las oportunidades y amenazas del entorno ... 15

2.2 Análisis interno de la empresa ................................................................ 16

2.2.1 Análisis del direccionamiento estratégico: visión, misión y objetivos organizacionales 16 
2.2.2 Análisis de la organización y estructura organizacional............................... 17

2.2.3 Identificación de los procesos más importantes ............................................ 17

2.2.4 Análisis de los indicadores generales de desempeño de los procesos claves 19

2.2.5 Determinación de posibles oportunidades de mejora .................................... 25

2.2.6 Selección del sistema o proceso a mejorar ………………………………..... 25

CAPÍTULO III: DIAGNÓSTICO DE LA EMPRESA ………………………………..... 27

3.1 Análisis del sistema o proceso objeto de estudio ……………………………...... 27

3.1.1. Caracterización detallada del sistema o proceso objeto de estudio ............................ 27

3.1.2. Análisis de los indicadores específicos de desempeño del sistema o proceso............ 33

3.2 Determinación de las causas raíces de los problemas seleccionados .............................. 33

3.2.1. Análisis de los factores que influyen favoreciendo o limitando los resultados

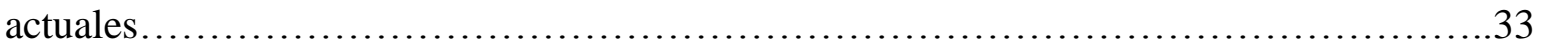

3.2.2. Identificación y evaluación de las fortalezas y debilidades de la empresa .................. 41

3.3. Determinación de objetivos del trabajo de investigación ................................................. 41

CAPÍTULO IV : DETERMINACIÓN DE LA PROPUESTA DE SOLUCIÓN .................. 43

4.1. Planteamiento de alternativas de solución a la problemática encontrada .............. 43

4.2. Selección de alternativas de solución....................................................................... 45

4.2.1. Determinación y ponderación de criterios evaluación de las alternativas ................... 45

4.2.2. Evaluación cualitativa y cuantitativa de alternativas de solución................................ 46

4.2.3. Priorización y programación de soluciones seleccionadas .......................................... 54

CAPITULO V: IMPLEMENTACIÓN DE LA SOLUCIÓN PROPUESTA ........................ 56

5.1. Ingeniería de la solución ............................................................................................ 56

5.2. Planificación de la implementación de la solución...................................................... 101

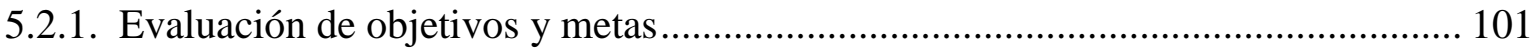

5.2.2. Elaboración del presupuesto general requerido para la ejecución de la solución.... 103

CAPÍTULO VI: EVALUACIÓN DE LA PROPUESTA Y BENEFICIOS SOCIALES . 106

6.1. Determinación de escenarios que afectarían la solución......................................... 106

6.2. Evaluación económica financiera de la solución ................................................. 108

6.3. Análisis del impacto social y ambiental de la solución......................................... 110

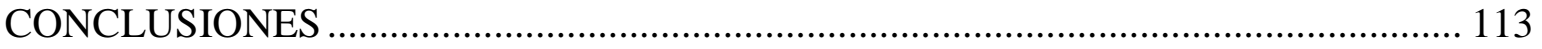

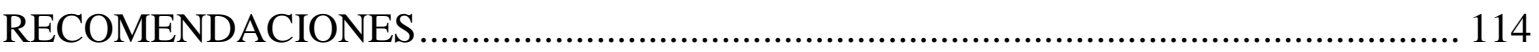




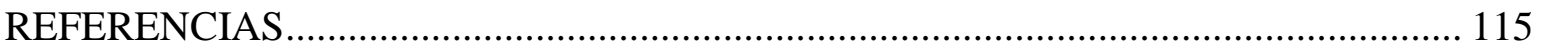

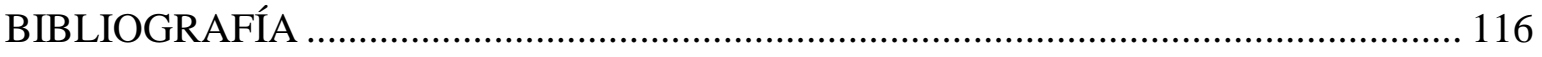

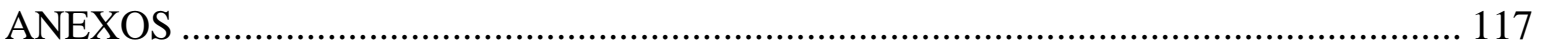




\section{ÍNDICE DE TABLAS}

Tabla 1. 1.Alcance y limitación de las actividades ..................................................... 6

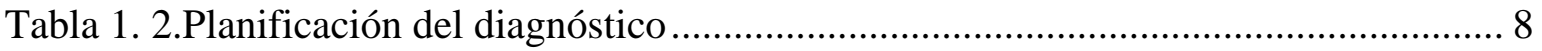

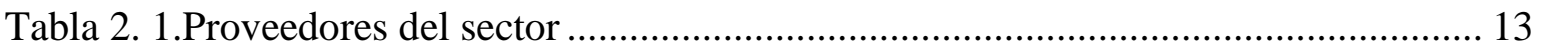

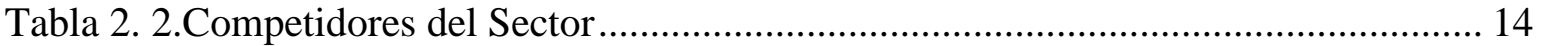

Tabla 2. 3.Motivos de ventas perdidas ...................................................................... 19

Tabla 2. 4.Ticket promedio de compra de clientes .................................................. 20

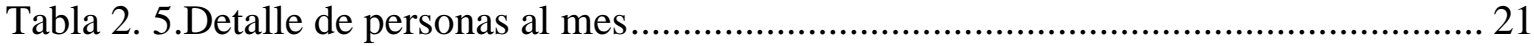

Tabla 2. 6.Detalle de costo de almacenamiento........................................................... 22

Tabla 2. 7.Gastos por daños, conservación o vencimiento de productos Enero - Agosto

2016

Tabla 2. 8.Motivos de gastos por daños, conservación o vencimiento de productos .......... 24

Tabla 2. 9.Resumen de indicadores de la empresa ..................................................... 26

Tabla 3. 1.Análisis de las causas del costo de política de almacenamiento ....................... 36

Tabla 3. 2.Análisis de las causas de gastos por daños y vencimiento de productos ........... 38

Tabla 3. 3.Análisis de causas - Gastos de transporte entre almacenes ............................ 40

Tabla 4. 1.Matriz de enfrentamiento de factores ................................................................ 45

Tabla 4. 2. Escala de factores ...................................................................................... 46

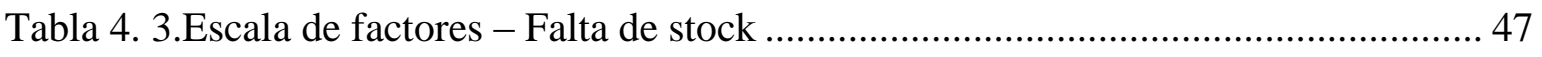

Tabla 4. 4.Escala de factores - Falta de precios competitivos ....................................... 48

Tabla 4. 5.Escala de factores - Ausencia de productos demandados ................................ 49

Tabla 4. 6.Escala de factores - Falta de control de caducidad ........................................ 50

Tabla 4. 7.Escala de factores - Cuidados inadecuados en los traslados ........................... 51

Tabla 4. 8.Escala de factores - Falta de control de plagas .............................................. 52

Tabla 4. 9.Escala de factores - Mala distribución entre almacenes ................................... 53

Tabla 4. 10.Escala de factores - Falta de Capacidad en almacén central......................... 54

Tabla 5. 1. Unidades agregadas de productos por línea................................................ 57

Tabla 5. 2. Pronóstico de la demanda 2016 de aceites en cajas agregadas ......................... 59

Tabla 5. 3. Pronóstico de la demanda 2016-2017 de fideos en cajas agregadas ................ 59 


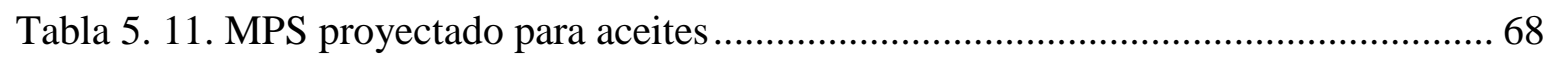

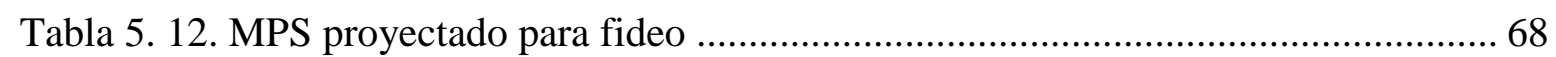

Tabla 5. 13. Resumen de pedidos 2016 real - 2016 optimizado ................................... 69

Tabla 5. 14. Inventario máximo de cada línea de producto ............................................ 70

Tabla 5. 15. Descuento de proveedores por pedidos anuales ....................................... 70

Tabla 5. 16. Productos demandados no vendidos - motivos y efectos............................ 71

Tabla 5. 17. Criterios limitantes para la capacidad de parihuelas................................... 85

Tabla 5. 18. Número de productos por parihuela ........................................................ 85

Tabla 5. 19. Capacidad por producto de cada almacén .................................................. 86

Tabla 5. 21. Análisis ABC de las líneas de productos ................................................... 87

Tabla 5. 22. Distribución interna de los productos en el almacén central ......................... 88

Tabla 5. 23. Distribución interna de los productos en el almacén auxiliar......................... 89

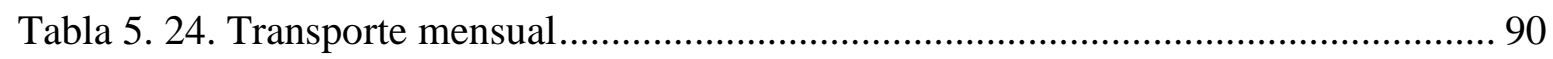

Tabla 5. 25. Viajes del camión al mes ..................................................................... 91

Tabla 5. 26. Medidas para la manipulación de productos .............................................. 96

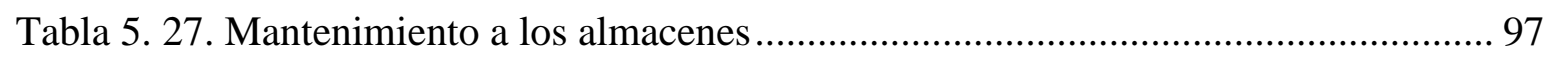

Tabla 5. 31. Presupuesto anual requerido ............................................................... 104

Tabla 5. 32. Cronograma de implementación ............................................................ 105

Tabla 6. 1. Escenarios de las soluciones propuestas ..................................................... 107

Tabla 6. 2. Análisis económico de la propuesta ......................................................... 108

Tabla 6. 3. Indicadores de evaluación económica ....................................................... 109

Tabla 6. 4. Descripción escenarios optimista y pesimista ............................................... 109

Tabla 6. 5. Resultados económicos de los escenarios.................................................. 109

Tabla 6. 6. Matriz de Leopold....................................................................................... 111 


\section{ÍNDICE DE FIGURAS}

Figura 1. 1. Logo de la empresa............................................................................... 3

Figura 1. 2. Matriz de Ansoff .................................................................................. 5

Figura 2. 1. Índice de competitividad regional de Lambayeque ...................................... 10

Figura 2. 2. Índice de Competitividad Regional de Lambayeque 2016 en detalle ............. 11

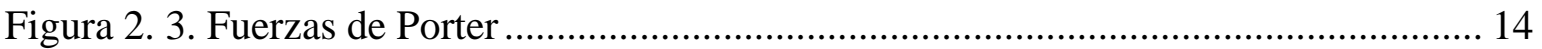

Figura 2. 4. Detalle de ventas mensuales 2015 - 2016 ................................................. 21

Figura 2. 5.Costo total de política de almacenamiento................................................ 22

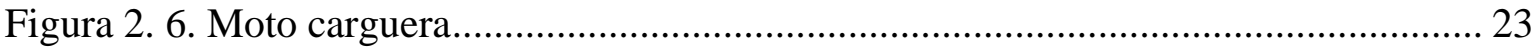

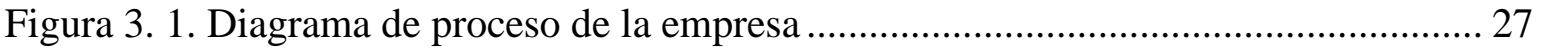

Figura 3. 2.Diagrama del proceso que el cliente realiza para comprar........................... 30

Figura 3. 3. Diagrama de Ishikawa - costo de política de almacenamiento ...................... 35

Figura 3. 4. Diagrama de Pareto - Costo de política de almacenamiento ......................... 36

Figura 3. 5. Diagrama de Ishikawa - Gastos por daños y vencimiento de productos ......... 37

Figura 3. 6.Diagrama de Pareto - gastos por daños y vencimiento de productos .............. 38

Figura 3. 7.Diagrama de Ishikawa - Gastos de transporte entre almacenes...................... 39

Figura 3. 8. Diagrama de Pareto - Gastos de transporte dentre almacenes ....................... 40

Figura 4. 1. Soluciones a los problemas principales de costo de política de almacenamiento

Figura 4. 2. Soluciones a los problemas principales de gastos por daños y vencimiento de productos.

Figura 4. 3. Soluciones a los problemas principales de gastos de transporte entre almacenes

Figura 5. 1. Demanda histórica y pronóstico - Aceites ................................................. 58

Figura 5. 2. Demanda histórica y pronóstico - Fideos ................................................... 58

Figura 5. 3.Demanda 2016 - Fideos y Aceites .............................................................. 60

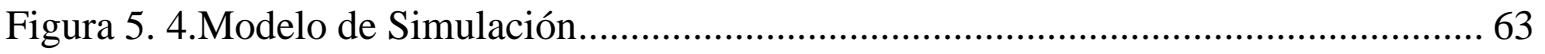

Figura 5. 5.Primera parte del modelo - Atención de la demanda .................................... 64 
Figura 5. 6. Segunda parte del modelo-Abastecimiento en función al estimado. 64

Figura 5. 7. Plano de primer piso de almacén central original ...................................... 73

Figura 5. 8. Plano de mezzanines de almacén central original ...................................... 74

Figura 5. 9. Plano de segundo piso de almacén central original .................................... 75

Figura 5. 10. Plano de tercer piso de almacén central original ...................................... 76

Figura 5. 11. Plano de almacén auxiliar- sector 1 ..................................................... 77

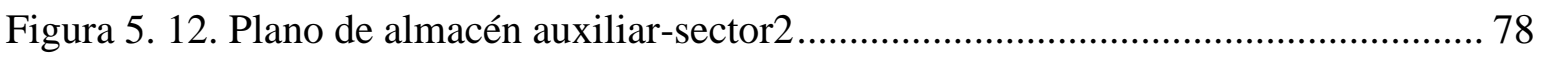

Figura 5. 13. Plano de primer piso de almacén central mejorado................................... 79

Figura 5. 14. Plano de mezzanines de almacén central mejorado .................................... 80

Figura 5. 15. Plano de segundo piso de almacén central mejorado ................................. 81

Figura 5. 16. Plano de tercer piso de almacén central mejorado ..................................... 82

Figura 5. 17. Plano del almacén auxiliar - sector 1 mejorado ....................................... 83

Figura 5. 18. Plano de almacén auxiliar -sector 2 mejorado........................................ 84

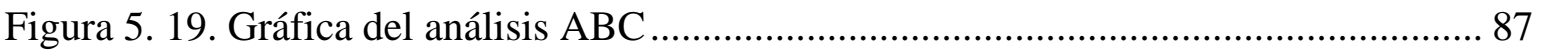

Figura 5. 20. Camión de 6.5 toneladas ............................................................................... 90

Figura 5. 21. Mezzanine propuesto ....................................................................... 92

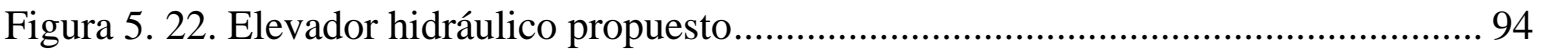

Figura 5. 23. Máximo de carga manual .................................................................... 95

Figura 5. 24. Plan de mantenimiento - fumigación de plagas........................................ 98

Figura 5. 25.Plan de mantenimiento - control de roedores ......................................... 99

Figura 5. 26. Plan de mantenimiento - limpieza general de almacén ............................ 100

Figura 6. 1. Magnitud e impacto ambiental del proyecto ............................................. 112 


\section{ÍNDICE DE ANEXOS}

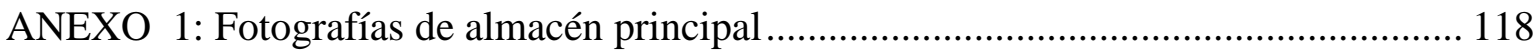

ANEXO 2: Fotografías de almacén auxiliar........................................................... 118

ANEXO 3: Entrevista al encargado de almacén central ............................................ 118

ANEXO 4: Entrevista a la encargada de ventas ..................................................... 118 


\section{RESUMEN EJECUTIVO}

El proyecto de mejora se centra en el sistema de abastecimiento de la empresa Proveedores de Abarrotes Santa Ana S.R.L. (PROASA) de la ciudad de Chiclayo, la cual se dedica a la venta al por mayor de productos de consumo masivo.

Después de haber analizado los principales indicadores de la empresa, se determinó que se tenía una oportunidad de mejora en reducir principalmente el costo de oportunidad por ventas perdidas; además, se podía optimizar el gasto por transporte desde el almacén auxiliar que la empresa ya posee debido a la falta de espacio en su almacén principal y el gasto por daños, conservación o vencimiento de productos. Todo esto no permite a la empresa percibir S/. 312,288 al año. Por ello, se propusieron soluciones para los problemas principales, los cuales fueron mejorar la distribución entre almacenes, realizar compras en mayor volumen, ampliar la cartera de productos, realizar un plan de control de vencimiento de productos, controlar la manipulación de productos, implementar plan de limpieza de almacenes, elaborar plan de pedidos y cambiar la distribución de la cantidad de productos entre los almacenes.

Según los cálculos realizados, se determina que para implementar las soluciones se requiere de una inversión S/. 151,140 los cuales se recuperarán en 0.76 años después de haberlas implementado, obteniendo un valor actual neto de S/. 297,170 al cabo de 3 años. 


\section{EXECUTIVE SUMMARY}

The improvement project is focused on the supply chain managemente of Proveedores de Abarrotes Santa Ana S.R.L. (PROASA) from Chiclayo, which is dedicated to the wholesale of consumer products.

After analyzing the main indicators of the company, it was determined that there is an opportunity in reducing lost sales cost. In addition, it was possible to optimize the transport expense from the auxiliary warehouse that the company already owns because the lack of space from main warehouse and the expense for damages, conservation or expiration of products. All this does not allow the company to receibe S /. 312,288 each year. For this reason, possible solutions are proposed in order to resolve main problems: at the first place the improvement of the distribution between warehouses, to make purchases in greater volume, to expand the product portfolio, to carry out a control plan of products expiration, to control the handling process of products, to implement a cleaning plan of warehouses and to elaborate a purchasing order plan.

According to the calculations made, it is determined that to implement the solutions requires an investment $\mathrm{S} /$. 151,140 which will be recovered in 0.76 years after being implemented, obtaining a net present value of S /. 297,170 after 3 years. 


\section{CAPÍTULO I : CONSIDERACIONES GENERALES DE LA INVESTIGACIÓN}

\subsection{Antecedentes de la empresa}

\subsubsection{Breve descripción de la empresa y reseña histórica}

La empresa "Proveedores de Abarrotes Santa Ana S.R.L" fue fundada por el señor Edilberto Montenegro Dávila y su esposa, la señora Sara Campos Gálvez en el año 2002. Desde entonces, se dedica a la venta mayorista de abarrotes en un único punto de venta en la ciudad de Chiclayo el cual se encuentra ubicado en una de las zonas más comerciales de esta localidad. Asimismo, cuenta con un almacén auxiliar en donde se guarda parte de la mercadería a vender a poca distancia del local comercial.

Tiene un portafolio variado de productos a la venta que son transportados de la ciudad de Lima y de localidades cercanas. El sistema de almacenamiento que se utiliza en los almacenes es de entrepisos y mezzanines lo cual permite generar y maximizar el espacio útil de la edificación, pudiendo destinar estos espacios a diferentes productos facilitando la labor de los encargados de despacho. Este tipo de almacenamiento es ideal cuando se tiene una alta variedad de productos y pedidos de los mismos. (Mora, 2011). Es importante mencionar que la estiba y desestiba de los productos se realiza manualmente, es decir, los operarios de almacén cargan los productos sin ayuda de carretillas o montacargas debido a que la empresa no cuenta con ellos.

Por otro lado, se puede reconocer que se cuenta con un tipo de proceso para abastecer los almacenes el cual es el de tipo push debido a que la empresa se anticipa al pedido de sus clientes, es decir, la empresa realiza las compras de mercadería según sus proyecciones de demanda no por pedidos realizados por los clientes. Estos conceptos se definen en las siguientes líneas: 
"Los procesos de pull inician la ejecución con respuesta a un pedido del cliente, en tanto los procesos push inician la ejecución con anticipación a los pedidos de los clientes basados en un pronóstico. Los procesos pull también se conocen como procesos reactivos porque responden a la demanda del cliente, los procesos push también se conocen como procesos especulativos porque responden a una demanda especulada(o pronosticada) en vez de a la real."(Chopra, Meindl, Navarro y Murrieta, 2013)

Por otro lado, es importante resaltar que segun lo mencionado por el encargado del almacén (Ver Anexo 3), la empresa realiza sus proyecciones de la demanda mediante un método cualitativo. A juicio de experto se determina cuánta mercadería se debe comprar al mes.

"Ponósticos Cualitativos: Los métodos cualitativos son principalmente subjetivos y se apoyan en el juicio humano." (Chopra, Meindl ,Navarro y Murrieta, 2013)

Finalmente, con el fin de dar a conocer la situación que se da en el área de almacén central de la empresa, se hizo una entrevista al encargado del almacén la cual se adjunta en los anexos. En resumen, el encargado manifestó que se presentan problemas de desorganización y falta de espacio debido a que la empresa realiza pedidos de gran volumen cuando no se posee el espacio suficiente provocando que estos deban ser almacenados en cualquier espacio disponible que se tenga, por tanto no se tiene el mismo producto en una misma ubicación. Por otro lado, PROASA no suele comprar los mismos productos cada mes y las mismas cantidades. Por ello, el encargado comenta que no se pueden establecer ubicaciones exactas a cada producto. La solución ante estos problemas indica que la cantidad que no se pueda almacenar se envía al otro almacén ocasionando que muchas veces se envíe gran cantidad de mercadería entre almacenes. Asimismo, menciona que se busca establecer ubicaciones que se puedan designar a los productos que no suelen comprarse con frecuencia. En cuanto a los indicadores que se manejan en el área, comenta que no se cuenta con ellos, sólo se hace un conteo del inventario cada 6 meses con el fin de determinar las diferencias que se tiene con el software que se maneja.

A continuación se mencionarán algunos datos genéricos de la empresa en estudio, incluyendo en la figura 1.1 el logo de la empresa: 
○ Razón Social: Proveedores de Abarrotes Santa Ana S.R.L.

○ Logo de la empresa:

Figura 1. 1.

Logo de la empresa

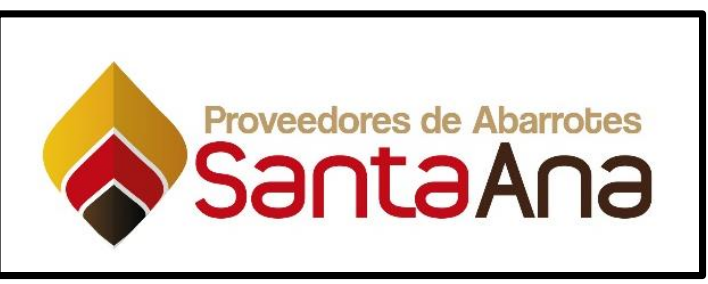

Fuente: Proveedores de Abarrotes Santa Ana S.R.L.(2016)

○ Dirección del punto de venta : Av. Simón Bolívar 496 - José L. Ortiz - Chiclayo

○ Dirección del almacén auxiliar : Av. Mariano Cornejo 895 - Nuevo San Lorenzo- José

L. Ortiz - Chiclayo

○ RUC : 20480113579

○ CIIU : 5122 - Venta al por mayor de alimentos, bebidas y tabaco

Entre las características que la destacan en el mercado están sus precios bajos, la cordialidad en la atención y sus productos de calidad y alta demanda gracias a sus proveedores estratégicos.

\subsubsection{Descripción de los productos o servicios ofrecidos}

A continuación, se detallan los productos que ofrece PROASA según sus proveedores principales:

- $\quad$ Industrias de Grasas y Aceites S.A. :

PROASA tiene la distribución exclusiva de sus aceites y jabones dentro de la ciudad de Chiclayo, contando con descuentos a los que otros mayoristas no pueden acceder. Esto otorga la posibilidad de ofrecer dichos productos a los precios más bajos siempre.

- $\quad$ ALICORP: 
Los productos que ofrece son: fideos, galletas, caramelos y harina de la marca Sayon.

- $\quad$ Distribuidora de Productos de Calidad S.A.C. (DEPRODECA):

Esta distribuidora abastece a la empresa de productos de la marca GLORIA en la categoría de leche evaporada en todas sus presentaciones.

- $\quad$ Distribuidora Lavagna S.A.C. :

PROASA compra los siguientes productos: Milo en sobre, Leche Ideal, ECO, Pañales HUGGIES, Papel Higiénico SUAVE, Café Kirma en display de 50 sobres.

- $\quad$ Despensa Peruana S.A. (DEPSA) :

Provee los siguientes productos: aceite Tondero, Detergente OPAL, jabón y detergente Marsella, lejía Clorox y pañales HUGGIES.

\subsubsection{Descripción del mercado objetivo de la empresa}

El mercado objetivo de la empresa son personas naturales y jurídicas de la ciudad de Chiclayo o ciudades contiguas, que deseen adquirir abarrotes al por mayor para venta o uso final del producto.

Los productos comercializados se destinan principalmente a un cliente final de NSE C, D y E; de todos los rangos de edad y ambos sexos.

\subsubsection{Estrategia general de la empresa}

La estrategia genérica usada por la empresa es el liderazgo en costos, la empresa busca reducir costos en su cadena de valor para ofrecer un mejor precio al consumidor para ganar en participación de mercado y ser líder en venta al por mayor de abarrotes. Asimismo, dentro de la cadena de valor, las principales estrategias son:

La estrategia alternativa intensiva de la empresa es penetración de mercado según la matriz ansoff mostrada en la figura 1.2. La empresa busca captar clientes de la competencia 
aumentando su participación de mercado mediante competitividad en precios y entrega oportuna de productos que los clientes requieren.

Figura 1. 2.

Matriz de Ansoff

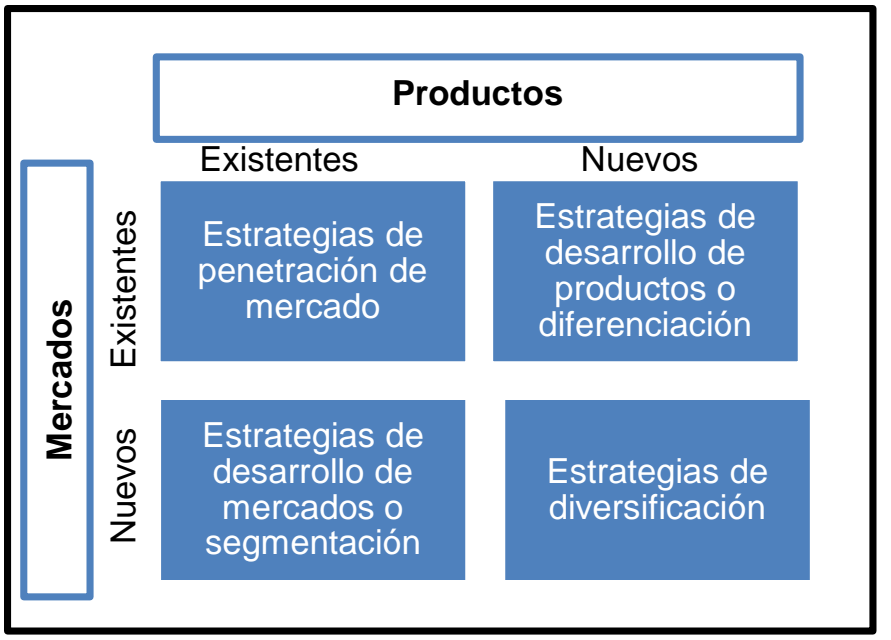

Elaboración propia

La estrategia comercial es concretar las ventas en un único punto, que es la tienda principal, teniendo dos puntos de despacho: el almacén principal y uno auxiliar. En cuanto al abastecimiento, se busca comprar productos al por mayor a las empresas productoras, de esta manera reducer los costos de venta.

\subsection{Objetivos de la investigación.}

\subsubsection{Objetivo general}

Realizar una mejora en el abastecimiento de la empresa mayorista "Proveedores de Abarrotes Santa Ana S.R.L." de tal manera que le permita a la organización incrementar su rentabilidad mediante la aplicación de técnicas de ingeniería.

\subsubsection{Objetivos Específicos}

- Diagnosticar el proceso de abastecimiento de la empresa.

- Identificar los indicadores críticos del proceso de abastecimiento que posee la empresa.

- Aplicar las herramientas de ingeniería para brindar soluciones a los problemas encontrados y que sean rentables. 


\subsection{Alcance y limitaciones de la investigación}

Para el presente trabajo de investigación, se define el alcance y limitaciones que se proponen a continuación en la tabla 1.1.:

Tabla 1. 1.

\section{Alcance y limitación de las actividades}

\begin{tabular}{|c|c|c|}
\hline Actividad & Alcance & Limitaciones \\
\hline $\begin{array}{c}\text { Análisis de los } \\
\text { principales indicadores } \\
\text { de gestión }\end{array}$ & $\begin{array}{c}\text { Análisis cuantitativo de los indicadores } \\
\text { de gestión, abocado a establecer el costo } \\
\text { de oportunidad. }\end{array}$ & $\begin{array}{c}\text { Se seleccionarán solo los } \\
\text { indicadores que estén } \\
\text { relacionados a la logística. }\end{array}$ \\
\hline $\begin{array}{c}\text { Hallazgo de las causas } \\
\text { principales de los } \\
\text { sobrecostos }\end{array}$ & $\begin{array}{c}\text { Análisis de causa-efecto de los } \\
\text { principales problemas de la organización, } \\
\text { hallando las causas raíces. }\end{array}$ & $\begin{array}{c}\text { No se analizará problemas fuera } \\
\text { de los procesos de la cadena de } \\
\text { suministros. }\end{array}$ \\
\hline $\begin{array}{c}\text { Análisis de propuestas } \\
\text { de solución }\end{array}$ & $\begin{array}{c}\text { Análisis cuantitativo y cualitativo de las } \\
\text { propuestas de solución, seleccionando la } \\
\text { mejor alternativa. }\end{array}$ & $\begin{array}{c}\text { La empresa finaciará las } \\
\text { soluciones con aportes de capital. }\end{array}$ \\
\hline $\begin{array}{c}\text { Desarrollo de las } \\
\text { alternativas de solución }\end{array}$ & $\begin{array}{c}\text { Estudio de la implementación e impacto } \\
\text { de las alternativas de solución } \\
\text { seleccionadas. }\end{array}$ & $\begin{array}{c}\text { No desarrolla las alternativas no } \\
\text { seleccionadas. }\end{array}$ \\
\hline
\end{tabular}

Elaboración propia

\section{$1.4 \quad$ Justificación de la investigación}

\subsubsection{Técnica}

Las técnicas que se emplearán para encontrar soluciones a los problemas de la empresa serán las adquiridas en Ingeniería Industrial. Entre estas encontramos las de diagnóstico y análisis como los diagramas de Pareto e Ishikawa que se utilizarán para determinar la situación de la empresa y la simulación de la demanda para calcular el abastecimiento necesario. Por otro lado, se analizarán los conceptos de técnicas de abastecimiento, como tipo push o pull, para identificar cuál se aplica a la empresa.

\subsubsection{Económica}

La inversión que se requiere para implementar esta mejora buscará mejorar la competitividad, solvencia y rentabilidad de la empresa, ofreciendo productos en el tiempo y en la cantidad que el cliente necesita. Además, se plantearán soluciones que no signifiquen una inversión significativa con el fin de maximizar el beneficio. 


\subsubsection{Social}

Esta mejora permitirá que la empresa tenga un mejor ambiente de atención al cliente y de trabajo lo cual permitirá que el personal atienda mejor al público; y por consiguiente, se aumentará el nivel de servicio.

\subsection{Hipótesis de la investigación}

La implementación de mejoras en la gestión de abastecimiento en la empresa "Proveedores de Abarrotes Santa Ana S.R.L." aumentará las ventas y reducirá costos, incrementado así la rentabilidad. De esta manera, la empresa podrá tener un crecimiento sostenible en el tiempo.

\subsection{Marco referencial de la investigación.}

- $\quad$ Alfaro Salkeld, Daniel (2015). Mejora en el Sistema de almacenamiento y despacho de arroz de la empresa Costeño Alimentos SAC (tesis para optar por el título de ingeniero industrial). Universidad de Lima

En este trabajo podemos tener ver técnicas de almacenamiento puestas en práctica en una empresa y cómo estas contribuyen al mejor aprovechamiento del espacio.

- Gordillo-Cerruti, Rodrigo (2016). Mejora en el proceso de elaboración y gestión de los pronósticos de demanda en una empresa dedicada a la venta de productos de belleza (tesis para optar por el título de ingeniero industrial).Universidad de Lima.

En este trabajo podemos observar las técnicas que se utilizaron para optimizar el pronóstico de demanda en productos con demanda estacional y no estacional.

- Morales Valerio, Fernanda (2015). Mejora a la gestión del proceso de abastecimiento de insumos clínicos para el Hospital San José (tesis para optar por el título de ingeniero civil industrial). Universidad de Chile.

En este trabajo podemos observar la implementación de un sistema para la gestión de abastecimiento. 
- $\quad$ Reyes Maquín, Gianni (2015). Mejora en la distribución de productos a nivel local de una empresa manufacturera de aceituna y sus derivados (tesis para optar por el título de ingeniero industrial). Universidad Católica del Perú.

En este trabajo podemos tener ver estrategias de distribución puestas en práctica en una empresa para optimizar tiempos en el proceso de comercialización.

\subsection{Marco conceptual}

Para realizar el diagnóstico es necesario definir el objeto, propósito y lineamientos del mismo. Se resume la aplicación del diagnóstico en la tabla 1.2.

Tabla 1. 2.

\section{Planificación del diagnóstico}

\begin{tabular}{|c|c|}
\hline \multicolumn{2}{|c|}{ Planeamiento del Diagnóstico } \\
\hline Objeto & Proveedores de Abarrote Santa Ana S.R.L. \\
\hline Propósito & Identificar y eliminar sobrecostos \\
\hline Tipo de diagnóstico & $\begin{array}{c}\text { Funcional (Análisis Causa-Efecto) } \\
\text { Sistémico (Enfoque a proceso de abastecimiento) } \\
\text { Económico (Análisis de indicadores y costos) }\end{array}$ \\
\hline Tiempo disponible & 6 meses (Julio a Diciembre del 2015) \\
\hline Fuentes de información & $\begin{array}{c}\text { Primarias (Entrevistas a los trabajadores) } \\
\text { Secundarias ( Bases de datos) }\end{array}$ \\
\hline Medios de recopilación & Diálogo, entrevistas, observación in situ \\
\hline Generación de alternativas & Brainstorming \\
\hline Evaluación de alternativas & Premisa: Bajo costo y fácil de implementar \\
\hline
\end{tabular}

Elaboración propia

Para el diagnóstico económico-financiero se usarán indicadores de gestión de la empresa y un análisis de costos. Esto ayudará a identificar cuáles son los principales sobrecostos de la empresa en los cuales se deben focalizar los esfuerzos.

En el diagnóstico funcional se analizará la empresa por áreas y relaciones entre ellas, lo que posibilitará medir el desempeño de los procesos de la empresa y encontrar algunas fallas funcionales lo cual será útil para identificar las causas de los costos hallados en el primer diagnóstico mencionado. 
Por otro lado, el diagnóstico sistémico nos permitirá conocer el proceso de abastecimiento.

Las herramientas que se utilizarán son el diagrama de Ishikawa y Pareto por cada indicador. A través del Ishikawa, se podrá reconocer las razones o causas de los costos estudiados y relaciones entre estas (identificar causas raíces). Y con el Pareto, se clasificará esas causas según criterios para conocer cuáles eran las críticas.

Como vemos, los tres tipos de diagnóstico se relacionan para posteriormente proponer alternativas de solución para cada causa crítica hallada. 


\section{CAPITULO II: ANÁLISIS SITUACIONAL DE LA EMPRESA Y SELECCIÓN DEL PROCESO A SER MEJORADO}

\subsection{Análisis externo de la empresa}

\subsubsection{Análisis del entorno global}

La región Lambayeque ha presentado un gran crecimiento económico en los últimos años lo cual se ve reflejado en las nuevas inversiones que se están realizando, principalmente en la ciudad de Chiclayo la cual es la capital de la región.

Actualmente, se encuentra desarrollando el Proyecto Olmos el cual promete desarrollo económico y mejorar las condiciones de vida de la región aumentando los puestos de trabajo y facilitando que los productos de la agricultura puedan ser exportados. Por otro lado, en los últimos meses la ciudad de Chiclayo está recibiendo vuelos directos de diversas partes del mundo lo cual aumenta el atractivo de la ciudad.

En la siguiente figura 2.1., se puede apreciar la posición relativa que posee la región con respecto a las demás mediante el índice de competitividad regional del Instituto de Economía del País el cuál es el resultado de 46 indicadores que permiten evaluar el rumbo de la región.

\section{Figura 2. 1.}

Índice de competitividad regional de Lambayeque

\begin{tabular}{|c|c|c|c|c|c|c|}
\hline \multirow{2}{*}{ Índice de Competitividad Regional } & \multicolumn{2}{|c|}{2016} & \multicolumn{2}{|c|}{2015} & \multicolumn{2}{|c|}{2014} \\
\hline & : Puesto & $\begin{array}{l}\text { Puntaje } \\
\text { (de } 0 \text { a } 10)\end{array}$ & $\begin{array}{l}\text { Puesto } \\
\text { (de 24) }\end{array}$ & $\begin{array}{l}\text { Puntaje } \\
\text { (de 0 a 10) }\end{array}$ & $\begin{array}{l}\text { Puesto } \\
\text { (de 24) }\end{array}$ & $\begin{array}{l}\text { Puntaje } \\
\text { (de 0 a io) }\end{array}$ \\
\hline Índice Total... & 8 & 5.0 & 8 & 5.0 & 9 & 4.8 \\
\hline Entorno Económico & 8 & 3.3 & 8 & 3.0 & 9 & 2.9 \\
\hline Infraestructura & 8 & 6.3 & 7 & 6.5 & 7 & 6.5 \\
\hline Salud & 6 & 6.5 & 5 & 6.7 & 5 & 6.5 \\
\hline Educación & 11 & 5.0 & 7 & 5.5 & 8 & 4.8 \\
\hline Laboral... & 11 & 4.3 & 16 & 3.9 & 19 & 3.7 \\
\hline Instituciones & $\because 21$ & 4.9 & 23 & 4.4 & 18 & 4.3 \\
\hline
\end{tabular}

Fuente: Instituto Peruano de Economía (2016) 
Como se puede observar, la región Lambayeque se encuentra en un puesto importante en comparación de las demás regiones de nuestro país. En los sectores, que se encuentra mejor posicionado es en el de salud, entorno económico e infraestructura lo cual justifica el atractivo actual de la región para los inversionistas.

A continuación en la figura 2.2. , se detalla los indicadores que se consideraron en cada sector.

Figura 2. 2.

\section{Índice de Competitividad Regional de Lambayeque 2016 en detalle}

\begin{tabular}{|c|c|c|c|c|c|c|c|}
\hline \multicolumn{8}{|c|}{ Índice de Competitividad Regional en detalle } \\
\hline Indicador & Valor $\mathrm{P}$ & \multicolumn{2}{|c|}{$\begin{array}{l}\text { Puesto* } \\
\text { [do 24] }\end{array}$} & Indicador & \multirow[t]{2}{*}{ Valor } & \multicolumn{2}{|c|}{$\begin{array}{l}\text { Puesto** } \\
\text { (do 24) }\end{array}$} \\
\hline \multicolumn{4}{|l|}{ 1. EnTORNo ECONómico } & \multicolumn{3}{|l|}{ 4. EDUCACIÓN } & \\
\hline Producto bruto interno real & s/. 10,496 & 10 & $=$ & Analfabetismo & $5.8 \%$ & 10 & $\Delta$ \\
\hline Producto bruto interno real per cápita & $\$ / .8,395$ & 15 & $\boldsymbol{\nabla}$ & Asistencia escolar inicial & $83.4 \%$ & 21 & $\boldsymbol{\nabla}$ \\
\hline Stock de capital por trabajador & $\$ / .16,504$ & 15 & $\boldsymbol{\nabla}$ & Asistencia escolar primaria y secundaria & $55.9 \%$ & 19 & $\boldsymbol{\nabla}$ \\
\hline Presupuesto público per cápita & $\$ / .2,332$ & 23 & $\boldsymbol{\Delta}$ & Población con secundaria a más & $46.6 \%$ & 7 & $\boldsymbol{\nabla}$ \\
\hline Gasto real por hogar mensual & $\$ / .1,592$ & 7 & $\boldsymbol{\Delta}$ & Rendimiento en lectura* & $21.9 \%$ & 7 & $\boldsymbol{\nabla}$ \\
\hline Incremento del gasto real por hogar & $1.0 \%$ & 3 & $\Delta$ & Rendimiento en matemáticas* & $18.3 \%$ & 12 & $\boldsymbol{\nabla}$ \\
\hline Disponibilidad de servicios flnancieros & 523 & 6 & $\Delta$ & Colegios con acceso a internet & $9.7 \%$ & 7 & $\boldsymbol{\nabla}$ \\
\hline Acceso al crédito & $34.7 \%$ & 7 & - & 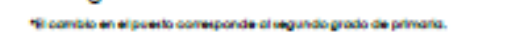 & & & \\
\hline \multicolumn{4}{|l|}{ 2. InFraEstructura } & \multicolumn{4}{|l|}{ 5. LaBoral } \\
\hline Cobertura de electricidad & $95.8 \pi$ & 6 & $\boldsymbol{\nabla}$ & Nivel de ingresos por trabajo & $3 / .1,000$ & 15 & $=$ \\
\hline Precio de la electricidad & 13.6 & 15 & $\boldsymbol{\nabla}$ & Brecha de género en ingresos laborales & $38.6 \%$ & 19 & $=$ \\
\hline Cobertura de agua & $90.5 \%$ & 9 & $=$ & Empleo adecuado & $50.1 \%$ & 9 & $\boldsymbol{\Delta}$ \\
\hline Continuidad de la provisión de agua & 10.1 & 19 & $\boldsymbol{\nabla}$ & Educación de la fuerza laboral & $27.7 \%$ & 9 & $\Delta$ \\
\hline Cobertura de desagüe & $73.8 \%$ & 6 & $\boldsymbol{\nabla}$ & Creación de empleo formal & $1.7 \%$ & 3 & 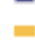 \\
\hline Hogares con internet & $24.7 \%$ & 5 & $=$ & Empleo informal & $77.1 \%$ & 8 & $\boldsymbol{\Delta}$ \\
\hline Hogares con al menos un celular & $90.6 \pi$ & 6 & $\boldsymbol{\nabla}$ & Desempleo juvenil urbano & $8.2 \%$ & 7 & $\boldsymbol{\Delta}$ \\
\hline Densidad del transporte aéreo & 361.3 & 11 & - & & & & \\
\hline \multicolumn{4}{|l|}{ 3. SALUD } & \multicolumn{4}{|l|}{ 6. INSTIUUCIONES } \\
\hline Esperanza de vida al nacer & 76.5 & 4 & $=$ & Ejecución de la inversión pública & $66.7 \%$ & 21 & $\Delta$ \\
\hline Mortalidad en la niñez & 16.0 & 4 & $\boldsymbol{\nabla}$ & Fondos públicos no concursados & $19.0 \%$ & 21 & $\boldsymbol{\nabla}$ \\
\hline Desnutrición crónica & $10.4 \pi$ & 8 & $=$ & Percepción de la gestión pública & $22.8 \%$ & 23 & $\boldsymbol{\nabla}$ \\
\hline Morbilidad & $69.6 \%$ & 17 & $\boldsymbol{\nabla}$ & Conflictos sociales & 5.0 & 11 & $\boldsymbol{\nabla}$ \\
\hline Cobertura del personal médico & 17.3 & 6 & $=$ & Criminaligad & 11.8 & 20 & $\boldsymbol{\nabla}$ \\
\hline Cobertura hospitalaria & 2.7 & 4 & $=$ & Homicidios & 5.2 & 8 & $\boldsymbol{\Delta}$ \\
\hline Partos institucionales & $91.3 \%$ & 11 & $\boldsymbol{\nabla}$ & Presencia policial & 788.9 & 13 & $=$ \\
\hline Acceso a seguro de salud & $70.7 \pi$ & 15 & $\Delta$ & Resolución expedientes judiciales & $26.3 \%$ & 15 & $\Delta$ \\
\hline \multicolumn{8}{|c|}{ 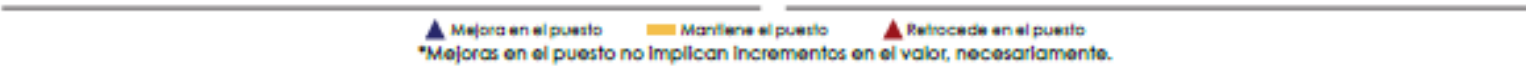 } \\
\hline
\end{tabular}

Fuente: Instituto Peruano de Economía (2016) 


\subsubsection{Análisis del entorno competitivo y del mercado}

En esta sección se analizará el sector según Porter quien propone que existen 5 fuerzas dentro de cada sector.

\section{Amenaza de nuevos ingresos}

Actualmente se requiere de un capital alto para ingresar al mercado debido a que se requiere de compras de gran volumen de productos y de un almacén ubicado en la misma zona en la que se encuentra la competencia, lo cual es costoso debido a que el precio del $\mathrm{m}^{2}$ es alto por la gran demanda de espacio en la zona.

Otra barrera es la buena imagen y el nivel de descuento que los actuales competidores del sector poseen, los cuales son las principales características que han atraído a sus clientes.

Debido a las características del mercado antes descritas, se concluye que esta fuerza es baja.

\section{Poder de negociación de los clientes}

Los clientes del sector que compran grandes cantidades cuentan con información directa sobre los precios de todos los productos de consumo masivo en los diversos mayoristas en la zona. Contando con estos datos, los clientes buscan al mayorista con los precios más bajos para realizar sus compras; sin embargo, debido al bajo margen de utilidad que las empresas poseen, los clientes no tienen un gran poder de negociación para bajar significativamente el precio de los productos ofrecidos.

Ante todo lo descrito, se determina que esta fuerza es media.

\section{Poder de negociación de los proveedores:}

A pesar que los proveedores son grandes empresas; éstas conocen que no pueden variar los precios de modo arbitrario ya que al encontrarse en el mercado mayorista de consumo masivo los clientes responden negativamente ante aumentos de precios prefiriendo otros productos sustitutos más baratos o buscando otros proveedores. Por ello se estima que el poder de negociación de los proveedores es medio-bajo. 
A continuación, en la tabla 2.1. se muestra los principales proveedores del sector:

Tabla 2. 1.

Proveedores del sector

\begin{tabular}{|c|}
\hline Proveedores \\
\hline Alicorp SAA \\
\hline SANCELA \\
\hline Industrias TEAL \\
\hline Distribuidor de Productos de Calidad \\
\hline Distribuidora LAVAGNA \\
\hline Despensa Peruana \\
\hline Procter \& Gamble \\
\hline Gloria \\
\hline MOLITALIA SA \\
\hline
\end{tabular}

Elaboración Propia

\section{Amenaza de productos sustitutos}

En este sector, se podría poner como servicio sustituto al servicio que ofrece la cadena de tiendas Makro ya que también permite la compra al por mayor de productos de consumo masivo que todas las empresas de este sector ofrecen. Este tipo de negocio ofrece comodidad al realizar las compras, buena atención y buenos precios por lo que tiene afluencia de público. Por otro lado, es importante mencionar que debido al valor agregado que Makro ha dado a su servicio incurre en gastos que los obligan a poner precios un poco más altos en comparación con los precios de estas tiendas mayoristas. Por ello, se concluye que esta fuerza es de mediana influencia en el mercado.

\section{Rivalidad entre los competidores}

Actualmente la rivalidad entre competidores es intensa debido a que existe gran número de competidores que realizan constantemente una guerra de precios que dificulta la estabilidad de los mismos en muchos productos.

Además, la capacidad de atención de pedidos y el tipo de servicio son similares entre los mayoristas ya que, al procurar igualar sus precios cuentan con un escenario similar de venta y de inventario. 
Debido a todo lo expuesto, se concluye que esta fuerza es alta.

A continuación, en la tabla 2.2. se muestra las empresas que pertenecen a este sector:

Tabla 2. 2.

\section{Competidores del Sector}

\begin{tabular}{|c|}
\hline Competidores \\
\hline Gremio de Comerciantes y Asociados \\
\hline Ventasa SAC \\
\hline Grenco SAC \\
\hline Franco Ballena Zapata EIRL \\
\hline Rimay SAC \\
\hline Proveedores de Abarrotes Santa Ana SRL \\
\hline Comercial Santa Ana SRL \\
\hline
\end{tabular}

Elaboración Propia

En la figura 2.3. se tiene un resumen de las fuerzas de Porter para el mercado de la empresa en estudio:

\section{Figura 2. 3.}

\section{Fuerzas de Porter}

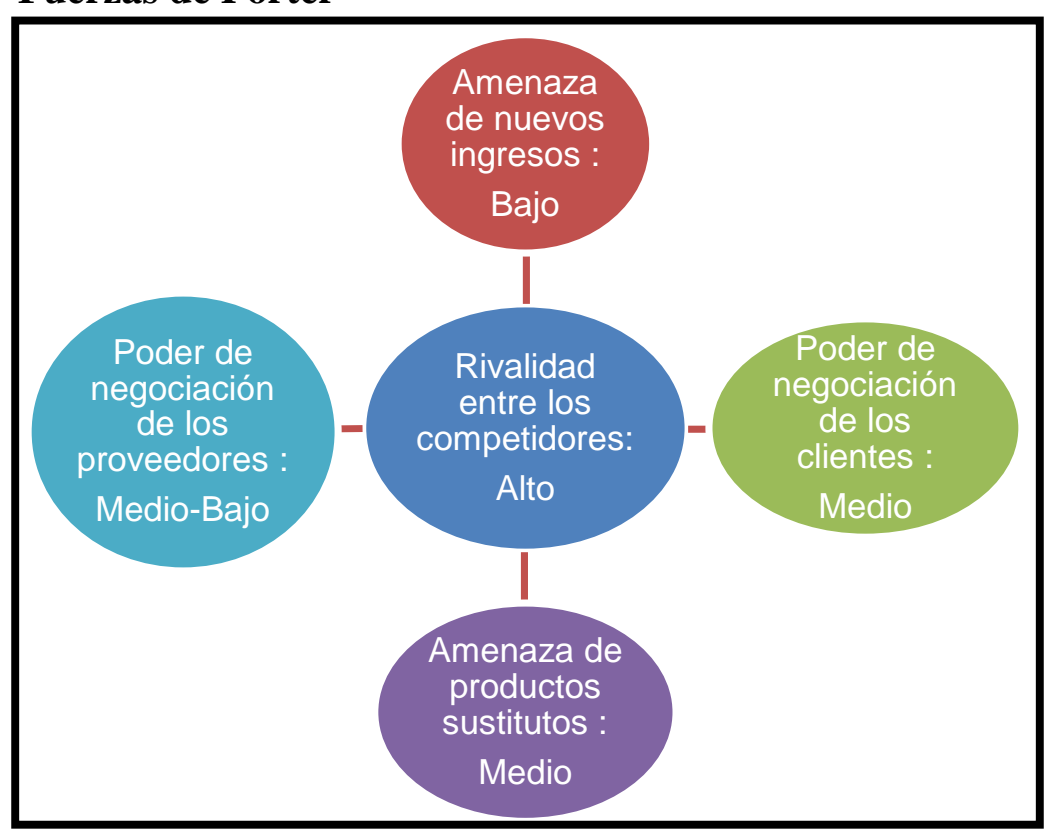

Elaboración propia 
Finalmente, cabe recalcar que Proveedores de Abarrotes Santa Ana cuenta con productos exclusivos y a un precio bajo que le permiten sobresalir sobre la competencia.

La principal competencia de la empresa son Franco Ballena Zapata EIRL y Grenco SAC. Ambas empresas pertenecen al mismo dueño. Estas posen productos similares y con cierta diferencia de precio lo cual ha provocado que los clientes prefieran comprar en estas. Asimismo, son empresas que poseen años de experiencia y que son reconocidas por ofrecer buenos productos. Por otro lado, es importante mencionar que los locales de estas empresas se encuentran cerca lo cual permite que nuestros clientes comparen precios y puedan optar por comprar en estas.

\subsubsection{Identificación y evaluación de las oportunidades y amenazas del entorno}

A continuación se presentan las oportunidades y amenazas del entorno:

- Oportunidades

De acuerdo a lo observado en el entorno de la empresa, se puede identificar las siguientes oportunidades:

- $\quad$ Mayor demanda de productos de consumo masivo.

- $\quad$ Mayor oferta de softwares de gestión adecuados al giro de negocio.

- $\quad$ Introducción de nuevos productos al mercado.

- $\quad$ Expansión de nuevos locales a nivel nacional.

- $\quad$ Mayor oferta profesional en la zona.

En Chiclayo, ya se puede encontrar mayor número de profesionales que puedan ayudar a las empresas a crecer, ordenarse y mejorar los procesos de gestión en ellas.

Actualmente, la empresa posee una gran variedad de productos que ofrece a sus clientes; sin embargo, no posee ciertos productos importantes. Por ejemplo, las conservas de pescado. Estas poseen una demanda alta en el mercado. Sería una oportunidad importante que se podría considerar con el fin de lograr captar nuevos clientes y satisfacer las necesidades de compra de nuestros clientes actuales sobre este producto. 
Por otro lado, sería importante considerar un nuevo software de gestión que les permita manejar mejor sus almacenes. Por ejemplo, que les permita registrar las fechas de vencimiento de los productos y de ingreso de la mercadería; además, que les permita identificar la zona en la que se encuentra cada producto.

- $\quad$ Amenazas

La empresa posee las siguientes amenazas:

- Nuevas competencias a precios bajos.

- $\quad$ Alzas repentinas de precios de los proveedores.

- Desaceleración de la economía nacional y regional provocado por el fenómeno del niño costero.

- $\quad$ Cambio climático en la region norte.

- $\quad$ Tendencia a reducir la cadena de suministros.

En el mercado, se puede apreciar que existen ciertas empresas que realizan ventas incorrectas al público arriesgando sus propias utilidades, es decir, estas rematan los productos con una diferencia significativa del precio de compra lo cual obliga a la competencia a disminuir sus precios convirtiendo este hecho en una amenaza que se debe tener en cuenta.

Otra amenaza importante es que algunos proveedores eleven sus precios debido a que la oferta del día del producto sea baja, como suele suceder con el azúcar en algunas ocasiones, o que sea temporada de mayor venta del producto, como es el caso del panetón.

\subsection{Análisis interno de la empresa}

\subsubsection{Análisis del direccionamiento estratégico: visión, misión y objetivos organizacionales}

La empresa actualmente no cuenta con una visión, misión y objetivos organizacionales. Sin embargo, después de conversar con los dueños se puede proponer lo siguiente cumpliendo con las especificaciones teóricas requeridas para definirlas: 


\section{Visión}

Ser una empresa que se encargue de la distribución exclusiva de la mayor parte de productos de consumo masivo que se venden en la región con el fin de satisfacer las necesidades de clientes mayoristas de las ciudades que la conforman.

\section{Misión}

Brindar un servicio que consista en tener siempre disponible nuestros productos de consumo masivo a un precio bajo en comparación a la competencia.

\section{Objetivos Organizacionales}

La empresa no cuenta con un plan de largo plazo; sin embargo, conversando con el dueño de la empresa, pudimos rescatar los siguientes objetivos:

- Aumentar el nivel de ventas, principalmente en los productos más rentables

- Disminuir costos innecesarios que afectan la rentabilidad del negocio.

- Identificar nuevas oportunidades de negocio y materializarlas.

\subsubsection{Análisis de la organización y estructura organizacional}

Actualmente la empresa no cuenta con un organigrama que defina los puestos de trabajo. Por ello, no se mostrará el organigrama de la empresa. Por otro lado, se puede identificar personas encargadas de las siguientes áreas: almacén, contabilidad, compras y ventas a las cuales les denominaremos jefes de estas.

\subsubsection{Identificación de los procesos más importantes}

En esta parte, se describirán los procesos más importantes de la empresa, los cuales serán clasificados entre principales y de soporte. Los principales son los siguientes:

- Comprar productos: Este proceso involucra todas las actividades necesarias para adquirir los productos que se ofrecen al cliente, y son las siguientes: verificar stock en el sistema, decidir la cantidad a comprar, pedir una cotización a proveedores, 
analizar a qué proveedor se le comprará, confirmar el pedido y registrar la llegada del producto.

- Almacenar productos: Las actividades incluidas en este proceso son aquellas que ayudan colocar los productos en un espacio adecuado dentro del almacén, y son las siguientes: verificar que la llegada de los productos, verificar si existe el espacio necesario para estos y colocar los productos en el lugar elegido en el almacén.

- Vender productos: Este proceso permite brindar el servicio de abastecer productos de consumo masivo a nuestros clientes. Dentro de este, encontramos que primero se recibe al cliente, se confirma que los productos que desea se encuentran en stock, se le comunica el total a pagar, se elabora la boleta o factura, se entrega el comprobante de pago a la cajera y finalmente se realiza el pago por parte del cliente

- Despachar productos: Este proceso está compuesto por las siguientes actividades: el cliente entrega el comprobante al encargado del almacén, se comunica la orden de productos a entregar y finalmente, se entrega los productos al cliente o al estibador contratado por el cliente.

- Planificación informal: Actualmente, la empresa no cuenta con una planificación estratégica a largo plazo. Por ello, realiza una planificación informal día a día según la experiencia de los dueños al decidir cuánto deben comprar, qué pagos a proveedores realizar en el día, en qué no invertir o invertir y qué pedidos realizar a los proveedores.

Como se mencionó anteriormente, la empresa posee procesos que sirven de soporte para realizar los procesos antes descritos, y estos son:

- Contabilidad: Este es necesario debido a que ayuda a la empresa a llevar un control de sus ingresos, costos y egresos a través de ciertos informes periódicos con el fin de cumplir con los requerimientos que el gobierno exige y para ayudar en la toma de decisiones.

- Administración: Este permite a la empresa a dar un uso eficiente a los recursos que esta posee con el objetivo de aumentar la rentabilidad de la empresa. 
- Mantenimiento: Debido al uso que se da al local donde se encuentra y a que almacena productos de consumo, la empresa realiza actividades de mantenimiento con el fin de mantener una buena imagen ante el público. Por ejemplo, se fumiga el almacén, se pinta la fachada periódicamente, etc.

- $\quad$ Selección de personal: El proceso permite a la empresa captar su personal quienes cumplen con diversas funciones las cuales contribuyen con el desarrollo de esta.

\subsubsection{Análisis de los indicadores generales de desempeño de los procesos claves}

Los indicadores de desempeño ayudan a la empresa a medir su performance durante un periodo de tiempo determinado, y sirven para sacar conclusiones convirtiendo estas métricas en oportunidades de mejora.

Este trabajo se centrará en aquellos indicadores relacionados al abastecimiento y almacenamiento que incurren en sobrecostos para la empresa y representan una oportunidad de ahorro importante.

\section{○ Costo total de política de almacenamiento:}

\section{a) Costo de oportunidad en ventas perdidas}

Según la entrevista que se realizó a la encargada de ventas la cual se adjunta en los anexos, estiman que el número de personas a la semana que la empresa pierde es de 50 clientes por los siguientes motivos explicados en la tabla 2.3.:

Tabla 2. 3.

Motivos de ventas perdidas

\begin{tabular}{|c|c|c|c|}
\hline Motivo & Descripción & Cantidad & Porcentaje \\
\hline A & Falta de Stock del producto solicitado & 25 & $50 \%$ \\
\hline B & La empresa no vende el producto & 13 & $26 \%$ \\
\hline Colicitado & Diferencia de precios con la competencia & 10 & $20 \%$ \\
\hline D & Otros & 2 & $4 \%$ \\
\hline
\end{tabular}

Fuente: Proveedores de abarrotes Santa Ana SRL (2016)

Elaboración Propia 
Asimismo, indican que cada porcentaje representa a clientes mayoristas y minoristas los cuales poseen un ticket promedio de compra que nos permitirá calcular las pérdidas producidas por esta fuga de clientes. Los cálculos se muestran a continuación en la tabla 2.4.:

Tabla 2. 4.

Ticket promedio de compra de clientes

\begin{tabular}{|c|c|c|c|}
\hline Motivo & Cantidad & Cliente & Ticket Promedio \\
\hline A & 25 & Mayorista & S/ 5500 \\
\hline B, C, D & 25 & Minorista & S/.700 \\
\hline
\end{tabular}

Fuente: Proveedores de abarrotes Santa Ana SRL (2016)

Elaboración Propia

Utilidad bruta promedio de la empresa $=3.5 \%$

Pérdida por fuga de clientes

al mes $\quad=(5,500 * 25+700 * 25) * 0.035 * 4.33=\mathrm{S} / .23,490$

\section{b) Nivel de servicio}

El nivel de servicio que se le brinda al cliente está relacionado con las políticas de almacenamiento; y esto a su vez, se refleja en la disponibilidad de productos que puedas ofrecerle en el momento al cliente.

"El nivel de servicio que se proporciona a los clientes estará determinado por la eficacia y la eficiencia de los procedimientos utilizados en la recepción, almacenamiento y despacho de productos “(Mora, 2011)

Como se mencionó anteriormente a la semana se pierden 50 clientes. Por lo tanto, al mes serían 200 clientes insatisfechos.

Según un análisis realizado durante el mes de Marzo en la atención de las ventanillas de venta que se tiene en la empresa, se pudo obtener que el total de personas que llegan en promedio al mes es 1184. Cabe mencionar que se escogió dicho mes debido a que es típico ya que no tiene festividades que suelan aumentar las ventas o donde la empresa incluya productos estacionales. A continuación se muestra en la tabla 2.5. los datos que se tomaron en cuenta para obtener el total y en la figura 2.4. se observa que el mes tomado en cuenta tiene ventas promedio durante el año. 
Tabla 2. 5.

Detalle de personas al mes

\begin{tabular}{|c|c|}
\hline Día de la semana & $\begin{array}{c}\text { Conteo de } \\
\text { personas } \\
\text { promedio }\end{array}$ \\
\hline Lunes & 42 \\
\hline Martes & 76 \\
\hline Miercoles & 31 \\
\hline Jueves & 35 \\
\hline Viernes & 71 \\
\hline Sábado & 41 \\
\hline Total semanal & 296 \\
\hline Total mensual & 1282 \\
\hline
\end{tabular}

Fuente: Proveedores de abarrotes Santa Ana SRL (2016) Elaboración Propia

Figura 2. 4.

Detalle de ventas mensuales 2015-2016

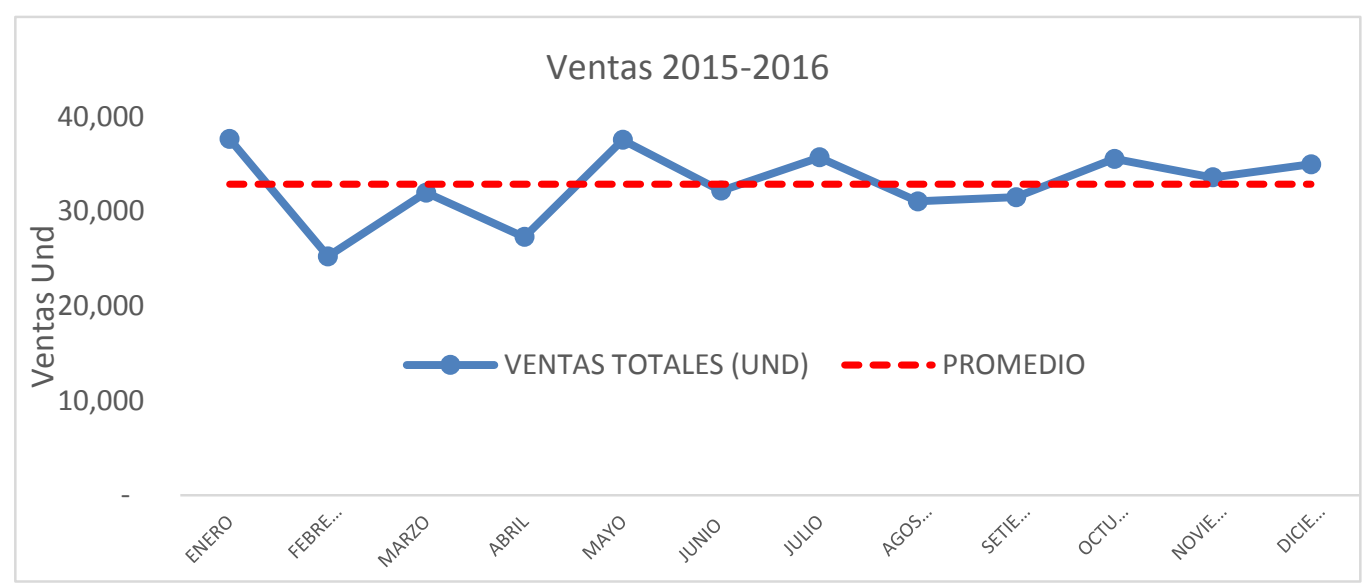

Fuente: Proveedores de abarrotes Santa Ana SRL (2016)

Elaboración Propia

Al obtener los datos del total de pedidos y de las personas insatisfechas, se determinó que el nivel de servicio de la empresa es $84 \%$ aplicando la siguiente fórmula:

Total de personas insatisfechas

- $\%$ Nivel de servicio $=100-\frac{\text { Total de demanda potencial }}{\text { x }}$ 100

- $\quad$ Demanda potencial $=$ Personas atendidas + Personas insatisfechas 
Asimismo, es importante mencionar que para que la empresa pueda lograr este nivel de servicio incurre en costos de almacén el cual se detalla en la siguiente tabla 2.6. :

Tabla 2. 6.

Detalle de costo de almacenamiento

\begin{tabular}{|c|c|}
\hline Detalle de costos & Total \\
\hline Personal & 2,550 \\
\hline Impuestos & 3,780 \\
\hline Mantenimiento & 600 \\
\hline Luz & 1,000 \\
\hline Costo mensual de almacenamiento & 7,930 \\
\hline
\end{tabular}

Fuente: Proveedores de abarrotes Santa Ana SRL (2016) Elaboración Propia

Tanto el costo de oportunidad por ventas perdidas como el costo por manejo de stock (Nivel de servicio) componen el costo total por la política de inventario de la empresa. La relación entre ambas variables se explica en la siguiente figura 2.5.:

\section{Figura 2. 5.}

\section{Costo total de política de almacenamiento}

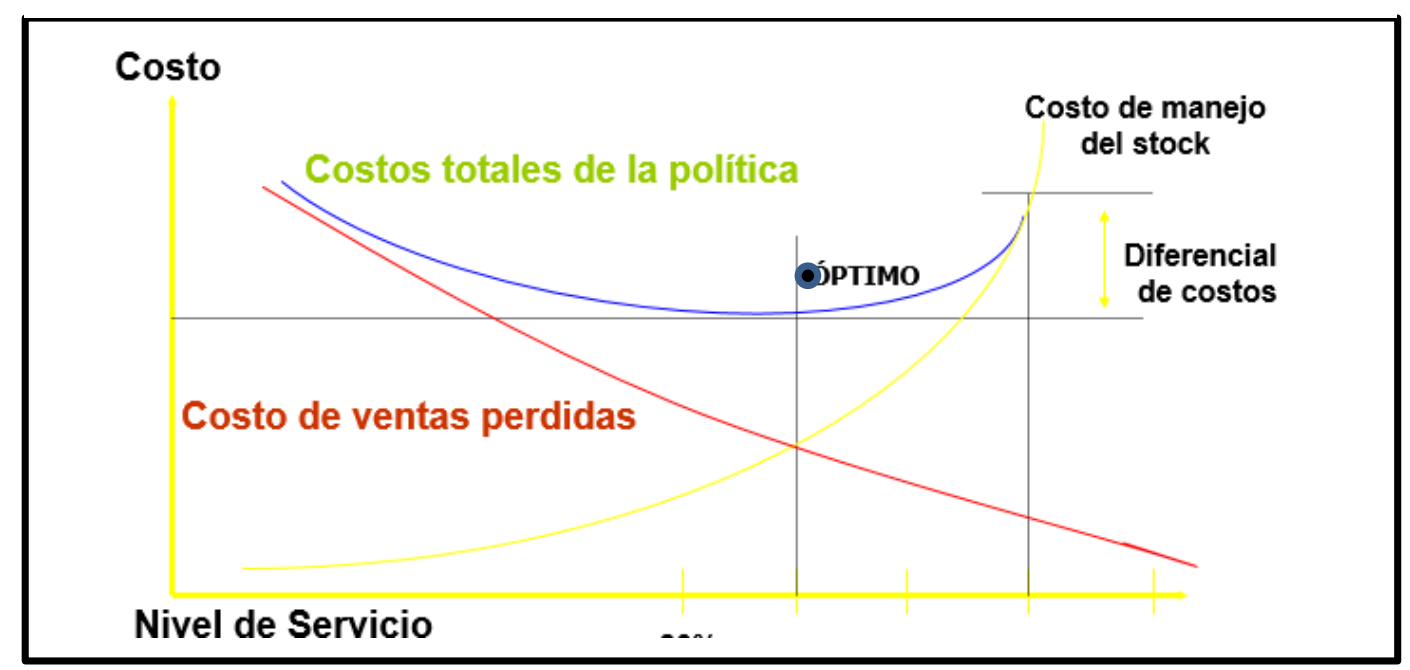

Fuente: Mora, G. L. A., (2012)

El objetivo es encontrar el nivel de servicio en donde el costo total se optimice, equilibrando el costo por ventas perdidas y por manejo de stock. 


\section{- Gastos de transporte de mercancías entre almacenes}

Debido a la gran cantidad de productos que PROASA ofrece, el almacén central ya no puede cubrir con la demanda de los clientes. Por ello, la empresa requiere de un medio de transporte que permita traer cierta cantidad de productos que se necesita en el día.

Actualmente la empresa utiliza la motos cargueras de 5 a 7 veces al día a un precio de S/ 15 el viaje produciendo un gasto entre 75 y 105 soles por cada día de trabajo, según lo que nos comentó la encargada de ventas en la entrevista que se le realizó la cual se adjunta en los anexos. A continuación, en la figura 2.6. se muestra dichas motos:

Figura 2. 6.

Moto carguera

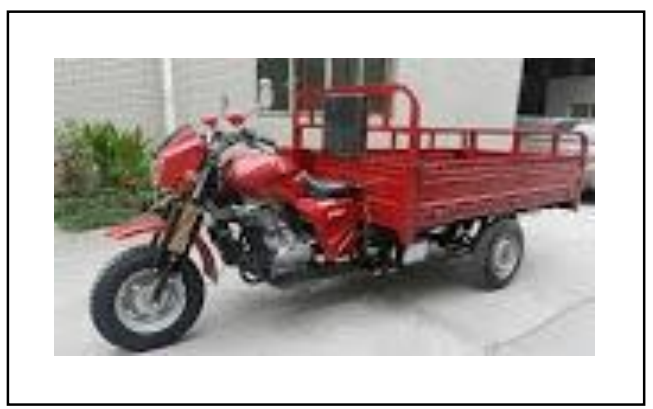

Fuente: Proveedores de Abarrotes Santa Ana SRL (2016)

\section{- Gastos por daños, conservación o vencimiento de productos:}

Según los datos registrados, se ha incurrido en los siguientes gastos en el 2016 los cuales se muestran en la tabla 2.7.:

Debido al traslado en camiones o en motos cargueras de los productos y por el mal almacenamiento de los productos, estos suelen vencerse o dañarse.

Usualmente PROASA apila sus productos en un número excesivo de filas lo cual ha producido la caída de los productos o el aplastamiento del contenido de estos generando a la empresa gastos en la compra de nuevos envases o en la pérdida de cierta cantidad del producto. Por otro lado, la empresa realiza ciertos pagos necesarios para la conservación correcta de los productos. 
Tabla 2. 7.

Gastos por daños, conservación o vencimiento de productos Enero - Diciembre 2016

\begin{tabular}{|c|c|c|c|c|c|c|c|c|}
\hline $\begin{array}{l}\text { PRODUC- } \\
\text { TOS }\end{array}$ & ENERO & $\begin{array}{c}\text { FEBRE- } \\
\text { RO }\end{array}$ & MARZO & ABRIL & MAYO & JUNIO & JULIO & AGOSTO \\
\hline Fideos & $\begin{array}{c}\text { S/. } \\
210.00\end{array}$ & S/. 122.00 & S/. 320.00 & $\begin{array}{c}\text { S/. } \\
155.00\end{array}$ & $\begin{array}{c}\text { S/. } \\
100.00\end{array}$ & $\begin{array}{c}\text { S/. } \\
100.00\end{array}$ & $\begin{array}{c}\text { S/. } \\
100.00\end{array}$ & S/. 100.00 \\
\hline Harinas & S/. 3.00 & S/. 6.00 & S/. 3.50 & S/. 4.00 & S/. 6.00 & S/. 5.00 & S/. 5.00 & S/. 6.50 \\
\hline Aceites & S/. 10.00 & S/. 24.00 & S/. 24.50 & S/. 5.00 & S/. 6.00 & S/. 5.00 & S/. 10.00 & S/. 29.50 \\
\hline Caramelos & S/. 3.00 & S/. 5.00 & S/. 5.00 & S/. 10.00 & S/. 6.00 & S/. 6.00 & S/. 15.00 & S/. 50.00 \\
\hline Jabón & S/. 13.00 & S/. 13.00 & S/. 13.00 & S/. 13.00 & S/. 13.00 & S/. 13.00 & S/. 13.00 & S/. 13.00 \\
\hline Jaboncillo & & & & S/. 2.00 & & & S/. 3.00 & \\
\hline $\begin{array}{c}\text { Betún } \\
\text { Nugget }\end{array}$ & & & $\begin{array}{c}\mathrm{S} / . \\
1,410.00\end{array}$ & & & & & \\
\hline P.higiénico & S/. 3.30 & & $\mathrm{~S} / .3 .30$ & & S/. 3.30 & & S/. 3.30 & \\
\hline Total gastos & $\begin{array}{c}\mathrm{S} / . \\
242.30\end{array}$ & S/. 170.00 & $\begin{array}{c}\mathrm{S} / . \\
1,779.30\end{array}$ & $\begin{array}{c}\text { S/. } \\
189.00\end{array}$ & $\begin{array}{c}\mathrm{S} / . \\
134.30\end{array}$ & $\begin{array}{c}\mathrm{S} / . \\
129.00\end{array}$ & $\begin{array}{c}\mathrm{S} / . \\
149.30\end{array}$ & S/. 199.00 \\
\hline
\end{tabular}

Fuente: Proveedores de Abarrotes Santa Ana SRL (2016)

Elaboración Propia

Asimismo, cabe recalcar que los productos que se encuentran en los pisos superiores son lanzados hacia el primer piso por el ducto que se tiene provocando que algunos productos terminen rompiéndose.

Los montos expresados en la tabla anterior fueron generados por los siguientes motivos mostrados en la tabla 2.8:

Tabla 2. 8.

Motivos de gastos por daños, conservación o vencimiento de productos

\begin{tabular}{|c|c|}
\hline Producto & Motivo \\
\hline Jabón & Compra de veneno para ratas \\
\hline Jaboncillo & Descuento en precio de venta por envases deteriorados \\
\hline Betún Nugget & Producto Vencido \\
\hline $\begin{array}{c}\text { Papel } \\
\text { higiénico }\end{array}$ & Compra de cinta de embalaje por fallas en la bolsa \\
\hline Fideos & Producto malogrado por gorgojo o envase roto \\
\cline { 2 - 3 } & Compra de cinta de embalaje, bolsas transparentes, \\
líquido para fumigar
\end{tabular}

Fuente: Proveedores de Abarrotes Santa Ana SRL (2016)

Elaboración Propia 


\subsubsection{Determinación de posibles oportunidades de mejora}

En la sección anterior, se puede apreciar las falencias que presenta la empresa. Sin embargo, estas no son problemas que se requiera de mucho tiempo e inversión para poder solucionarlas. Por lo cual las mejoras que se propongan serán sencillas y fáciles de implementar.

Con respecto a las ventas perdidas, se identifica como oportunidad de mejora el abastecer a tiempo y con los productos que el público requiera al almacén con el fin de aumentar el nivel de servicio. Por otro lado, sería importante que el encargado de la tienda mantenga actualizado los precios de los productos y realizar ciertos descuentos con el fin de evitar que los clientes prefieran realizar sus compras en la competencia. Asimismo, equilibrar el costo de mantener un stock adecuado con el nivel de servicio óptimo que permita minimizar los costos.

En cuanto a los gastos por transporte del almacén auxiliar, se puede realizar una proyección de las ventas que minimice los traslados semanales en la moto carguera disminuyendo dichos gastos.

Por otro lado, para los gastos por daños, conservación o vencimiento de productos, se puede implementar un control de las fechas de vencimiento de los productos y aplicar medidas para la manipualción correcta de los productos.

\subsubsection{Selección del sistema o proceso a mejorar}

Según lo mostrado líneas atrás, la empresa ha incurrido en pérdidas y gastos los cuales se han promediado por cada indicador y se muestran en la siguiente tabla 2.9. 
Tabla 2. 9.

Resumen de indicadores de la empresa

\begin{tabular}{|c|c|c|}
\hline Indicador & Promedio & Unidad de medida \\
\hline $\begin{array}{c}\text { Costo de oportunidad por ventas } \\
\text { perdidas } \\
\text { (Política de almacenamiento) }\end{array}$ & 23,490 & $\mathrm{~S} / . / \mathrm{MES}$ \\
\hline $\begin{array}{c}\text { Gastos por daños, conservación o } \\
\text { vencimiento de } \\
\text { productos }\end{array}$ & 374 & $\mathrm{~S} / . / \mathrm{MES}$ \\
\hline $\begin{array}{c}\text { Gastos de transporte } \\
\text { desde almacén auxiliar. }\end{array}$ & 3,150 & $\mathrm{~S} / . / \mathrm{MES}$ \\
\hline
\end{tabular}

Elaboración Propia

Calculando el monto total de dinero por año que la empresa dejaría de percibir, se obtiene lo siguiente:

$$
\text { Monto total }=(23,490+374+3,150) * 12=\text { S } / .324,168 \text { por año }
$$

Por ello, se ha decidido resolver los tres problemas que se perciben en estos indicadores; y además, porque estos requieren de soluciones de corto plazo que casi no requieren de inversión asociada y son fáciles de implementar. 


\section{CAPÍTULO III: DIAGNÓSTICO DE LA EMPRESA}

\subsection{Análisis del sistema o proceso objeto de estudio}

\subsubsection{Caracterización detallada del sistema o proceso objeto de estudio}

A continuación, se muestra la figura 3.1. en la cual se describe el diagrama de proceso que posee la empresa para poder cumplir con sus funciones.

\section{Figura 3. 1.}

\section{Diagrama de proceso de la empresa}

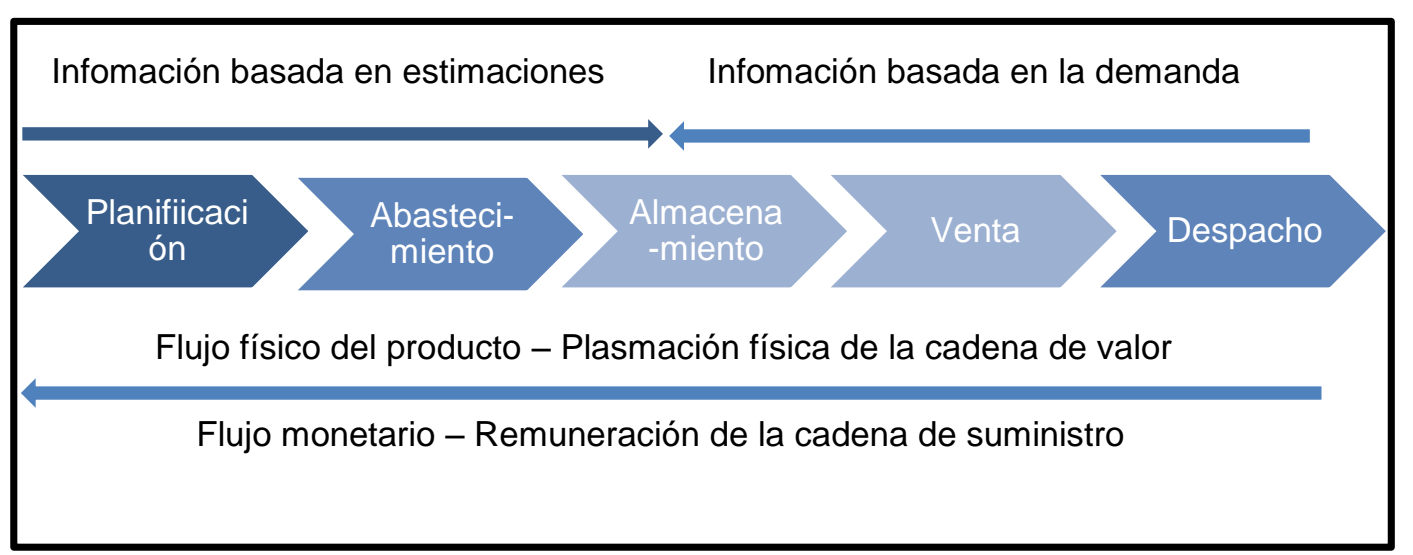

Fuente: Proveedores de Abarrotes Santa Ana SRL (2017)

Elaboración Propia

Como se mencionó anteriormente, la empresa se dedica a la venta al por mayor de productos de consumo masivo por lo cual requiere de un proceso que le permita atender la necesidad de abastecimiento de producto de sus clientes. Por ello, se establece como principales procesos al de venta y despacho. Es importante resaltar que el proceso de planificación se realiza de manera informal debido a que se basa en la experiencia del dueño.

A continuación se describirán las actividades de cada uno de los procesos principales: 


\subsubsection{Proceso de Venta:}

- Recibir al cliente

Cuando el cliente ingresa al local se le saluda amablemente y se le pregunta cuál es su pedido.

- Confirmar si se tiene stock del producto pedido

La encargada de ventas, al escuchar el pedido, revisa el stock del producto solicitado con el fin de verificar si se encuentra la cantidad requerida en el almacén.

- Comunicar el total a pagar

Después que el cliente recibe la confirmación, pregunta el precio y si este posee algún descuento debido al volumen a comprar. Por ello, se le comunica el total a pagar.

Esta actividad es muy importante ya que de esta depende si el cliente sigue con el proceso debido a que evaluará los beneficios que esta compra le otorgaría.

- $\quad$ Elaborar boleta o factura

Siguiendo con las exigencias de SUNAT y con el fin de llevar un control de las ventas, se emite un comprobante de pago por los productos que se desea obtener.

Dependiendo del monto o del requerimiento del cliente, se establecerá si se emite una boleta o factura.

- $\quad$ Entregar el comprobante de pago a la cajera

La encargada de atender el pedido del cliente imprime el comprobante de pago y le entrega a la cajera directamente con el fin de prevenir posibles engaños por parte de los clientes.

\section{- Realizar el pago por parte del cliente}

El cliente le entrega el dinero a la cajera. Seguidamente, esta le entrega su respectivo vuelto y sella el comprobante como cancelado.

\subsubsection{Proceso de Despacho}

- Entregar el comprobante al encargado del almacén

La cajera entrega el comprobante de pago sellado al cliente y este lo entrega al encargado del almacén si es que desea recoger su pedido inmediatamente.

\section{- Comunicar la orden de productos a entregar}

El almacenero comunica el pedido de productos que el cliente ha comprado a los estibadores de la empresa que él seleccionó previamente debido a la ubicación de estos.

- Entregar los productos al cliente o al estibador contratado por el cliente 
Finalmente, se sella el comprobante de pago como entregado y se entrega la mercadería al cliente o al estibador contratado por el cliente.

En la siguiente figura 3.2. , se describe el proceso completo que realiza el cliente para realizar su compra el cual está compuesto por los procesos importantes de las empresa. 
Figura 3. 2.

Diagrama del proceso que el cliente realiza para comprar

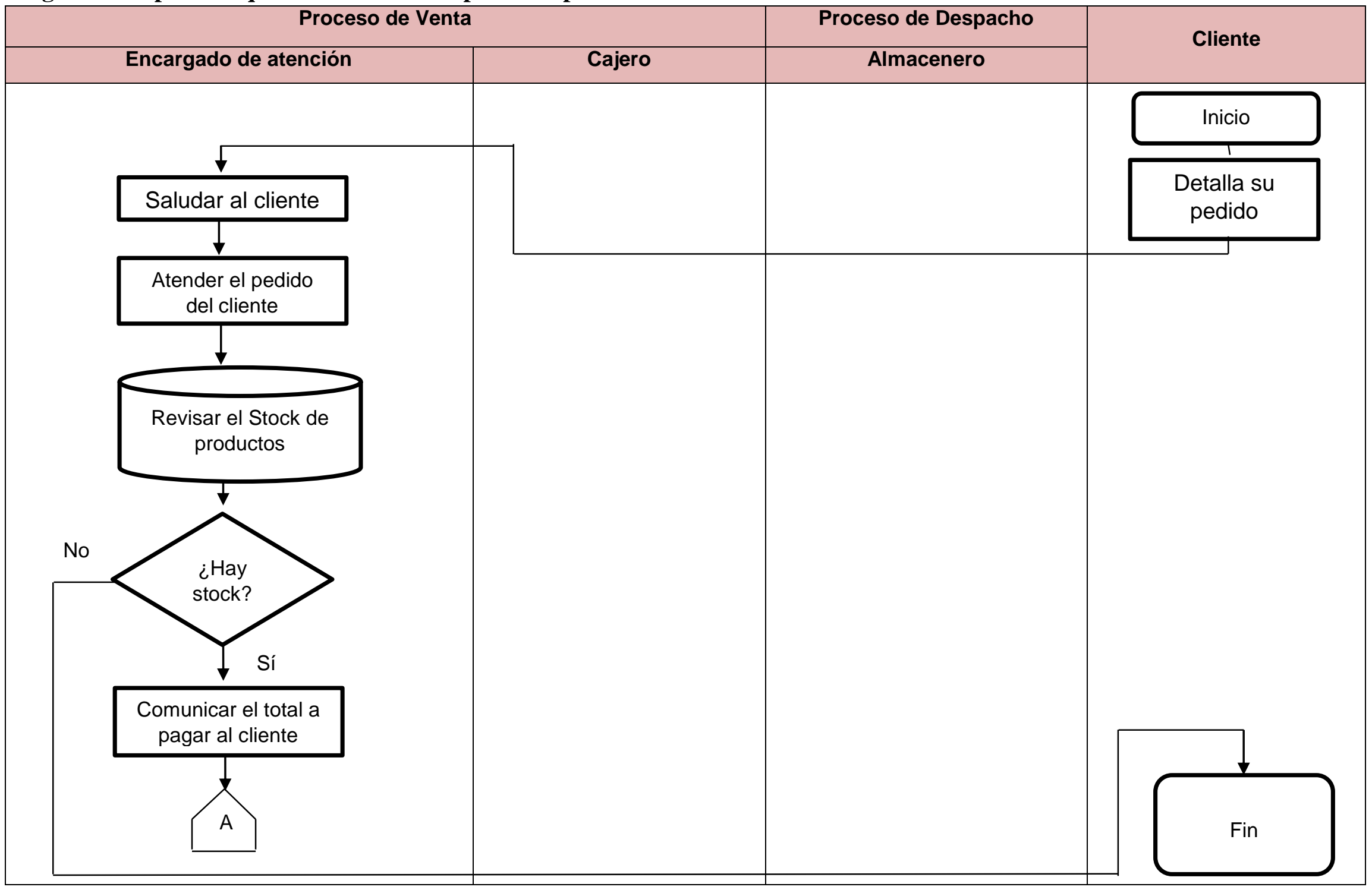




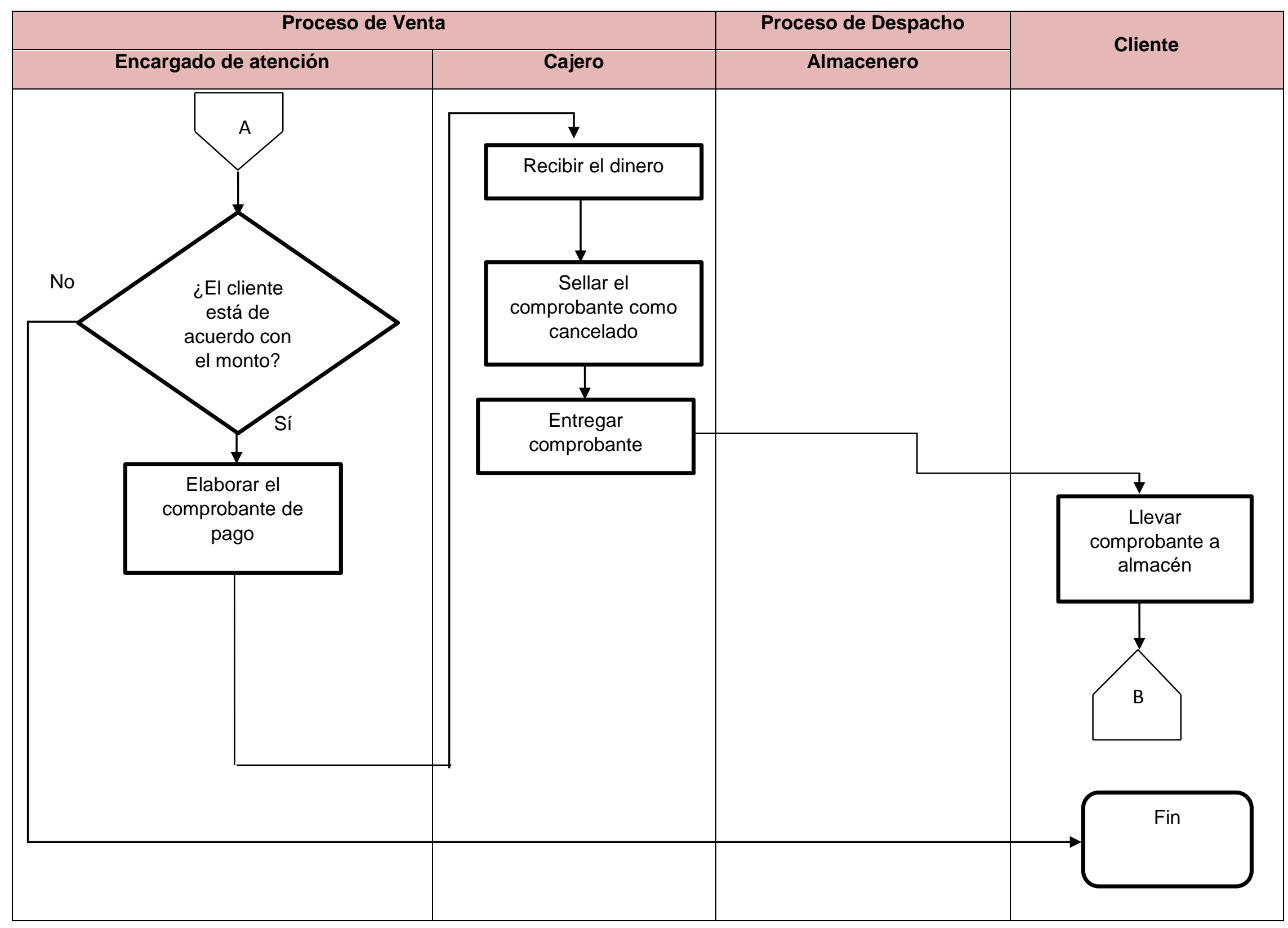




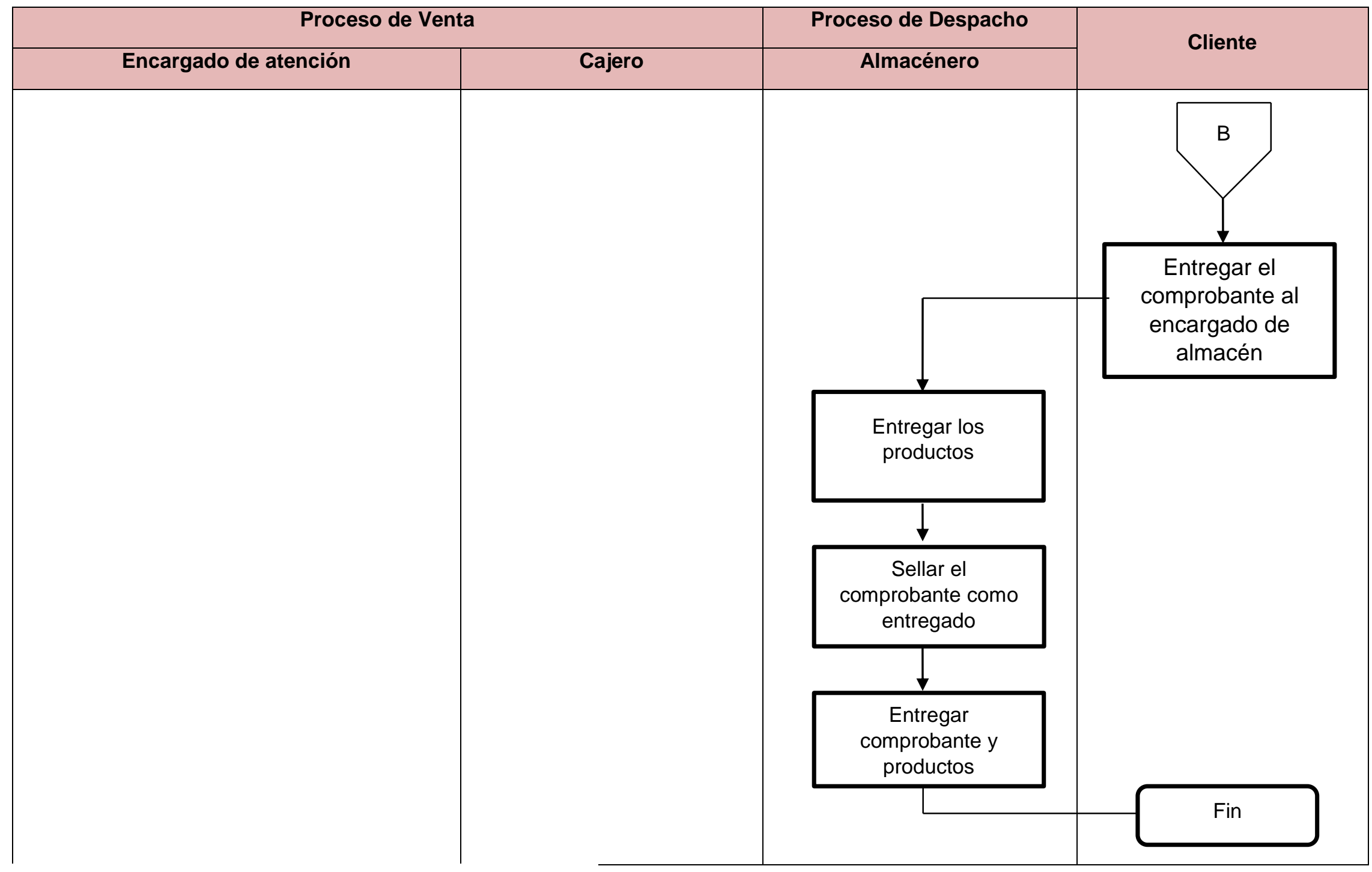

Fuente: Proveedores de Abarrotes Santa Ana SRL (2017) Elaboración propia 


\subsubsection{Análisis de los indicadores específicos de desempeño del sistema o proceso}

\section{a) Costo total de política de almacenamiento:}

El costo de la política actualmente no es el adecuado, debido a que se tiene mucha fuga de clientes por falta de stock y por consiguiente ventas perdidas. En la misma línea, el nivel de servicio no es considerado como correcto según la gerencia de la empresa.

Para este punto, primero se debe definir el nivel de stock que se quiere tener, para calcular el abastecimiento necesario y el nivel de stock adecuado para cumplir con la demanda.

\section{b) Gastos de transporte de mercancías entre almacenes:}

El gasto logístico de transportar mercancías entre almacenes es elevado y se explica en una mala planificación de demanda. Además, es un costo elevado por viaje y se lleva pocas mercancías, por lo que se puede tener dos frentes de optimización.

\section{c) Gastos por daños y vencimiento de productos:}

La ocurrencia de daños de productos es alta y se da por malas prácticas en los traslados de productos. Sin embargo, los gastos más importantes se dan por vencimiento de productos, y esto se da por la mala organización del almacén.

\subsection{Determinación de las causas raíces de los problemas seleccionados}

\subsubsection{Análisis de los factores que influyen favoreciendo o limitando los resultados actuales}

El fin de esta investigación es mejorar la rentabilidad de la empresa la cual está directamente relacionada con el desempeño de la cadena de suministro. Por ello, es que se revisó los controladores que se menciona en el párrafo citado posteriormente para determinar las causas que se relacionan con los problemas de la empresa que son parte del estudio.

"Para entender cómo puede mejorar una compañía el desempeño de la cadena de suministro en términos de capacidad de respuesta y eficiencia, debemos examinar sus elementos logísticos e interfuncionales: instalaciones, inventario, transporte, información, aprovisionamiento, y fijación de precios. Estos controladores interactúan para determinar el desempeño de la cadena de suministro en función de la capacidad de respuesta y eficiencia.” (Chopra, Meindl, Navarro y Murrieta, 2013) 
A continuación se muestra las causas que cada problema posee mediante los diagramas de Ishikawa, mostrados en las figuras 3.3., 3.5., y 3.7.; y además, se señala la causa principal obtenida por medio de los diagramas de Pareto. 
- Ventas perdidas :

Figura 3. 3.

Diagrama de Ishikawa - costo de política de almacenamiento

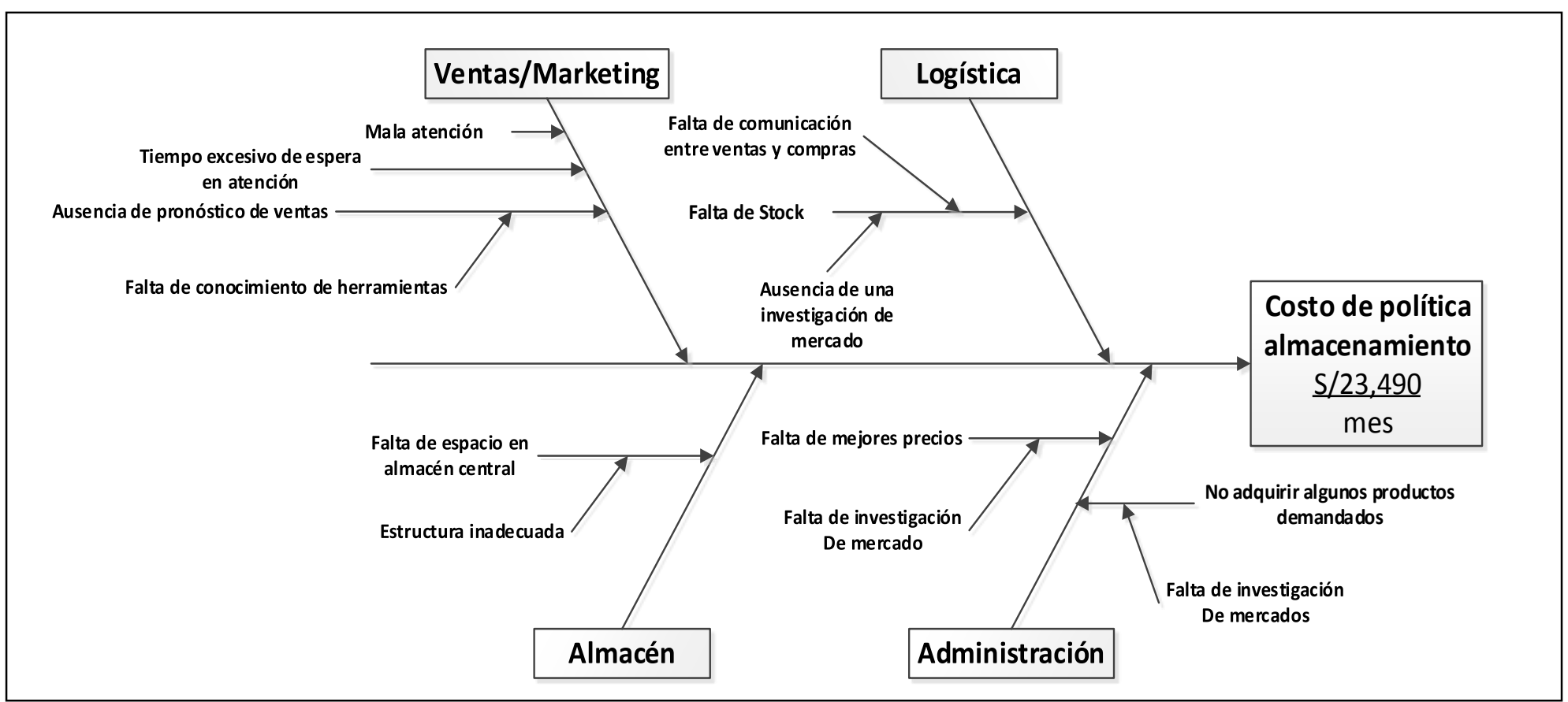

Elaboración propia 
Después de haber encontrado las causas, se procedió a analizar la causa principal. Para ello, se seleccionaron las tres que más han influido en la evaluación de este indicador; y a la vez, se agrupó a las demás con la denominación “otras” debido a su baja ocurrencia. El procedimiento se muestra a continuación mediante la tabla 3.1. y la figura 3.4.:

Tabla 3. 1.

Análisis de las causas del costo de política de almacenamiento

\begin{tabular}{|c|c|c|c|}
\hline Causas & $\begin{array}{c}\mathbf{N}^{\circ} \text { de } \\
\text { ocurrencia }\end{array}$ & \% & \% Acum \\
\hline Falta de stock & 25 & $50 \%$ & $50 \%$ \\
\hline $\begin{array}{c}\text { Ausencia del producto } \\
\text { demandado }\end{array}$ & 13 & $26 \%$ & $76 \%$ \\
\hline $\begin{array}{c}\text { Falta de precios } \\
\text { competitivos }\end{array}$ & 10 & $20 \%$ & $96 \%$ \\
\hline Otros & 2 & $4 \%$ & $100 \%$ \\
\hline TOTAL & 50 & $100 \%$ & \\
\hline
\end{tabular}

Fuente: Proveedores de Abarrotes Santa Ana SRL (2016)

Elaboración propia

Figura 3. 4.

Diagrama de Pareto - Costo de política de almacenamiento

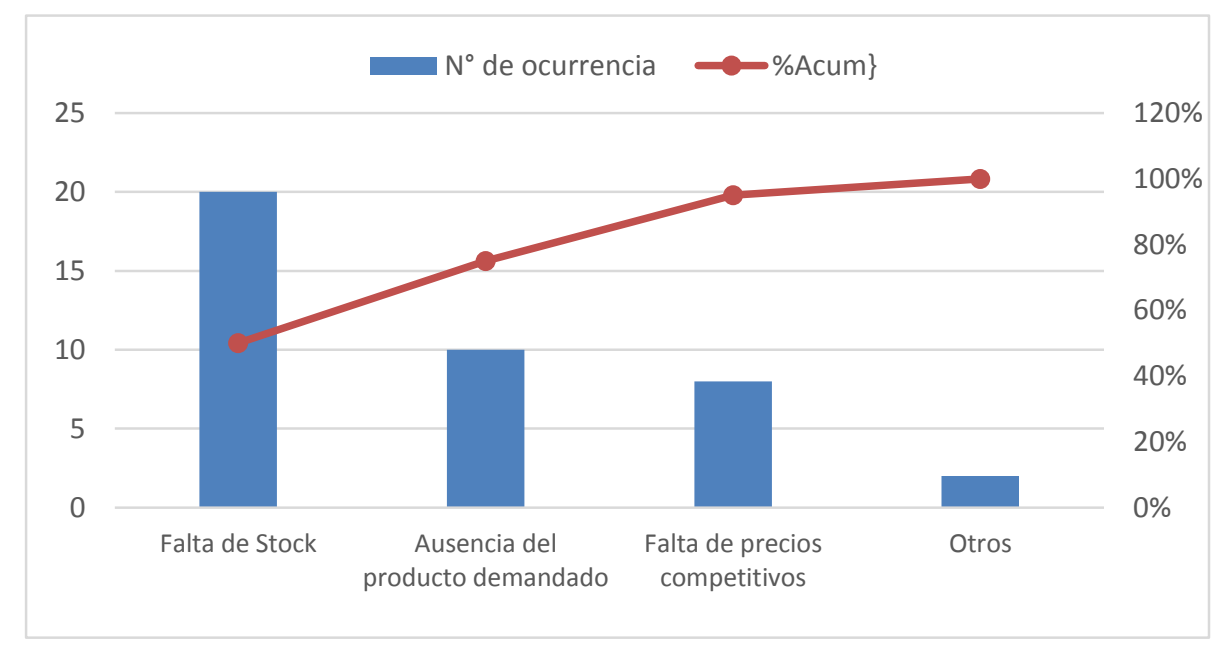

Elaboración propia 
Según el análisis, se establece como zona A a la falta de stock, falta de precios competitivos y ausencia de productos demandados debido a que representan más del $80 \%$ del total de ocurrencias de las causas. Por ello, se concluye que estas representan los principales motivos por los cuales se producen las ventas perdidas.

\section{- Gastos por daños, conservación o vencimiento de productos:}

Figura 3. 5.

Diagrama de Ishikawa - Gastos por daños y vencimiento de productos

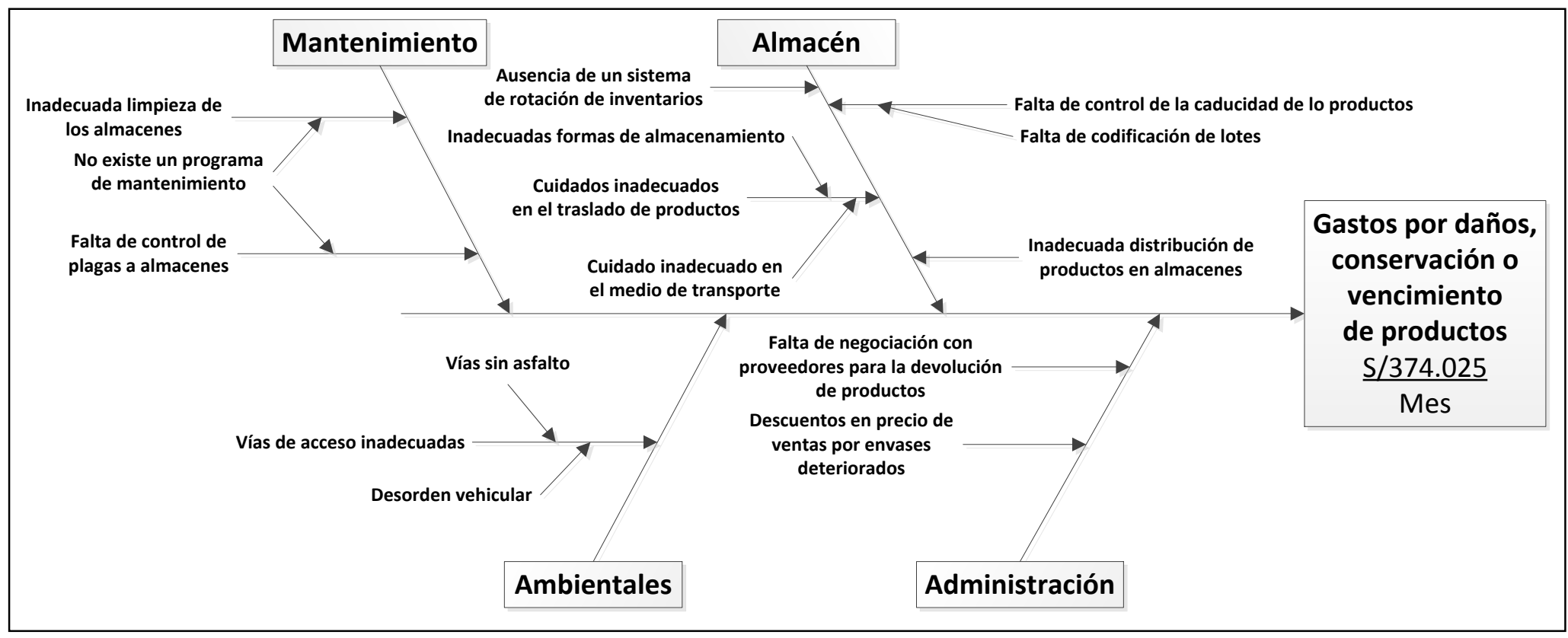

Elaboración propia 
Identificadas las causas se procedió a identificar las causas más frecuentes. Asimismo, se agrupó a las de menos frecuencia en la categoría "otras". En la siguiente tabla 3.2 y diagrama de Pareto de la figura 3.6. , se muestra el procedimiento para hallar la causa principal:

Tabla 3. 2.

Análisis de las causas de gastos por daños y vencimiento de productos

\begin{tabular}{|c|c|c|c|}
\hline Causas & $\begin{array}{c}\text { Gasto en } \\
\text { Soles }\end{array}$ & \% & \% Acum \\
\hline $\begin{array}{c}\text { Falta de control de } \\
\text { la caducidad de productos }\end{array}$ & 175.25 & $46.86 \%$ & $46.86 \%$ \\
\hline $\begin{array}{c}\text { Cuidados inadecuados en el } \\
\text { traslado de productos }\end{array}$ & 94.2125 & $25.19 \%$ & $72.04 \%$ \\
\hline Falta de control de plagas & 87.4375 & $23.38 \%$ & $95.42 \%$ \\
\hline $\begin{array}{c}\text { Descuento en precio de } \\
\text { ventas por } \\
\text { envases deteriorados }\end{array}$ & 12.125 & $3.24 \%$ & $98.66 \%$ \\
\hline Otros & 5 & $1.34 \%$ & $100.00 \%$ \\
\hline Total & 374.025 & $100.00 \%$ & \\
\hline
\end{tabular}

Elaboración propia

Figura 3. 6.

Diagrama de Pareto - gastos por daños y vencimiento de productos

\begin{tabular}{|c|c|c|c|c|c|c|c|}
\hline $\begin{array}{r}200 \\
180 \\
160 \\
140 \\
120 \\
100 \\
80 \\
60 \\
40 \\
20 \\
0\end{array}-$ & 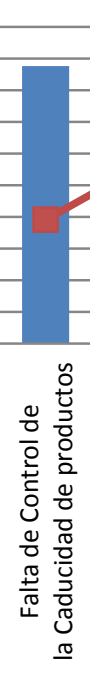 & 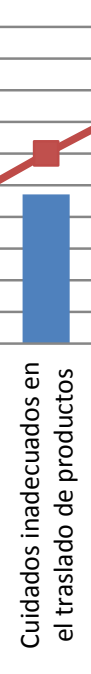 & $\begin{array}{l}0 \\
0 \\
00 \\
\frac{0}{0} \\
0 \\
0 \\
0 \\
0 \\
0 \\
0 \\
0 \\
0 \\
0 \\
0 \\
\frac{\pi}{0} \\
\frac{\pi}{\pi} \\
4\end{array}$ & 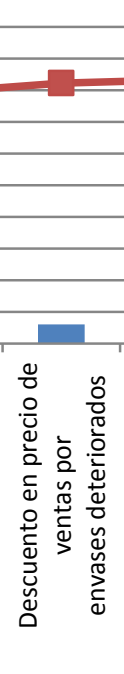 & 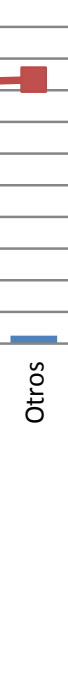 & $\begin{array}{l}120.00 \% \\
100.00 \% \\
80.00 \% \\
60.00 \% \\
40.00 \% \\
20.00 \% \\
0.00 \%\end{array}$ & $\begin{array}{l}\text { Gasto en Soles } \\
\text { \%Acum }\end{array}$ \\
\hline
\end{tabular}

Elaboración Propia 
Según lo observado en el diagrama de Pareto, se determina como causas principales a la falta de control de la caducidad de productos, cuidados inadecuados en el traslado de productos y a la falta de control de plagas debido a que influyen en más del $80 \%$ en la ocurrencia de este indicador.

- Gastos de transporte desde almacén auxiliar.

Figura 3. 7.

Diagrama de Ishikawa - Gastos de transporte entre almacenes

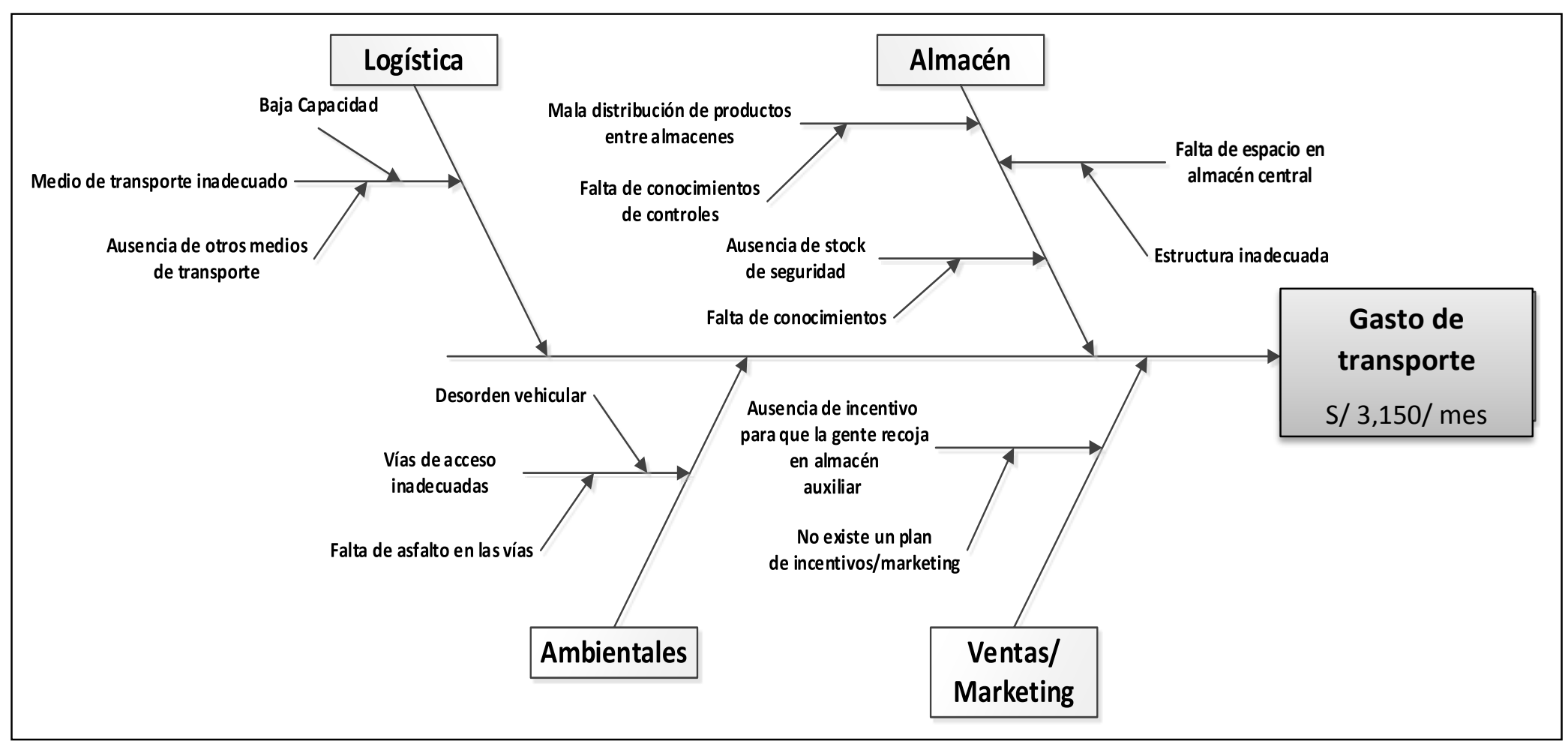

Elaboración propia 
Después de haber realizado el diagrama de Ishikawa, se procedió a analizar cuál es la causa principal de este problema mediante un diagrama de Pareto. El procedimiento se muestra a continuación a través de la table 3.3. y la figura 3.8.

Tabla 3. 3.

Análisis de causas - Gastos de transporte entre almacenes

\begin{tabular}{|c|c|c|c|}
\hline Causa & $\begin{array}{c}\mathbf{N}^{\circ} \text { Viajes a } \\
\text { la semana }\end{array}$ & $\%$ Acum \\
\hline $\begin{array}{c}\text { Mala distribución de productos } \\
\text { entre almacenes }\end{array}$ & 25 & $69 \%$ & $69 \%$ \\
\hline $\begin{array}{c}\text { Falta de capacidad } \\
\text { de almacén central }\end{array}$ & 5 & $14 \%$ & $83 \%$ \\
\hline $\begin{array}{c}\text { Baja capacidad } \\
\text { de transporte }\end{array}$ & 4 & $11 \%$ & $94 \%$ \\
\hline Otros & 2 & $6 \%$ & $100 \%$ \\
\hline Total & 36 & $100 \%$ & \\
\hline
\end{tabular}

Elaboración propia

Figura 3. 8.

Diagrama de Pareto - Gastos de transporte dentre almacenes

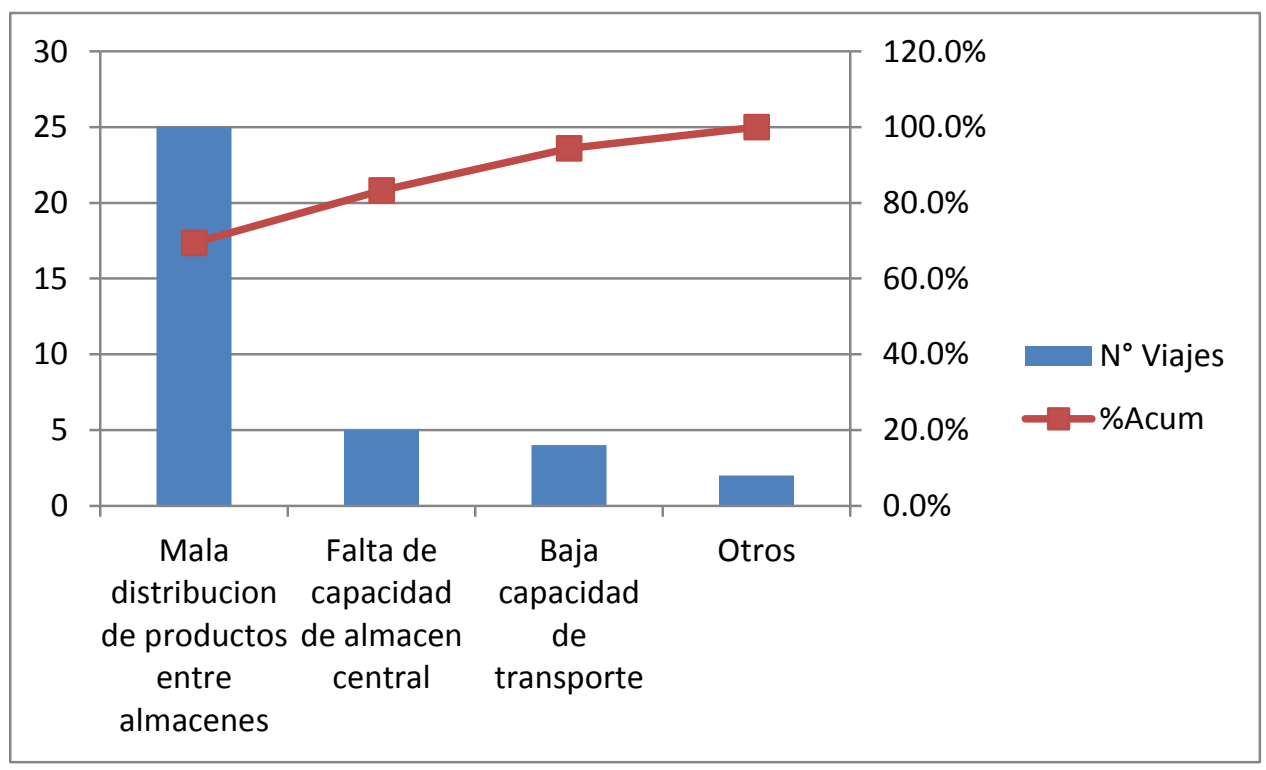

Elaboración propia

Al observar los resultados de este diagrama, se concluye que las principales causas de este indicador son la mala distribución de productos entre almacenes y la falta de capacidad de almacén central debido a que representan el $83 \%$ de los gastos. 


\subsubsection{Identificación y evaluación de las fortalezas y debilidades de la empresa}

- $\quad$ Fortalezas

- Contar con una cartera de productos competitiva: Se tiene una variedad de productos importante, de marcas reconocidas.

- $\quad$ Ubicación estratégica del local: El local se ubica en la zona comercial de Chiclayo.

- Relación duradera con clientes: Se desarrolla la fidelidad de los clientes, al ofrecerles descuentos especiales por su preferencia.

- Personal comprometido: Las personas que trabajan en la organización es contratada en base a recomendaciones.

- Alianza estratégica con proveedores: Acuerdos con los principales proveedores para la exclusividad de productos y precios especiales.

- $\quad$ Debilidades

- Excesivos costos logísticos: Los costos de transporte son los principales en la cadena de valor.

- Inexperiencia administrativa: Falta de políticas establecidas.

- Poco espacio para atención al público y de almacén: Desorden en la tienda principal dificulta el servicio brindado.

- Ausencia de indicadores de gestión: Existe la información pero no es analizada en forma de indicadores.

\subsection{Determinación de objetivos del trabajo de investigación}

Según lo conversado con los dueños de la empresa y la evaluación realizada de la empresa, se pudo determinar los objetivos que tendrá el presente trabajo. A continuación, se detallan:

- Se realizará la inversión en las soluciones si estas reducen el 90\% de los gastos o del dinero que la empresa deja de percibir.

- $\quad$ Se contará con 200,000 soles para la implemtación de las soluciones. No se podrá pedir algún adicional de capital. Por ello, se deberá respetar el límite.

- Cualquiera de las soluciones no deberá requerir numerosas paradas en la jornada de trabajo. 
- $\quad$ No se deberá requerir de conocimientos especializados, es decir, deben ser fáciles de implementar por el personal a cargo.

- Se deberá tener en cuenta al proponer las soluciones que estas deben ayudar a mejorar las condiciones de seguridad en el trabajo. 


\section{CAPÍTULO IV : DETERMINACIÓN DE LA PROPUESTA DE SOLUCIÓN}

\subsection{Planteamiento de alternativas de solución a la problemática encontrada}

A continuación, mediante la técnica de brainstorming se muestra las soluciones posibles que se propone para cada uno de los problemas raíces que se posee en cada uno de los indicadores de gestión de la empresa. Dichas soluciones se muestran en las figuras 4.1. , 4.2. y 4.3.

\section{Figura 4. 1.}

Soluciones a los problemas principales de costo de política de almacenamiento Indicador : Costo de política de almacenamiento
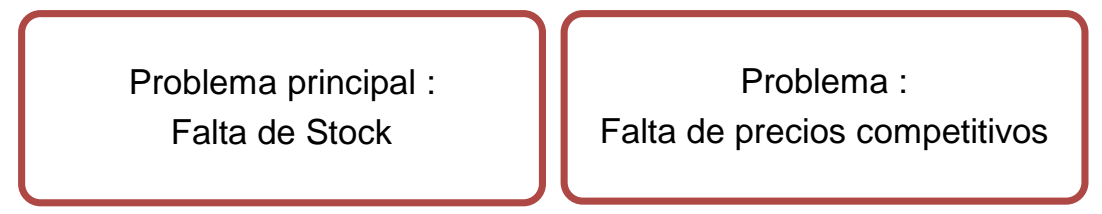

Problema :

Ausencia de producto demandado porque no es parte de la cartera
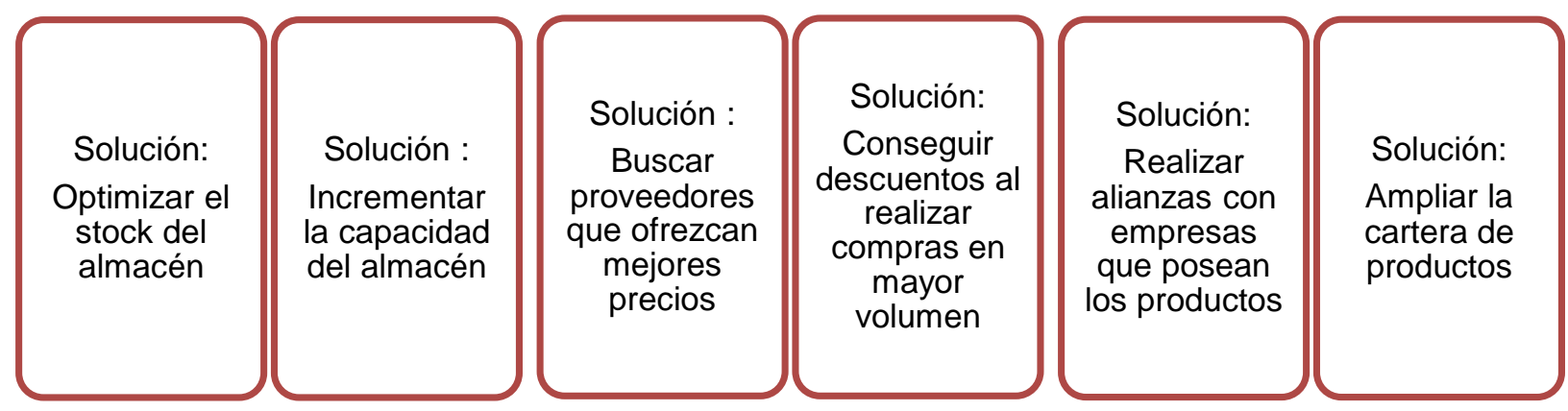

Elaboración propia 
Figura 4. 2.

\section{Soluciones a los problemas principales de gastos por daños y vencimiento de productos}

Indicador : Gastos por daños, conservación o vencimiento de productos

\section{Problema principal: Falta de control de caducidad de productos}

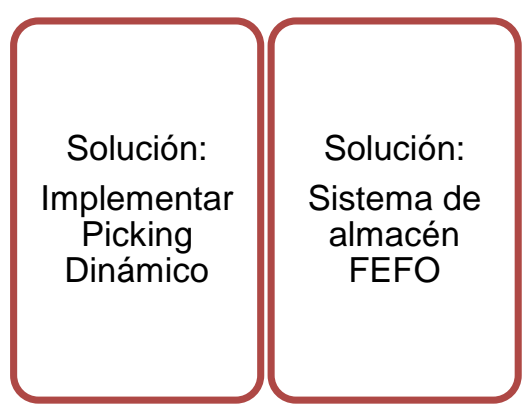

\section{Problema:}

Cuidados inadecuados en el traslado de productos

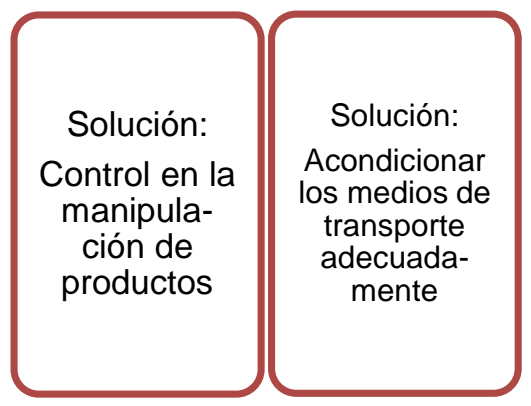

Problema:

Falta de control de plagas

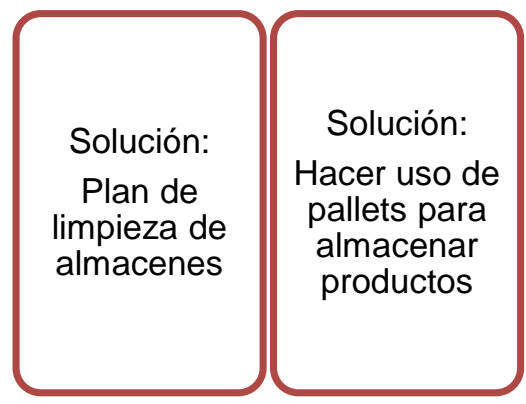

Elaboración propia

Figura 4. 3.

Soluciones a los problemas principales de gastos de transporte entre almacenes

Indicador : Gastos de transporte desde almacén auxiliar
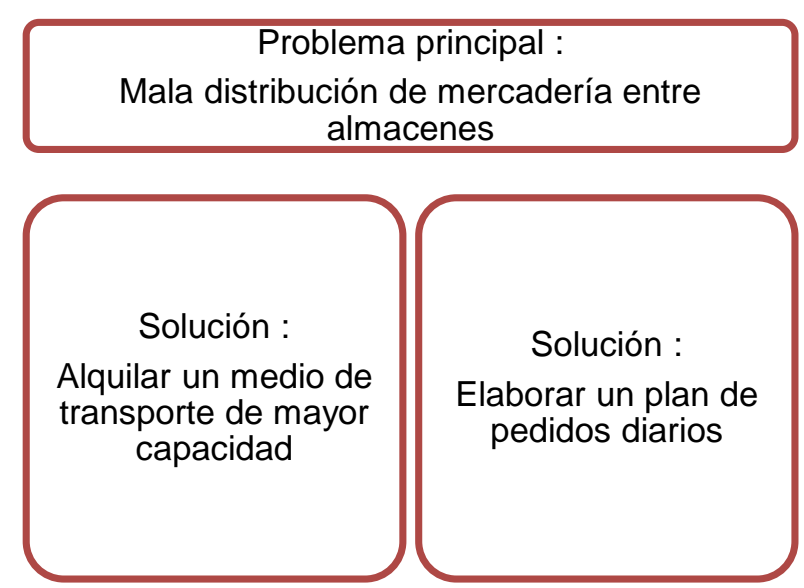

Problema:

Falta de capacidad de almacén central

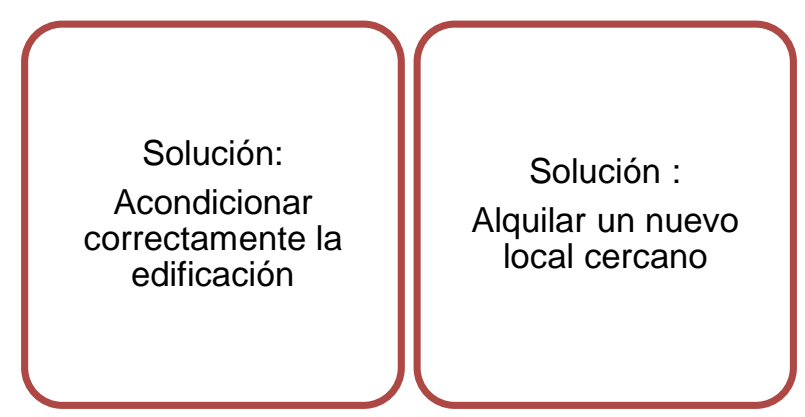

Elaboración propia 


\subsection{Selección de alternativas de solución}

\subsubsection{Determinación y ponderación de criterios evaluación de las alternativas}

Después de haber planteado posibles soluciones a cada uno de los problemas raíces, se procedió a seleccionar una solución óptima para estos. Para ello, se utilizó el método de matriz de enfrentamiento y ranking de factores. Se escogió como factores a la inversión que se requiere, tiempo de implementación que se necesita, el aporte que brindaría a mejorar las condiciones de seguridad en la empresa y a las restricciones que esta pueda tener para su implementación, como por ejemplo, la cantidad de personal que necesita dedicar tiempo, el nivel de conocimientos necesarios, número de paradas de la empresa, riesgos, etc.

Teniendo los factores que se utilizarán en la evaluación, se procedió a determinar el peso de cada uno de ellos como se muestra en la table 4.1.:

Tabla 4. 1.

Matriz de enfrentamiento de factores

\begin{tabular}{|l|c|c|c|c|c|c|}
\hline \multicolumn{1}{|c|}{ Factores } & Inversión & $\begin{array}{l}\text { Tiempo de } \\
\text { implementación }\end{array}$ & Restricciones & $\begin{array}{l}\text { Mejorar } \\
\text { condiciones } \\
\text { de seguridad }\end{array}$ & Total & Peso \\
\hline Inversión & - & 1 & 1 & 1 & 3 & $43 \%$ \\
\hline $\begin{array}{l}\text { Tiempo de } \\
\text { implementación }\end{array}$ & 0 & - & 1 & 0 & 1 & $14 \%$ \\
\hline Restricciones & 0 & 1 & - & 0 & 1 & $14 \%$ \\
\hline $\begin{array}{l}\text { Mejorar } \\
\text { condiciones de } \\
\text { seguridad }\end{array}$ & 0 & 1 & 1 & - & $29 \%$ \\
\cline { 1 - 6 }
\end{tabular}

Elaboración propia

Cabe recalcar que cada uno de estos tendrá escalas que permitirán hallar el puntaje ponderado de cada solución. Dichas escalas se muestran en la tabla 4.2.: 
Tabla 4. 2.

\section{Escala de factores}

\begin{tabular}{|c|c|c|}
\hline Factor & Calif. & Valor \\
\hline \multirow[t]{4}{*}{ Inversión } & 1 & Inversión muy alta (>S/.10,000) \\
\hline & 2 & Inversión alta $([\mathrm{S} / .1,000-\mathrm{S} / 10,000)$ \\
\hline & 3 & Inversión baja ([S/.100-S/.1,000) \\
\hline & 4 & Inversión muy baja o sin inversión $(<\mathrm{S} / .100)$ \\
\hline \multirow{4}{*}{$\begin{array}{c}\text { Tiempo de } \\
\text { Implementación }\end{array}$} & 1 & Más de 12 meses \\
\hline & 2 & $6-12$ meses \\
\hline & 3 & $1-6$ meses \\
\hline & 4 & Menos de un mes \\
\hline \multirow[t]{4}{*}{ Restricciones } & 1 & $\begin{array}{c}\text { Excesivas restricciones (excesivo personal, } \\
\text { conocimientos especializados, } \\
\text { paralizaciones excesivas de la tienda, etc.) }\end{array}$ \\
\hline & 2 & $\begin{array}{c}\text { Muchas restricciones(mucho personal, conocimientos } \\
\text { intermedios, } \\
\text { paralizaciones regulares en la tienda) }\end{array}$ \\
\hline & 3 & $\begin{array}{c}\text { Pocas restricciones (poco personal, conocimientos } \\
\text { intermedios, } \\
\text { pocas paralizaciones en la tienda, etc.) }\end{array}$ \\
\hline & 4 & $\begin{array}{c}\text { Sin restricciones relevantes (Poco personal, } \\
\text { conocimientos básicos, } \\
\text { sin paralizaciones, etc.) }\end{array}$ \\
\hline \multirow{4}{*}{$\begin{array}{l}\text { Mejorar } \\
\text { condiciones de } \\
\text { seguridad }\end{array}$} & 1 & No influye en mejorar las condiciones de seguridad \\
\hline & 2 & $\begin{array}{c}\text { Mejora las condiciones de seguridad pero no permite el } \\
\text { buen desempeño de las labores }\end{array}$ \\
\hline & 3 & $\begin{array}{l}\text { Mejora las condiciones de seguridad y causa } \\
\text { incomodidad durante el desempeño de las labores }\end{array}$ \\
\hline & 4 & $\begin{array}{c}\text { Mejora las condiciones de seguridad y permite el buen } \\
\text { desempeño de las labores }\end{array}$ \\
\hline
\end{tabular}

Elaboración propia

\subsubsection{Evaluación cualitativa y cuantitativa de alternativas de solución}

A continuación se muestran los resultados del ranking de factores que se obtuvieron en cada una de las soluciones de los problemas: 
- Costo de política de almacenamiento

Tabla 4. 3.

Escala de factores - Falta de stock

\begin{tabular}{|c|c|c|c|c|c|}
\hline \multirow{4}{*}{ Factores } & \multirow{4}{*}{ Peso } & \multicolumn{4}{|c|}{$1^{\circ}$ Problema principal : Falta de stock } \\
\hline & & \multicolumn{4}{|c|}{ Soluciones } \\
\hline & & \multicolumn{2}{|c|}{$\begin{array}{c}\text { Optimizar el stock } \\
\text { en cada almacén } \\
\text { (Mejorar nivel de } \\
\text { servicio) }\end{array}$} & \multicolumn{2}{|c|}{$\begin{array}{c}\text { Incrementar la } \\
\text { capacidad } \\
\text { del almacén central }\end{array}$} \\
\hline & & Calif. & Puntaje & Calif. & Puntaje \\
\hline Inversión & 0.43 & 3 & 1.29 & 2 & 0.86 \\
\hline $\begin{array}{c}\text { Tiempo de } \\
\text { implementación }\end{array}$ & 0.14 & 3 & 0.42 & 2 & 0.28 \\
\hline Restricciones & 0.14 & 3 & 0.42 & 2 & 0.28 \\
\hline $\begin{array}{c}\text { Mejorar condiciones } \\
\text { de seguridad }\end{array}$ & 0.29 & 4 & 1.16 & 4 & 1.16 \\
\hline \multicolumn{2}{|l|}{ Total } & & 3.29 & & 2.58 \\
\hline
\end{tabular}

Elaboración propia

Como se observa en la tabla 4.3., la solución con mayor puntaje es optimizar el stock en cada almacén lo cual nos indica que es la más óptima para aplicar. A esta solución se le aplicó la calificación 3 en el factor inversión debido a que no se requiere mayor inversión que un pequeño estudio de planificación apoyado con las bases de datos existentes. Asimismo, se utilizó 3 al tiempo de implementación ya que se requiere de una cantidad de meses que permita planificar y llegar al modelo más exacto. Por otro lado, se le asignó 3 a restricciones debido a que requiere de poco personal para llevarlo a cabo. Finalmente, el último factor recibió la calificación de 4 ya que permitirá que el almacén no tenga cantidades innecesarias de los productos lo cual permitirá tener más orden y más espacio para los pasadizos. 
Tabla 4. 4.

Escala de factores - Falta de precios competitivos

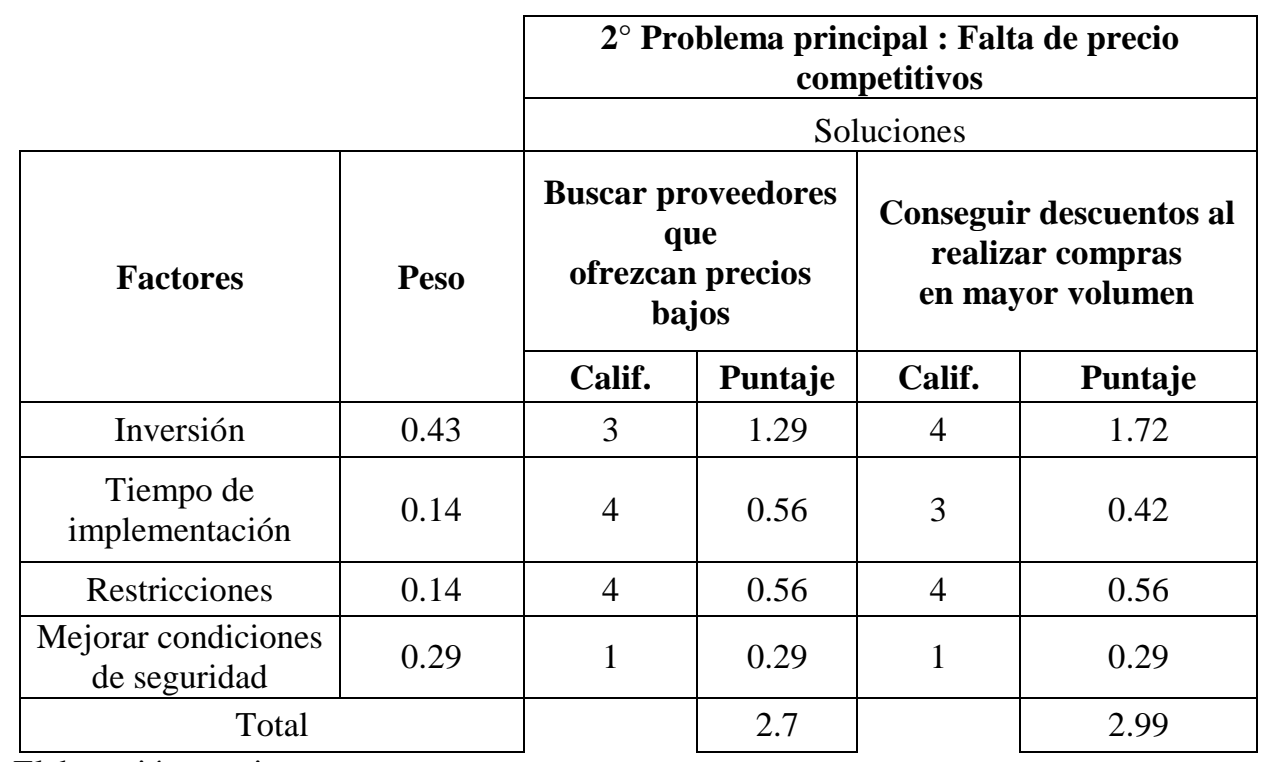

Elaboración propia

Según la tabla 4.4. , se determina como óptima la segunda solución. Se le otorgó la calificación de 4 en inversión debido a que no requiere de inversión alta, no más de una buena planificación. Cabe recalcar que no se considera como inversión la compra de mercadería debido a que esta es considerada dentro de los costos de operación de la empresa. Por otro lado, se asignó 3 al tiempo de implementación debido a que requerirá un tiempo mayor a un mes para determinar cuánto es lo que podría comprar la empresa la cual se encuentra limitada por el espacio en almacenes y el dinero que se pretende destinar a esta. Finalmente, el factor restricciones posee la calificación de 4 ya que requiere de poco personal, conocimientos básicos y no necesita realizar paradas en el tiempo de operación. Cabe mencionar que se dio la calificación 1 al factor cuarto debido a que no influye en la mejora de las condiciones de seguridad en el trabajo. 
Tabla 4. 5.

Escala de factores - Ausencia de productos demandados

\begin{tabular}{|c|c|c|c|c|c|}
\hline \multirow{4}{*}{ Factores } & \multirow{4}{*}{ Factor } & \multirow{2}{*}{\multicolumn{4}{|c|}{$\begin{array}{c}3^{\circ} \text { Problema principal : Ausencia de producto } \\
\text { demandado }\end{array}$}} \\
\hline & & & & & \\
\hline & & \multicolumn{2}{|c|}{$\begin{array}{l}\text { Realizar alianzas } \\
\text { con empresas que } \\
\text { posean los productos }\end{array}$} & \multicolumn{2}{|c|}{$\begin{array}{c}\text { Ampliar la cartera de } \\
\text { productos con productos } \\
\text { demandados }\end{array}$} \\
\hline & & Calif. & Puntaje & Calif. & Puntaje \\
\hline Inversión & 0.43 & 2 & 0.86 & 3 & 1.29 \\
\hline $\begin{array}{c}\text { Tiempo de } \\
\text { implementación }\end{array}$ & 0.14 & 2 & 0.28 & 3 & 0.42 \\
\hline Restricciones & 0.14 & 4 & 0.56 & 3 & 0.42 \\
\hline $\begin{array}{l}\text { Mejorar condiciones } \\
\text { de seguridad }\end{array}$ & 0.29 & 1 & 0.29 & 1 & 0.29 \\
\hline \multicolumn{2}{|l|}{ Total } & & 1.99 & & 2.42 \\
\hline
\end{tabular}

Elaboración propia

En esta tabla 4.5., se observa que la solución ganadora es ampliar la cartera de productos con productos demandados. Se otorgó la calificación de 3 a inversión debido a que se necesitará invertir entre 100 a 1000 soles para realizar una investigación de los requerimientos del mercado y de los proveedores que vendan los productos demandados, los datos a usarse principalmente es la experiencia del personal y tendencias del mercado. Para el segundo factor, se otorgó la calificación 3 ya que dicha investigación requerirá de más de un mes para finalizarse, se requiere negociar con proveedores y llegar a acuerdos. Finalmente, para el tercer factor, se le asignó la calificación de 3 debido a que se requiere de poco personal y conocimientos intermedios para analizar oportunidades. Cabe mencionar que esta solución no influye en la mejora de las condiciones de seguridad en el trabajo. Por ello , recibió la calificación 1 en el último factor. 
- Gastos por daños y vencimiento de productos

Tabla 4. 6.

Escala de factores - Falta de control de caducidad

\begin{tabular}{|c|c|c|c|c|c|}
\hline \multirow{4}{*}{ Factores } & \multirow{4}{*}{ Peso } & \multirow{2}{*}{\multicolumn{4}{|c|}{$\begin{array}{c}1^{\circ} \text { Problema principal : Falta de control de } \\
\text { caducidad de productos }\end{array}$}} \\
\hline & & & & & \\
\hline & & \multicolumn{2}{|c|}{$\begin{array}{c}\text { Implementar } \\
\text { Picking Dinámico }\end{array}$} & \multicolumn{2}{|c|}{$\begin{array}{l}\text { Implementar Sistema de } \\
\text { almacén FEFO }\end{array}$} \\
\hline & & Calif. & Puntaje & Calif. & Puntaje \\
\hline Inversión & 0.43 & 1 & 0.43 & 3 & 1.29 \\
\hline $\begin{array}{c}\text { Tiempo de } \\
\text { implementación }\end{array}$ & 0.14 & 3 & 0.42 & 2 & 0.28 \\
\hline Restricciones & 0.14 & 3 & 0.42 & 2 & 0.28 \\
\hline $\begin{array}{c}\text { Mejorar condiciones } \\
\text { de seguridad }\end{array}$ & 0.29 & 4 & 1.16 & 4 & 1.16 \\
\hline \multicolumn{2}{|l|}{ Total } & & 2.43 & & 3.01 \\
\hline
\end{tabular}

Elaboración propia

Para este problema, la solución más óptima a implementar es tener un sistema de almacén "First Expired, First Out", según los resultados mostrados en la tabla 4.6. Dicha solución no requiere de una inversión alta ya que se necesitará pocos materiales; asimismo, el tiempo de implementación es menor a 6 meses; y además, exige poco personal, pocas paradas en el tiempo de operación y conocimientos intermedios para su aplicación. Por otro lado, es importante mencionar que esta solución influye en la mejora de las condiciones de seguridad en el trabajo. 
Tabla 4. 7.

Escala de factores - Cuidados inadecuados en los traslados

\begin{tabular}{|c|c|c|c|c|c|}
\hline \multirow{4}{*}{ Factores } & \multirow{4}{*}{ Peso } & \multirow{2}{*}{\multicolumn{4}{|c|}{$\begin{array}{c}2^{\circ} \text { Problema principal : Cuidados inadecuados } \\
\text { en el traslado } \\
\text { de productos }\end{array}$}} \\
\hline & & & & & \\
\hline & & \multicolumn{2}{|c|}{$\begin{array}{l}\text { Control en la } \\
\text { manipulación de } \\
\text { productos }\end{array}$} & \multicolumn{2}{|c|}{$\begin{array}{l}\text { Acondicionar los medios } \\
\text { de transporte } \\
\text { adecuadamente }\end{array}$} \\
\hline & & Calif. & Puntaje & Calif. & Puntaje \\
\hline Inversión & 0.43 & 4 & 1.72 & 2 & 0.86 \\
\hline $\begin{array}{c}\text { Tiempo de } \\
\text { implementación }\end{array}$ & 0.14 & 4 & 0.56 & 3 & 0.42 \\
\hline Restricciones & 0.14 & 3 & 0.42 & 3 & 0.42 \\
\hline $\begin{array}{c}\text { Mejorar } \\
\text { condiciones de } \\
\text { seguridad }\end{array}$ & 0.29 & 4 & 1.16 & 1 & 0.29 \\
\hline \multicolumn{2}{|l|}{ Total } & & 3.86 & & 1.99 \\
\hline
\end{tabular}

Elaboración propia

Después de haber realizado el análisis, se observa en la tabla 4.7. que la solución más óptima a aplicar es el control de manipulación de productos debido a que no requiere de una inversión mayor a 100 soles ya que será un control desarrollado por los mismos trabajadores y sólo se necesitaría de una capacitación que realizaría el jefe de almacén a estos para la correcta manipulación que no tomará más de un mes para implementarse. Por otro lado, se necesita de conocimientos intermedios y pocas paradas en el proceso. Finalmente, se otorgó la calificación 4 al último factor debido a que desminuirá la probabilidad de accidentes ya que se manejarán los productos de manera óptima. 
Tabla 4. 8.

Escala de factores - Falta de control de plagas

\begin{tabular}{|c|c|c|c|c|c|}
\hline \multirow{4}{*}{ Factores } & \multirow{4}{*}{ Peso } & \multicolumn{4}{|c|}{$3^{\circ}$ Problema principal : Falta de control de plagas } \\
\hline & & \multicolumn{4}{|c|}{ Soluciones } \\
\hline & & \multicolumn{2}{|c|}{$\begin{array}{l}\text { Realizar y ejecutar un } \\
\text { plan de limpieza de } \\
\text { almacenes }\end{array}$} & \multicolumn{2}{|c|}{$\begin{array}{l}\text { Hacer uso de pallets para } \\
\text { almacenar productos }\end{array}$} \\
\hline & & Calif. & Puntaje & Calif. & Puntaje \\
\hline Inversión & 0.43 & 4 & 1.72 & 2 & 0.86 \\
\hline $\begin{array}{c}\text { Tiempo de } \\
\text { implementación }\end{array}$ & 0.14 & 4 & 0.56 & 3 & 0.42 \\
\hline Restricciones & 0.14 & 3 & 0.42 & 2 & 0.28 \\
\hline $\begin{array}{c}\text { Mejorar } \\
\text { condiciones de } \\
\text { seguridad }\end{array}$ & 0.29 & 1 & 0.29 & 1 & 0.29 \\
\hline \multicolumn{2}{|l|}{ Total } & & 2.99 & & 1.85 \\
\hline
\end{tabular}

Elaboración propia

Como se muestra en la tabla 4.8., la solución ganadora es el plan de limpieza de almacenes ya que requerirá de baja inversión debido a que será hecho por los mismos trabajadores de la empresa y los elementos de limpieza a utilizar no son de un costo alto; y además, sólo se necesitará menos de un mes para su aplicación, pocas paradas en el proceso y poco personal. Es importante mencionar que está solución no mejora las condiciones de seguridad en la empresa. Por tanto, se dio la calificación 1. 


\section{- Gastos de transporte entre almacenes}

Tabla 4. 9.

Escala de factores - Mala distribución de mercadería entre almacenes

\begin{tabular}{|c|c|c|c|c|c|}
\hline \multirow{4}{*}{ Factores } & \multirow{4}{*}{ Peso } & \multirow{2}{*}{\multicolumn{4}{|c|}{$\begin{array}{c}1^{\circ} \text { Problema principal : Mala distribución de } \\
\text { mercadería entre almacenes }\end{array}$}} \\
\hline & & & & & \\
\hline & & \multicolumn{2}{|c|}{$\begin{array}{l}\text { Alquilar un medio } \\
\text { de transporte de } \\
\text { mayor capacidad }\end{array}$} & \multicolumn{2}{|c|}{$\begin{array}{l}\text { Elaborar un plan de } \\
\text { pedidos diarios }\end{array}$} \\
\hline & & Calif. & Puntaje & Calif. & Puntaje \\
\hline Inversión & 0.43 & 2 & 0.86 & 4 & 1.72 \\
\hline $\begin{array}{c}\text { Tiempo de } \\
\text { implementación }\end{array}$ & 0.14 & 3 & 0.42 & 3 & 0.42 \\
\hline Restricciones & 0.14 & 3 & 0.42 & 3 & 0.42 \\
\hline $\begin{array}{l}\text { Mejorar } \\
\text { condiciones de } \\
\text { seguridad }\end{array}$ & 0.29 & 4 & 1.16 & 4 & 1.16 \\
\hline \multicolumn{2}{|c|}{ Total } & & 2.86 & & 3.72 \\
\hline
\end{tabular}

Elaboración propia

En esta tabla 4.9, se observa que la solución ganadora es cambiar la distribución de mercadería entre almacenes y tener un plan de pedidos ya que no necesita de mucha inversión debido a que este será implementado por los mismos trabajadores. Asimismo, se requerirá de un periodo de 1 a 6 meses ya que se realizará una investigación para determinar las cantidades a pedir de cada producto. Finalmente, se deberá contar con poco personal que posea conocimientos intermedios para poder implementarlo. Por otro lado, ayudará a disminuir el esfuerzo físico del personal ya que se disminuirá la frecuencia de los pedidos. 
Tabla 4. 10.

Escala de factores - Falta de Capacidad en almacén central

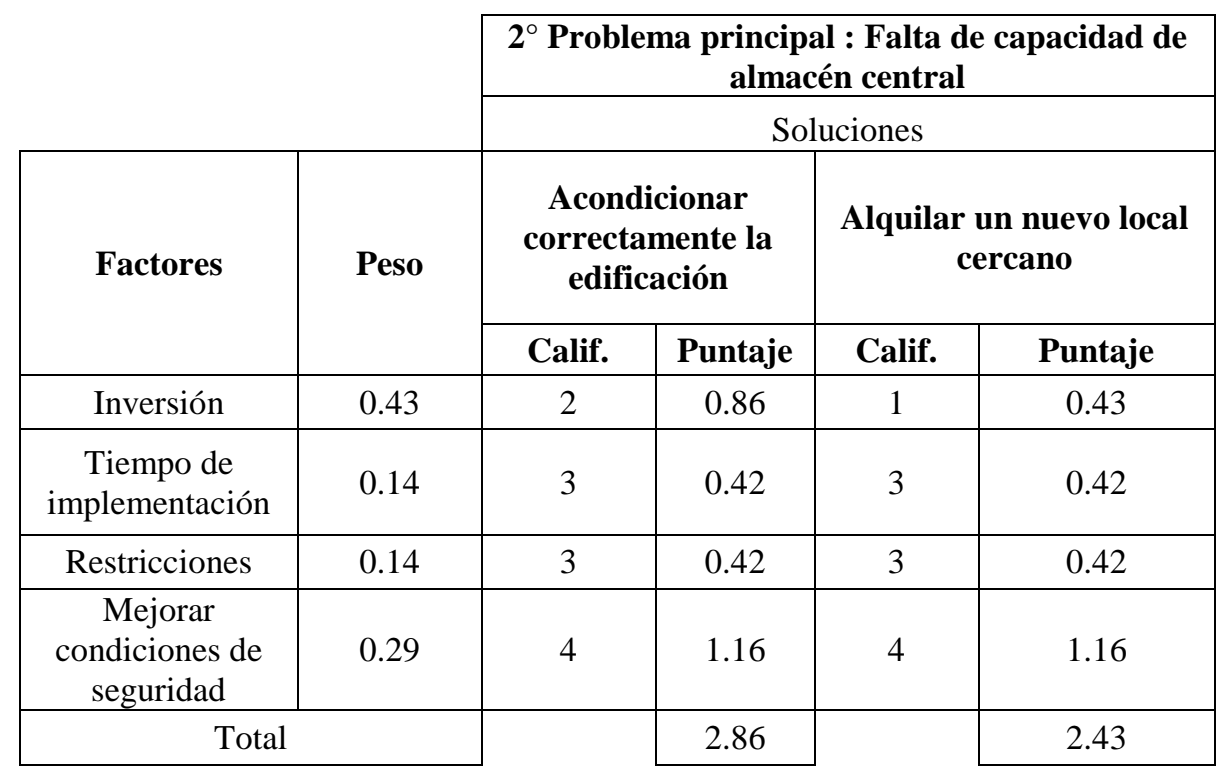

Elaboración propia

Para este segundo problema, se determina como mejor solución acondicionar correctamente la edificación, según lo observado en la tabla 4.10. La inversión se encuentra en un rango mayor a 10,000 soles debido a que se requerirá la compra de ciertos equipos, materiales, etc.El detalle de la inversión se detallará en el capítulo 5. Asimismo, el tiempo de implementación será mayor a 1 mes ya que conlleva un tiempo para buscar proveedores e instalación.Finalmente, permitirá que el almacén mejore las condiciones de trabajo en la empresa ya que ayudará a trasladar entre los pisos del edificio los productos de una manera más óptima.

\subsubsection{Priorización y programación de soluciones seleccionadas}

La mayoría de soluciones son de implementación inmediata y de bajo costo, ya que se ha priorizado que las soluciones no comprometan inversión y paralizaciones en las operaciones de la empresa.

Para el indicador de costo de política de mantenimiento, se prioriza optimizar el stock del almacén, ya que ello ayudará a mejorar la planificación de compras y conocer el espacio 
real disponible para almacenar. Además con ello se puede garantizar la presencia en stock de los productos solicitados por el cliente, lo que primero ayudaría a retener los clientes actuales. Luego de ello, a mediano plazo se buscaría realizar compras en mayor volumen, de acuerdo a la mejor distribución y volumen disponible del almacén. A largo plazo de trabajaría en aumentar el portafolio de productos, como evolución de la cartera de la empresa.

Para el siguiente indicador, de gastos por daños, conservación y vencimiento de productos, la prioridad es un sistema de almacenamiento FEFO. Asimismo, ejecutar un plan de limpieza ya que es primordial para el correcto almacenaje de producto. Después de ello, ejecutar el control en la manipulación de productos, debido a que la capacitación y uso de las buenas prácticas se daría en mediano plazo.

Para el tercer indicador, de gastos de transporte desde el almacén auxiliar, se prioriza hacer mejorar la distribución de los productos entre almacenes, complementando la planeación de la empresa tanto en compras como en almacenamiento. 


\section{CAPITULO V: IMPLEMENTACIÓN DE LA SOLUCIÓN PROPUESTA}

\subsection{Ingeniería de la solución}

\section{- Costo total de política de almacenamiento}

\section{Optimizar el stock de los productos en cada almacén}

La solución propuesta es elevar el nivel de servicio optimizando el stock de productos para cubrir la demanda mensual de los diferentes productos.

Para optimizar el stock necesario, se calculará el tamaño de compra óptimo de acuerdo a la demanda.Como se mencióno anteriormente, el pedido de los productos se realizan por medios de dos procesos de tipo push.

Para el primer caso, a través de un software de simulación, se calculará el ahorro en el costo total de la política al incrementar el nivel de stock para obtener un nivel de servicio deseado por gerencia (más del 95\%), y así disminuir las ventas perdidas por falta de stock, contrarrestado por el mayor costo de almacenamiento. Al mismo tiempo, se podrá saber la planeación de compras mensual de estos productos.

Para hallar el potencial ahorro, se va a comparar el escenario real del 2016 con el escenario estimado con la nueva metodología.

En el segundo caso, se hallará el tamaño de pedido óptimo para garantizar el nivel de servicio actual, que en el 2016 fue del 100\%, ya que se contaba con sobre stock de estos productos.

Antes de ello, se trabajará el concepto de unidades agregadas para realizar los cálculos en base a una sola unidad por cada línea de producto, debido a que algunos productos se venden en diferentes presentaciones. A continuación en la tabla 5.1. se muestran las equivalencias entre cada tipo de producto. 
Tabla 5. 1.

Unidades agregadas de productos por línea

\begin{tabular}{|c|c|c|c|}
\hline Línea & Presentación & Volumen (m3) & $\begin{array}{c}\text { Und. Equivalentes } \\
\text { (cajas) }\end{array}$ \\
\hline \multirow{5}{*}{ Aceite } & Caja de aceite de 5L x 4 gal. & 0.042 & 1 \\
\hline & Caja de aceite de $900 \mathrm{ml} \times 12$ botellas & 0.009 & 0.2 \\
\hline & Balde de Aceite 18L & 0.028 & 0.67 \\
\hline & Caja de aceite de $500 \mathrm{ml} \times 24$ botellas & 0.007 & 0.16 \\
\hline & Caja de aceite de $1 \mathrm{~L}$ x 12 botellas & 0.026 & 0.63 \\
\hline \multirow{3}{*}{ Fideo } & Fideo granel & 0.024 & 1 \\
\hline & Fideo largo & 0.012 & 0.5 \\
\hline & Fideo pequeño & 0.012 & 0.5 \\
\hline \multirow{2}{*}{ Jabón } & San Isidro 230gr x40 barras Blanco & 0.360 & 1 \\
\hline & San Isidro 240gr x40 barras Bebé & 0.360 & 1 \\
\hline Leche & Leche Gloria Lata 48 und x 400 gr & 0.039 & 1 \\
\hline Harina & Saco de $50 \mathrm{Kg}$ & 0.088 & 1 \\
\hline Pila & Display Pila AA & 0.004 & 1 \\
\hline Café & Caja De 40 sobres & 0.008 & 1 \\
\hline
\end{tabular}

Elaboración propia

A continuación se presenta el análisis realizado para la línea de productos de aceites y fideos, en base a las unidades agregadas. Se escogió estas dos líneas de producto ya que representan aproximadamente el $90 \%$ de las ventas de la empresa lo cual las convierte en las líneas de producto más importantes, como se muestra en el ABC de la figura 5.19.

En el nuevo escenario, se calcula el abastecimiento necesario a través de una estimación de la demanda por series de tiempo, tomando en cuenta el histórico y la estacionalidad del mismo. En la figura 5.1. y 5.2. se muestra la demanda histórica que ha tenido la empresa del 2013 al 2015,y la demanda proyectada. 


\section{Figura 5. 1.}

\section{Demanda histórica y pronóstico - Aceites}

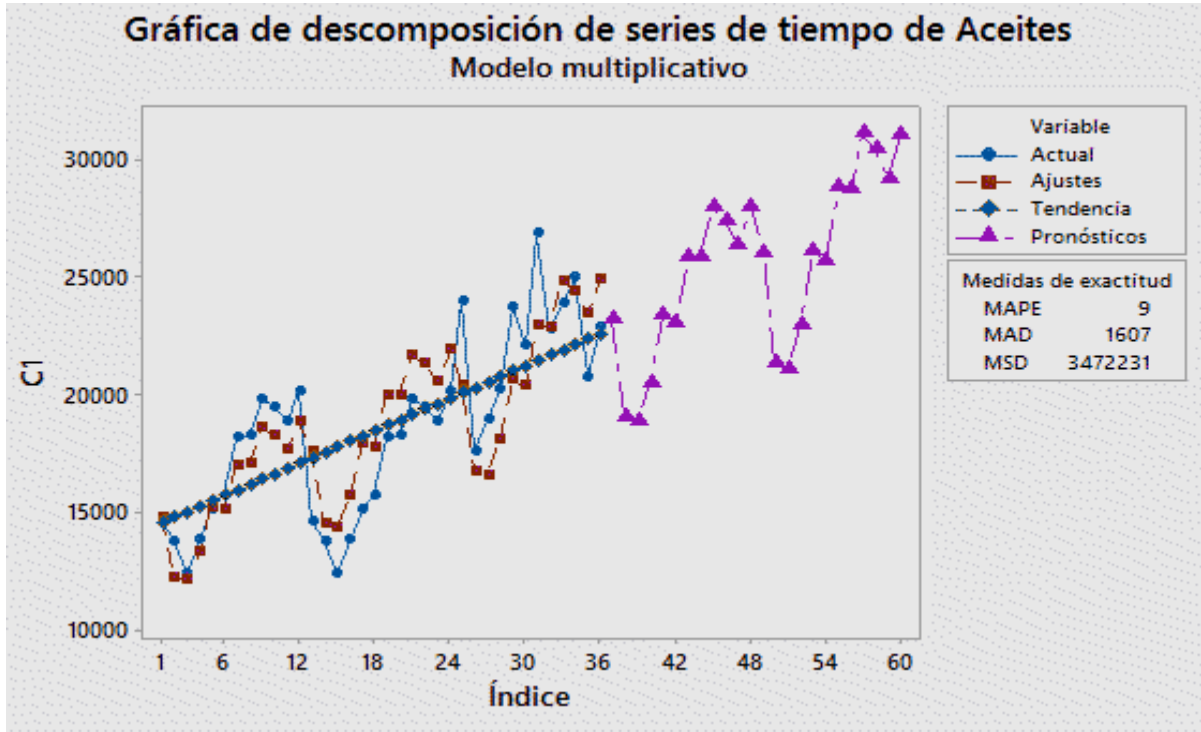

Elaboración Propia

\section{Figura 5. 2.}

\section{Demanda histórica y pronóstico - Fideos}

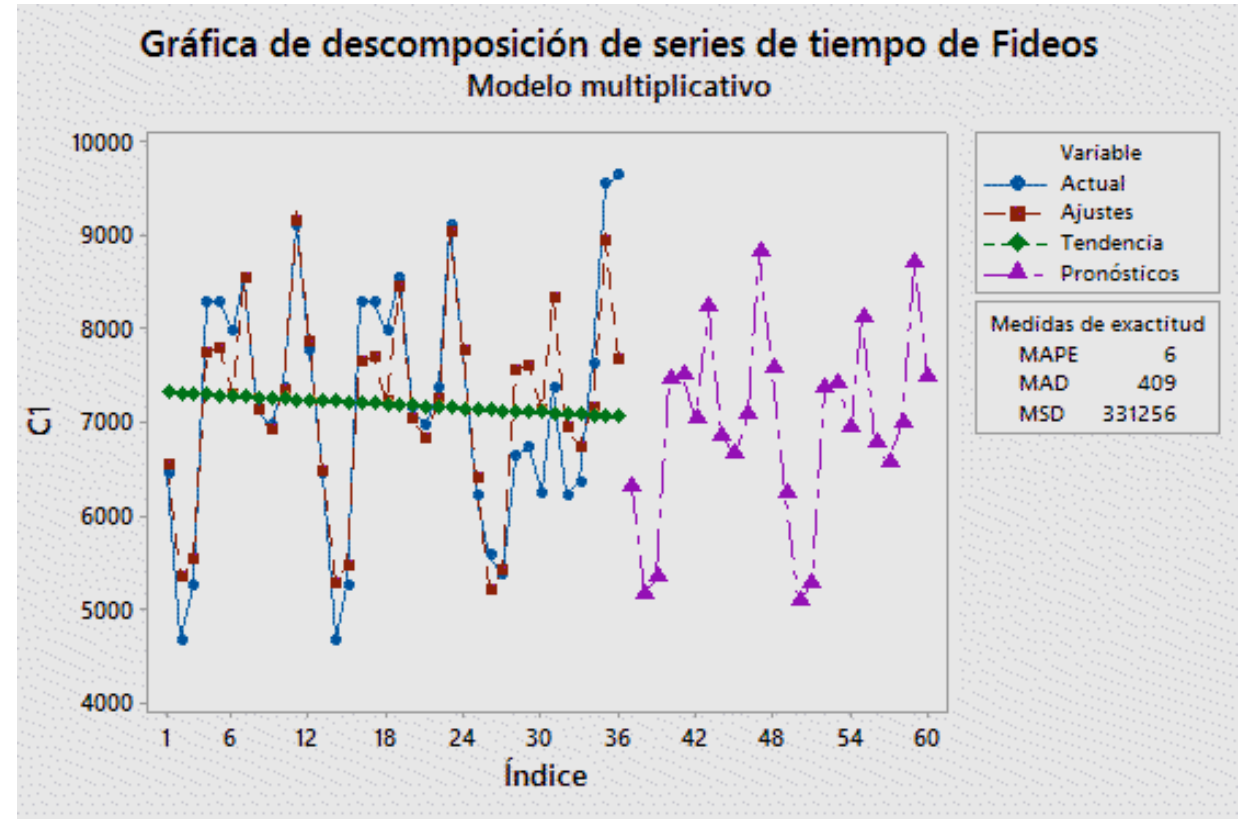

Elaboración Propia 
A continuación, en las tablas 5.2. y 5.3., se colocan la estimación de la demanda para el año 2016 y 2017, asimismo, se compara la desviación con respecto al real en la figura 5.3.

Tabla 5. 2.

Pronóstico de la demanda 2016 de aceites en cajas agregadas

\begin{tabular}{|c|c|c|c|c|c|}
\hline Mes & $\mathbf{2 0 1 6}$ & $\mathbf{2 0 1 7}$ & Mes & $\mathbf{2 0 1 6}$ & $\mathbf{2 0 1 7}$ \\
\hline Enero & 23,233 & 26,050 & Julio & 25,879 & 28,838 \\
\hline Febrero & 19,036 & 21,322 & Agosto & 25,831 & 28,757 \\
\hline Marzo & 18,808 & 21,043 & Setiembre & 27,987 & 31,127 \\
\hline Abril & 20,514 & 22,928 & Octubre & 27,412 & 30,459 \\
\hline Mayo & 23,357 & 26,079 & Noviembre & 26,332 & 29,232 \\
\hline Junio & 23,034 & 25,693 & Diciembre & 28,018 & 31,076 \\
\hline
\end{tabular}

Elaboración Propia

Tabla 5. 3.

Pronóstico de la demanda 2016-2017 de fideos en cajas agregadas

\begin{tabular}{|c|c|c|c|c|c|}
\hline Mes & $\mathbf{2 0 1 6}$ & $\mathbf{2 0 1 7}$ & Mes & $\mathbf{2 0 1 6}$ & $\mathbf{2 0 1 7}$ \\
\hline Enero & 6,300 & 6,221 & Julio & 8,215 & 8,111 \\
\hline Febrero & 5,134 & 5,070 & Agosto & 6,847 & 6,761 \\
\hline Marzo & 5,328 & 5,261 & Setiembre & 6,645 & 6,560 \\
\hline Abril & 7,455 & 7,361 & Octubre & 7,063 & 6,974 \\
\hline Mayo & 7,487 & 7,393 & Noviembre & 8,805 & 8,694 \\
\hline Junio & 7,024 & 6,936 & Diciembre & 7,556 & 7,460 \\
\hline
\end{tabular}

Elaboración Propia 


\section{Figura 5. 3.}

\section{Demanda 2016 - Fideos y Aceites}

Demanda Aceite y Fideos 2016

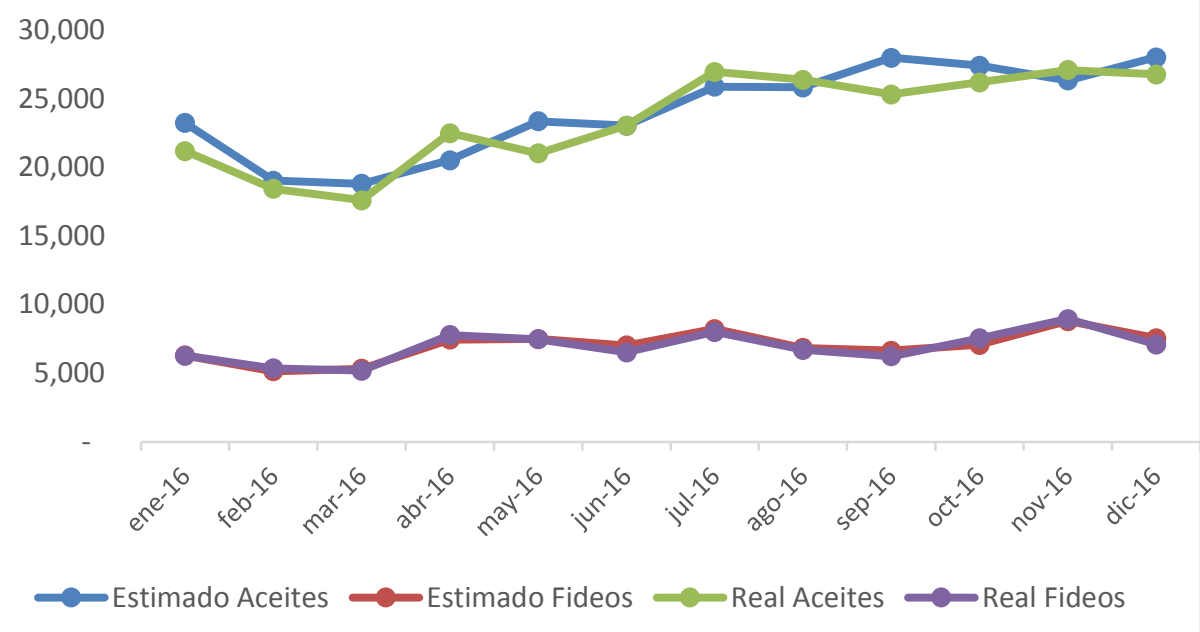

Elaboración Propia

Este pronóstico de demanda se usa como input para calcular el abastecimiento en el modelo de simulación, y finalmente el nivel de servicio.

Para garantizar que el pronóstico es bueno y puede usarse en el proceso de cálculo de cantidades para abastecer, es necesario hacer un control de pronósticos. Se usará el control de desviación media absoluta y señal de rastreo, con lo que se hará seguimiento de la exactitud de los pronósticos. Este cálculo y control estará a cargo del asistente adminstrativo y de abastecimeinto quien en conjunto con el dueño decidirá si es necesario realizar un ajuste a las estimaciones.

Se ha definido como admisible una señal de rasteo de +-4 DMA. En las tablas 5.4 y 5.5 se puede ver como ejemplo de cómo hubiera sido la exactitud del pronóstico para el 2016 en aceites y fideos. 
Tabla 5. 4.

Control de pronóstico de aceites 2016

\begin{tabular}{|c|c|c|c|c|c|c|c|}
\hline Pronóstico & Reales & Desviación & $\begin{array}{c}\text { Desviación } \\
\text { Aculumada }\end{array}$ & $\begin{array}{c}\text { Desviación } \\
\text { Absoluta }\end{array}$ & $\begin{array}{c}\text { Desviación } \\
\text { Absoluta } \\
\text { aculumada }\end{array}$ & $\begin{array}{c}\text { Desviación } \\
\text { media } \\
\text { acumulada }\end{array}$ & $\begin{array}{c}\text { Señal de } \\
\text { Rastreo }\end{array}$ \\
\hline 23,233 & 27,776 & 4,543 & 4,543 & 4,543 & 4,543 & 4,543 & 1.0 \\
\hline 19,036 & 16,083 & $-2,954$ & 1,589 & 2,954 & 7,497 & 3,748 & 0.4 \\
\hline 18,808 & 17,672 & $-1,135$ & 454 & 1,135 & 8,632 & 2,877 & 0.2 \\
\hline 20,514 & 21,215 & 701 & 1,155 & 701 & 9,333 & 2,333 & 0.5 \\
\hline 23,357 & 21,109 & $-2,247$ & $-1,093$ & 2,247 & 11,580 & 2,316 & -0.5 \\
\hline 23,034 & 19,237 & $-3,797$ & $-4,889$ & 3,797 & 15,377 & 2,563 & -1.9 \\
\hline 25,879 & 28,189 & 2,310 & $-2,580$ & 2,310 & 17,687 & 2,527 & -1.0 \\
\hline 25,831 & 26,567 & 735 & $-1,844$ & 735 & 18,422 & 2,303 & -0.8 \\
\hline 27,987 & 26,423 & $-1,564$ & $-3,408$ & 1,564 & 19,986 & 2,221 & -1.5 \\
\hline 27,412 & 29,689 & 2,277 & $-1,131$ & 2,277 & 22,263 & 2,226 & -0.5 \\
\hline 26,332 & 26,990 & 659 & -473 & 659 & 22,922 & 2,084 & -0.2 \\
\hline 28,018 & 24,893 & $-3,125$ & $-3,598$ & 3,125 & 26,047 & 2,171 & -1.7 \\
\hline
\end{tabular}

Elaboración Propia 


\section{Tabla 5. 5.}

Control de pronóstico de fideos 2016

\begin{tabular}{|c|c|c|c|c|c|c|c|}
\hline Pronóstico & Reales & Desviación & $\begin{array}{c}\text { Desviación } \\
\text { Aculumada }\end{array}$ & $\begin{array}{c}\text { Desviación } \\
\text { Absoluta }\end{array}$ & $\begin{array}{c}\text { Desviación } \\
\text { Absoluta } \\
\text { aculumada }\end{array}$ & $\begin{array}{c}\text { Desviación } \\
\text { media } \\
\text { acumulada }\end{array}$ & $\begin{array}{c}\text { Señal de } \\
\text { Rastreo }\end{array}$ \\
\hline 6,300 & 6,521 & 221 & 221 & 221 & 221 & 221 & 1.0 \\
\hline 5,134 & 5,838 & 704 & 925 & 704 & 925 & 462 & 2.0 \\
\hline 5,328 & 5,615 & 287 & 1,212 & 287 & 1,212 & 404 & 3.0 \\
\hline 7,455 & 6,951 & -504 & 708 & 504 & 1,716 & 429 & 1.7 \\
\hline 7,487 & 7,056 & -431 & 277 & 431 & 2,147 & 429 & 0.6 \\
\hline 7,024 & 6,547 & -477 & -200 & 477 & 2,624 & 437 & -0.5 \\
\hline 8,215 & 7,728 & -487 & -687 & 487 & 3,111 & 444 & -1.5 \\
\hline 6,847 & 6,521 & -327 & $-1,014$ & 327 & 3,438 & 430 & -2.4 \\
\hline 6,645 & 6,668 & 23 & -991 & 23 & 3,460 & 384 & -2.6 \\
\hline 7,063 & 8,001 & 938 & -53 & 938 & 4,398 & 440 & -0.1 \\
\hline 8,805 & 10,007 & 1,202 & 1,148 & 1,202 & 5,600 & 509 & 2.3 \\
\hline 7,556 & 7,859 & 303 & 1,451 & 303 & 5,903 & 492 & 3.0 \\
\hline
\end{tabular}

Elaboración Propia

En resumen, el proceso simulado de la demanda se resume en la siguiente figura 5.4. Para el control adecuado se hará seguimiento de la señal de rastreo, actualizando anualmente los datos input para el pronóstico.

Este modelo nos permite calcular indicadores como el costo de oportunidad de ventas perdidas por falta de stock, costo de inventario, nivel de servicio y la exactitud del abastecimiento. 


\section{Figura 5. 4.}

\section{Modelo de Simulación}

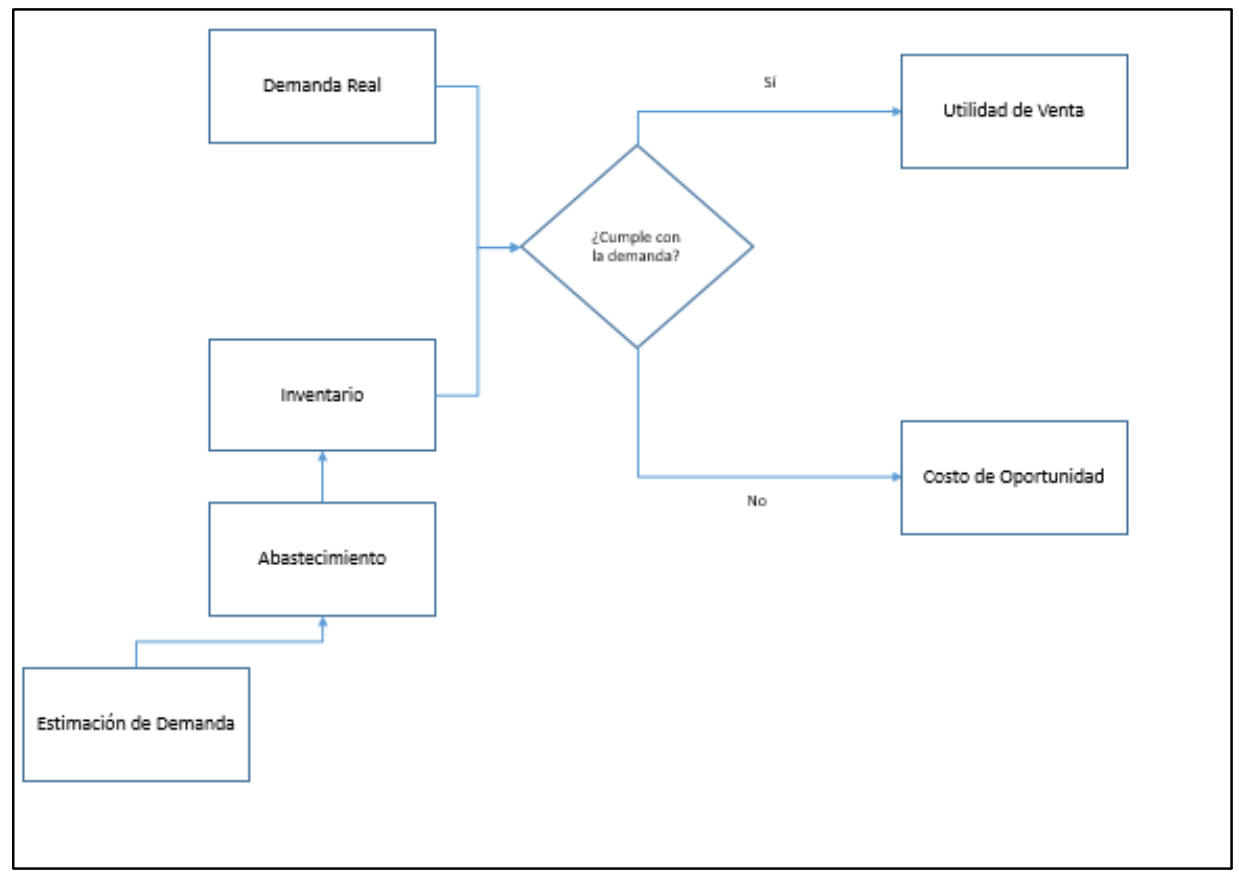

Elaboración Propia

En el modelo, como se pude apreciar, se tienen dos procesos principales: atención de demanda y abastecimiento del inventario. La primera parte del modelo se puede observar en la siguiente figura 5.5., en donde se compara la demanda con el inventario disponible, y también se calculan todos los indicadores de servicio y cobertura. La segunda parte, que se muestra el figura 5.6., representa el proceso de abastecimiento de la empresa. Se simula un abastecimiento mensual en base a la estimación de la demanda y el inventario disponible, asegurando que no se abastezca cuando ya exista suficiente inventario para satisfacer la demanda próxima y siempre considerar que se debe tener un stock de seguridad para la variabilidad de la demanda. Todo esto trabajado con el software arena. 
Figura 5. 5.

Primera parte del modelo - Atención de la demanda

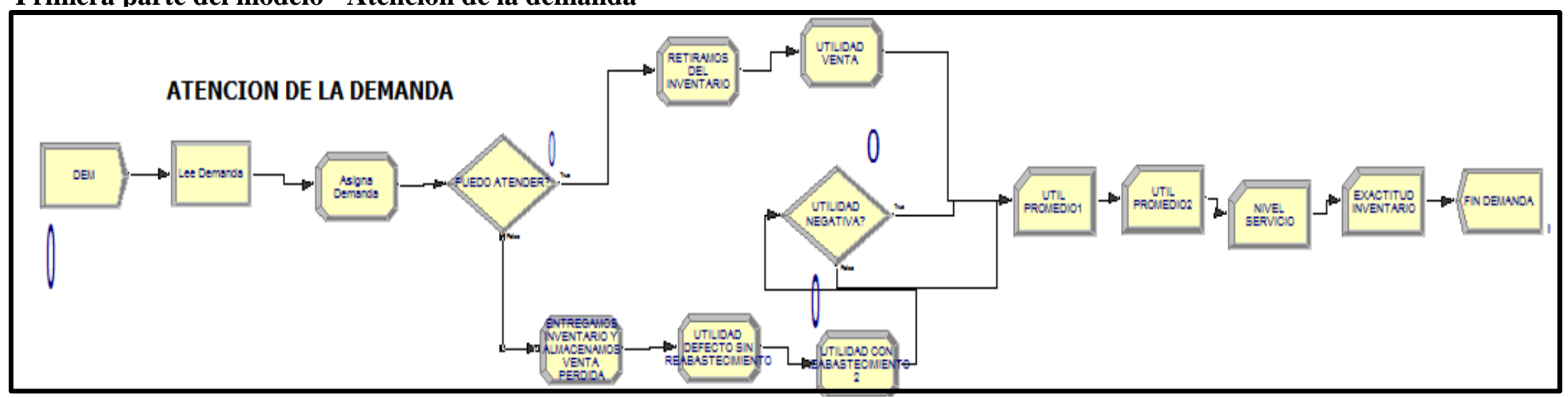

Elaboración Propia

\section{Figura 5. 6.}

Segunda narte del modelo-Abastecimiento en función al estimado

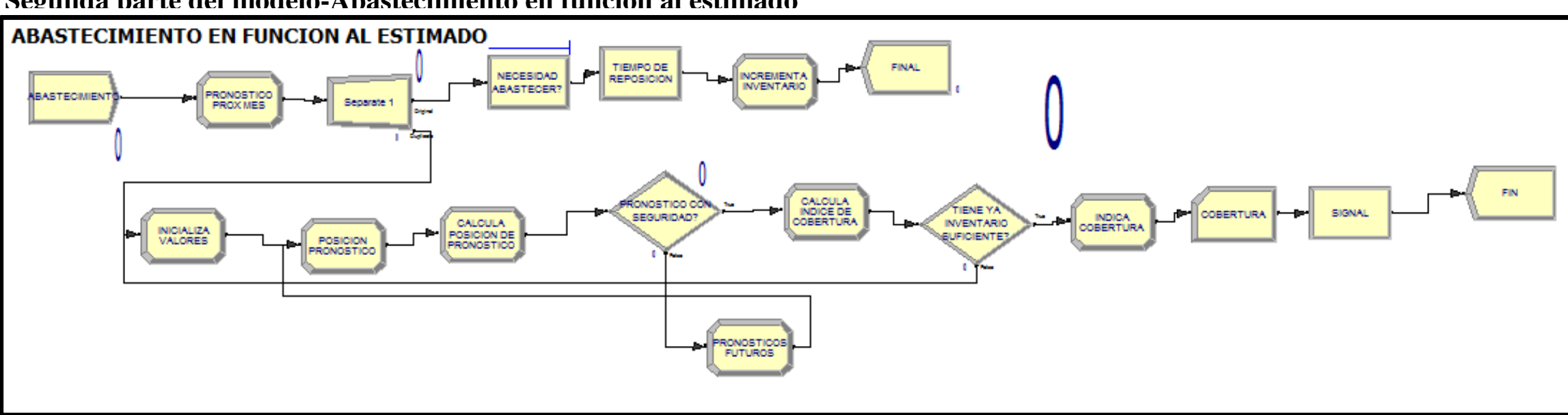

Elaboración Propia 
Se trabajó bajo dos escenarios: el real y el propuesto de incrementar el abastecimiento para alcanzar el nivel de servicio deseado y por consiguiente el inventario promedio. Los escenarios se muestran en las tablas 5.6. y 5.7. para aceites ,y las tablas 5.8. y 5.9. para fideos.

Tabla 5. 6.

Escenario real - aceites (año 2016)

\begin{tabular}{|c|c|}
\hline Indicador & Valor \\
\hline Nivel de Servicio & $84 \%$ \\
\hline Inventario Promedio & 7,895 und (cajas) \\
\hline Utilidad Promedio & $\mathrm{S} / 41,510$ \\
\hline
\end{tabular}

Elaboración Propia

Tabla 5. 7.

Escenario optimizado - aceites (año 2016)

\begin{tabular}{|c|c|}
\hline Indicador & Valor \\
\hline Nivel de Servicio & $96 \%$ \\
\hline Inventario Promedio Mensual & 10,680 und (cajas) \\
\hline Utilidad Promedio & S/55,690 \\
\hline
\end{tabular}

Elaboración Propia

Tabla 5. 8.

Escenario real - fideos (año 2016)

\begin{tabular}{|c|c|}
\hline Indicador & Valor \\
\hline Nivel de Servicio & $84 \%$ \\
\hline Inventario Promedio & 2,586 und (cajas) \\
\hline Utilidad Promedio & $\mathrm{S} / 7,985$ \\
\hline
\end{tabular}

Elaboración Propia 


\section{Tabla 5. 9.}

\section{Escenario optimizado - fideos (año 2016)}

\begin{tabular}{|c|c|}
\hline Indicador & Valor \\
\hline Nivel de Servicio & $95 \%$ \\
\hline Inventario Promedio Mensual & 4,050 und (cajas) \\
\hline Utilidad Promedio & S/14,090 \\
\hline
\end{tabular}

Elaboración Propia

Asimismo, se utilizó el OutPut Analyzer para encontrar diferencias estadísticas significativas entre ambos escenarios. En los dos indicadores más importantes, el nivel de servicio y la utilidad marginal se encontró diferencias estadísticas con un nivel de confianza del $95 \%$.

En cuanto al nivel de servicio, se encontró una diferencia promedio de $12 \%$ en aceites y $10.5 \%$ en fideos al $95 \%$ de confianza.

A continuación, se muestra los intervalos de confianza que se obtuvo para los aceites.

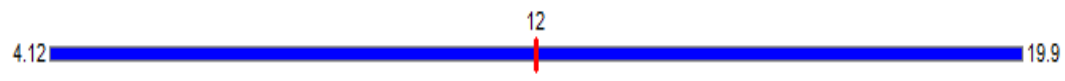

Por otro lado, para los fideos, se obtuvo lo siguiente.

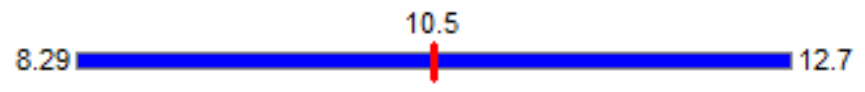

En cuanto a la utilidad promedio, la diferencia es de S/14,200 en aceites y S/6,100 en fideos al 95\% de confianza, esto corresponde a una disminución en el costo de oportunidad por ventas perdidas contrarrestado por un aumento en el costo logístico por el mayor nivel de almacenamiento.

A continuación, se presenta los intervalos de confianza que se obtuvieron para cada uno.

- $\quad$ Aceites

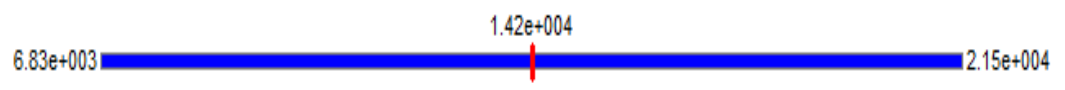

- $\quad$ Fideos

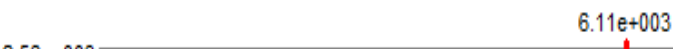


Al encontrarse una diferencia estadística, se puede concluir que hay una mejora en los indicadores de nivel de servicio y costo total de la política generando una utilidad marginal para la empresa. (S/20,300 mensual).

Se puede concluir, que bajo el nuevo escenario de abastecer la empresa en un mayor nivel, se aumenta el nivel de servicio y se gana en utilidad de venta.

\section{Compras en mayor volumen}

En esta solución, se utilizó la proyección de la demanda en base estimaciones por series de tiempo en los productos de aceite y fideos, los cuales se muestran en las tablas 5.2. y 5.3. y que son utilizados para obtener el abastecimiento e inventario de dichos productos. Cabe recalcar que los productos en mención son los únicos en los que se podría obtener un descuento representativo por compras en mayor volumen.

Para calcular el nuevo nivel de pedidos de los productos de tipo PUSH, se va a mostrar la planificación proyectada. Se consideró un stock de seguridad debido a que existe variabilidad del tiempo entrega de productos por parte del proveedor (1-2 días); y en la demanda. Estos se muestran en la tabla 5.10.

\section{Tabla 5. 10.}

\section{Stock de seguridad}

\begin{tabular}{|l|c|c|c|}
\cline { 2 - 4 } \multicolumn{1}{c|}{} & $\begin{array}{c}\text { Demanda diaria } \\
\text { promedio }\end{array}$ & $\begin{array}{c}\text { Desviación } \\
\text { Estándar }\end{array}$ & $\begin{array}{c}\text { SS=Demanda diaria } \\
\text { promedio } \\
+1.96 * \text { DesvEst. }\end{array}$ \\
\hline Aceites & 619 & 88 & 792 \\
\hline Fideos & 190 & 22 & 234 \\
\hline
\end{tabular}

Elaboración propia 
A continuación se muestran los resultados proyectados de requerimientos por cada línea de producto de tipo PUSH aplicando los porcentajes de importancia de cada uno sobre las ventas en unidades. Dicha información se encuentra en las siguientes tablas 5.11 y 5.12 .

Tabla 5. 4.

MPS proyectado para aceites

\begin{tabular}{|c|c|c|c|c|c|c|c|c|c|c|c|c|}
\hline \multirow[b]{3}{*}{ Producto final } & \multicolumn{12}{|c|}{$\underline{\text { Aceite }}$} \\
\hline & \multicolumn{12}{|c|}{2017} \\
\hline & Ene & $\mathrm{Feb}$ & Mar & Abr & May & Jun & Jul & Ago & Sep & Oct & Nov & Dic \\
\hline Demanda Total & 23,233 & 19,036 & 18,808 & 20,514 & 23,357 & 23,034 & 25,879 & 25,831 & 27,987 & 27,412 & 26,332 & 28,018 \\
\hline Inventario Inicial & 6,580 & 9,652 & 9,925 & 10,460 & 9,941 & 10,730 & 11,011 & 10,379 & 10,073 & 10,596 & 11,248 & 11,631 \\
\hline Abastecimiento Requerido & 26,305 & 19,309 & 19,343 & 19,994 & 24,147 & 23,314 & 25,248 & 25,525 & 28,509 & 28,065 & 26,715 & 28,748 \\
\hline Inventario Final & 9,652 & 9,925 & 10,460 & 9,941 & 10,730 & 11,011 & 10,379 & 10,073 & 10,596 & 11,248 & 11,631 & 12,361 \\
\hline
\end{tabular}

Elaboración propia

Tabla 5. 5.

\section{MPS proyectado para fideo}

\begin{tabular}{|c|c|c|c|c|c|c|c|c|c|c|c|c|}
\hline \multirow[b]{3}{*}{ Producto final } & \multicolumn{12}{|c|}{$\underline{\text { Fideo }}$} \\
\hline & \multicolumn{12}{|c|}{2017} \\
\hline & Ene & $\mathrm{Feb}$ & Mar & Abr & May & Jun & Jul & Ago & Sep & Oct & Nov & Dic \\
\hline Demanda Total & 6,300 & 5,134 & 5,328 & 7,455 & 7,487 & 7,024 & 8,215 & 6,847 & 6,645 & 7,063 & 8,805 & 7,556 \\
\hline Inventario Inicial & 3,287 & 2,310 & 1,874 & 1,833 & 1,979 & 2,232 & 2,180 & 2,426 & 2,399 & 2,574 & 2,498 & 2,378 \\
\hline Abastecimiento Requerido & 7,154 & 6,782 & 7,506 & 10,023 & 9,485 & 8,702 & 10,025 & 8,404 & 8,158 & 8,346 & 9,852 & 9,000 \\
\hline Inventario Final & 4,141 & 3,958 & 4,052 & 4,401 & 3,977 & 3,910 & 3,990 & 3,983 & 3,912 & 3,857 & 3,545 & 3,822 \\
\hline
\end{tabular}

Elaboración propia 
Después de obtener estos resultados, se procedió a comparar los pedidos proyectados para el 2016 y los realizados en ese mismo año. Dicha comparación se muestra en la tabla 5.13 .

Tabla 5. 6.

Resumen de pedidos 2016 real-2016 optimizado

\begin{tabular}{|c|c|c|c|}
\hline & Mes & Aceites & Fideos \\
\hline \multirow{12}{*}{ 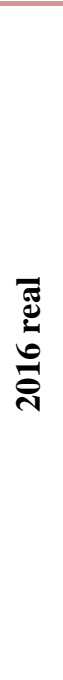 } & Enero & 19,816 & 5,683 \\
\hline & Febrero & 14,253 & 4,755 \\
\hline & Marzo & 15,122 & 5,802 \\
\hline & Abril & 14,722 & 7,982 \\
\hline & Mayo & 17,415 & 7,200 \\
\hline & Junio & 18,033 & 6678 \\
\hline & Julio & 18,311 & 7,410 \\
\hline & Agosto & 18,759 & 5,903 \\
\hline & Septiembre & 20,491 & 6,450 \\
\hline & Octubre & 20,506 & 6,300 \\
\hline & Noviembre & 19,133 & 6,666 \\
\hline & Diciembre & 20,737 & 6,293 \\
\hline \multirow{12}{*}{ 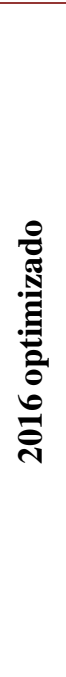 } & Enero & 26,305 & 7,154 \\
\hline & Febrero & 19,309 & 6,782 \\
\hline & Marzo & 19,343 & 7,506 \\
\hline & Abril & 19,994 & 10,023 \\
\hline & Mayo & 24,147 & 9,485 \\
\hline & Junio & 23,314 & 8,702 \\
\hline & Julio & 25,248 & 10,025 \\
\hline & Agosto & 25,525 & 8,404 \\
\hline & Septiembre & 28,509 & 8,158 \\
\hline & Octubre & 28,065 & 8,346 \\
\hline & Noviembre & 26,715 & 9,852 \\
\hline & Diciembre & 28,748 & 9,000 \\
\hline \multicolumn{2}{|c|}{$\begin{array}{l}\text { \% promedio mensual } \\
\text { de variabilidad }\end{array}$} & 26.2 & 25.4 \\
\hline
\end{tabular}

Elaboración propia 
Asimismo, se procedió a calcular el inventario máximo.Los resultados que se obtuvieron para los productos tipo PUSH se muestran en la tabla 5.14.

\section{Tabla 5. 7.}

\section{Inventario máximo de cada línea de producto}

\begin{tabular}{|c|c|}
\hline Línea de productos & Inventario máximo mensual (cajas) \\
\hline Aceites & 12,361 \\
\hline Fideos & 4,401 \\
\hline
\end{tabular}

Elaboración propia

Gracias a toda información obtenida, se podrá realizar compras de productos en mayor cantidad .Esto a su vez permitirá que los proveedores ofrezcan descuentos a la empresa. En la siguiente tabla 5.15., se resume los porcentajes de descuento que, consultado con el proveedor, se obtendría.

\section{Tabla 5. 8.}

\section{Descuento de proveedores por pedidos anuales}

\begin{tabular}{|c|c|c|}
\hline Productos & $\begin{array}{c}\text { \% de aumento en } \\
\text { la cantidad de } \\
\text { total de pedido } \\
\text { actual }\end{array}$ & Descuento por compras en volumen \\
\hline Aceites & $>20 \%$ & $\begin{array}{c}\text { PROASA ofreció } 5 \% \text { de descuento adicional } \\
\text { en toda la compra. }\end{array}$ \\
\hline Fideos & $>20 \%$ & $\begin{array}{c}\text { Alicorp ofreció } 2 \% \text { de descuento adicional } \\
\text { en toda la compra. }\end{array}$ \\
\hline
\end{tabular}

Elaboración propia

Con la información brindada en la tabla anterior y la de las tablas de proyecciones, se puede ver que se cumple con lo requerido por los proveedores para obtener dichos descuentos. Por ello, se concluye que se puede recuperar las ventas perdidas en un $90 \%$, definido por experiencia del personal de ventas, debido a que en estos productos se pierden ventas por no tener precios competitivos los cuales en muchas oportunidades se encontraban por encima del $2 \%$ aproximadamente en comparación a la competencia. El total de recupero sería: 
Total de recupero al mes(S/.) $=\%$ Recuperación de ventas perdidas $*$ Ventas perdidas por precios (und) * Ticket promedio de venta $(\mathrm{S} /) * \%$ Utilidad promedio por venta

Total de recupero al mes $=90 \% \times 10 \times 700 \times 3.5 \% \times 4.33=\mathrm{S} / .955$

\section{Ampliar la cartera de productos}

Según la entrevista con la encargada de ventas y la observación in situ, se concluye que los productos ausentes demandados no deben incluirse en la cartera de productos debido a diversos motivos los cuales son mostrados en la table 5.16.; y además, se mostrará los efectos que estos podrían generar en la empresa.

\section{Tabla 5. 9.}

Productos demandados no vendidos - motivos y efectos

\begin{tabular}{|c|c|c|}
\hline $\begin{array}{c}\text { Productos } \\
\text { ausentes en la } \\
\text { cartera de } \\
\text { productos }\end{array}$ & Motivos & Efectos \\
\hline Arroz & $\begin{array}{c}\text { Mercado informal : } \\
\text { los sembradores son los que venden los productos a } \\
\text { menor costo sin factura }\end{array}$ & Multas por SUNAT \\
\hline $\begin{array}{c}\text { Aceite Cristalino } \\
\text { Conservas de } \\
\text { atún }\end{array}$ & $\begin{array}{c}\text { Varios distribuidores autorizados lo cual impedirá } \\
\text { obtener un margen de ganancia atractivo }\end{array}$ & $\begin{array}{c}\text { No generará grandes } \\
\text { ganancias y ocupará gran } \\
\text { espacio en almacén }\end{array}$ \\
\hline $\begin{array}{c}\text { Se adultera la calidad y marca de los productos } \\
\text { No se entrega factura }\end{array}$ & $\begin{array}{c}\text { Desconfianza del cliente } \\
\text { Multas por SUNAT }\end{array}$ \\
\hline Bajo margen de utilidad & $\begin{array}{c}\text { No generará grandes } \\
\text { ganancias y ocupará gran } \\
\text { espacio en almacén }\end{array}$ \\
\hline
\end{tabular}

Elaboración propia 


\section{- Gasto de transporte entre almacenes}

\section{Elaborar un plan de pedidos diarios}

En esta sección, se describirá cómo debería distribuirse los productos de una manera óptima permitiendo tener el acceso adecuado a la mercadería mediante la distribución por zonas. Los productos se organizarán de acuerdo al peso, fragilidad y rotación en dichas zonas. Cabe recalcar que las propuestas descritas en los planos mostrados en las figuras 5.13. , 5.14, 5.15., 5.16., 5.17., 5.18. se realizaron teniendo en cuenta que el ancho de los pasadizos sean mayores a 30 pulgadas debido a que solo transitarán dos personas como máximo a la vez. Cabe mencionar que la entrega de productos la realizan los dos operarios de almacén con los que cuenta la empresa: y además, se manejará sólo una carretilla si se llegara a necesitar. Las dimensiones de las parihuelas son las de medida estándar $1.2 \mathrm{~m}$ x $1 \mathrm{~m}$; y además, aprovechando al máximo el espacio que se tiene.

Por otro lado, la propuesta busca no generar gastos significativos a la empresa y que sea de rápida ejecución. Por ello, se realizará la distribución volumétrica a un solo nivel en parihuelas debido a que los productos serán despachados manualmente, es decir, no se utilizarán montacargas. Es importante mencionar que el espacio actual de los almacenes es adecuado a la proyección de ventas que tiene la empresa como se demuestra en los cuadros de proyecciones de demanda en la tabla 5.20.

A continuación se muestran los planos originales de los almacenes en las figuras 5.7. ; 5.8. ; 5.9. ; 5.10.; 5.11. у 5.12. 
Figura 5. 7.

Plano de primer piso de almacén central original

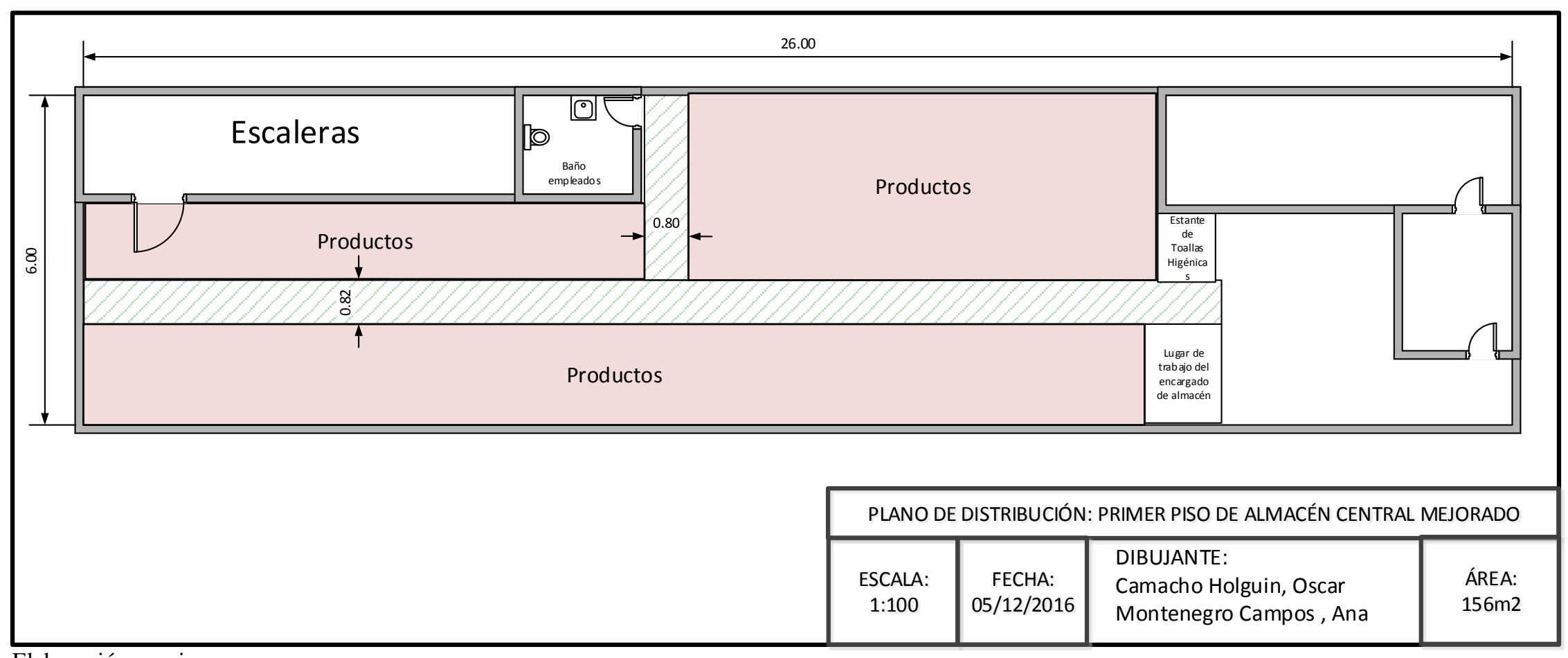

Elaboración propia 
Figura 5. 8.

Plano de mezzanines de almacén central original

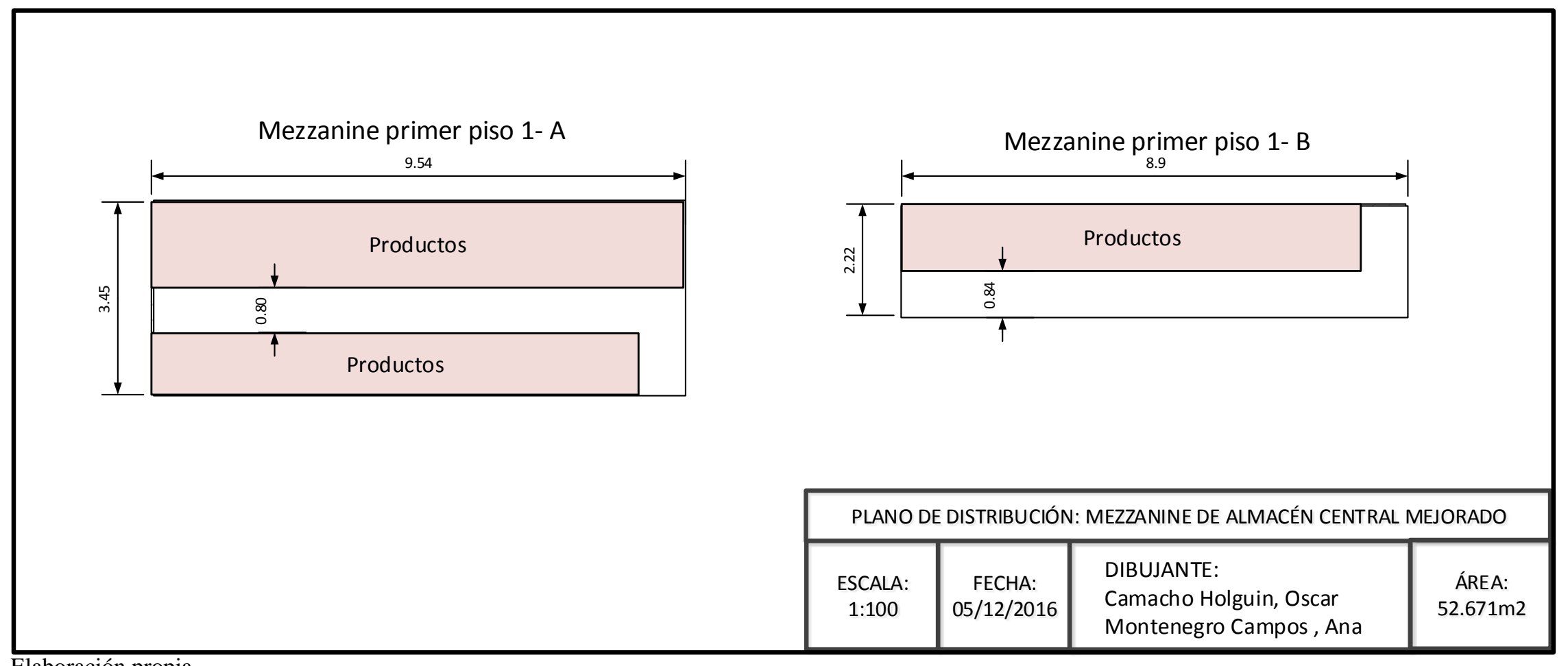

Elaboración propia 
Figura 5.9.

\section{Plano de segundo piso de almacén central original}

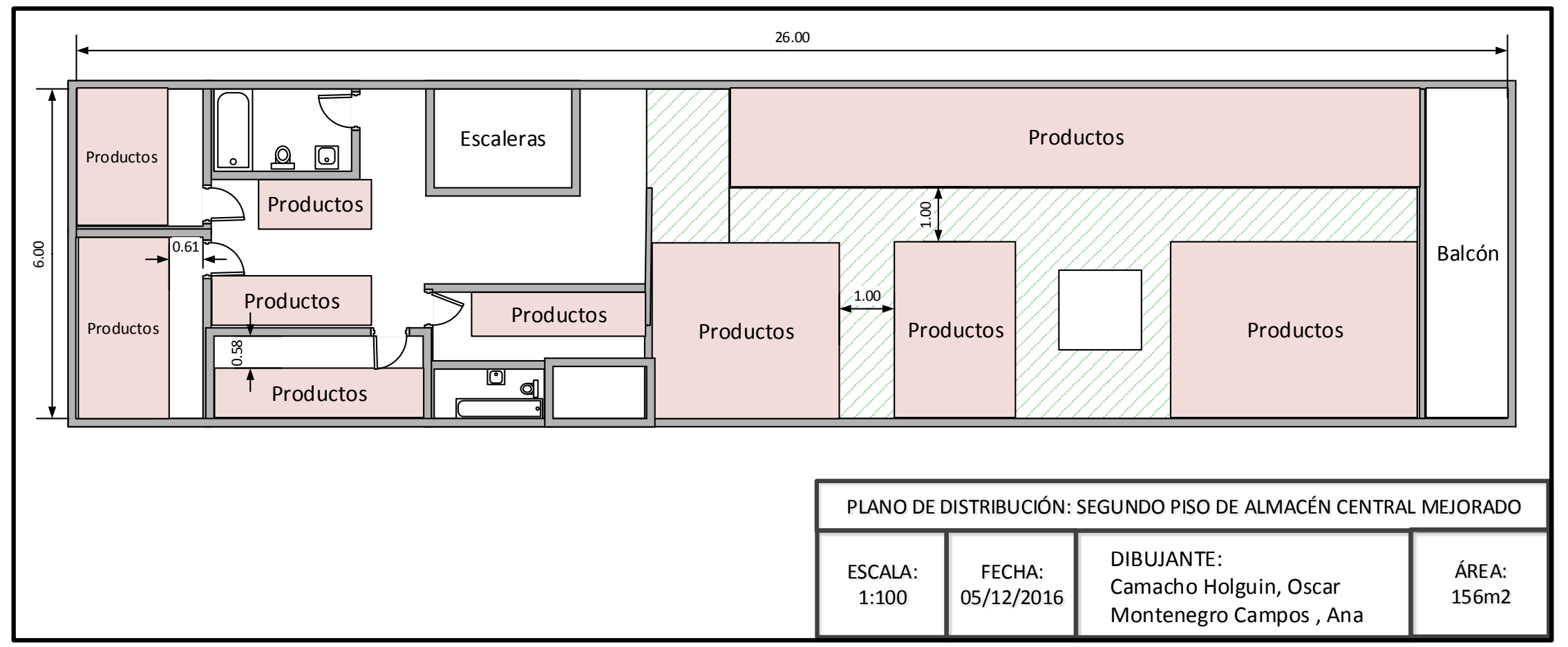

Elaboración propia 
Figura 5. 10.

Plano de tercer piso de almacén central original

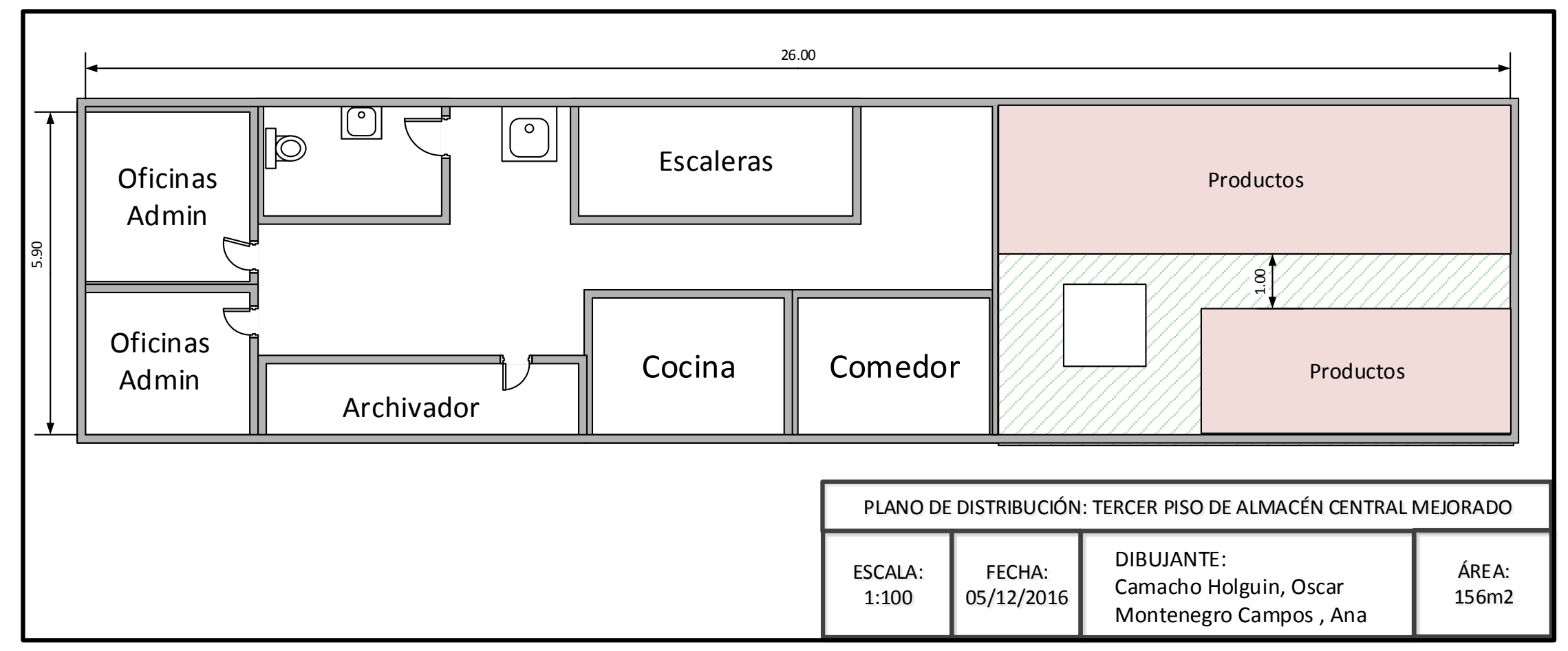

Elaboración propia 


\section{Figura 5.11.}

Plano de almacén auriliar - sector 1

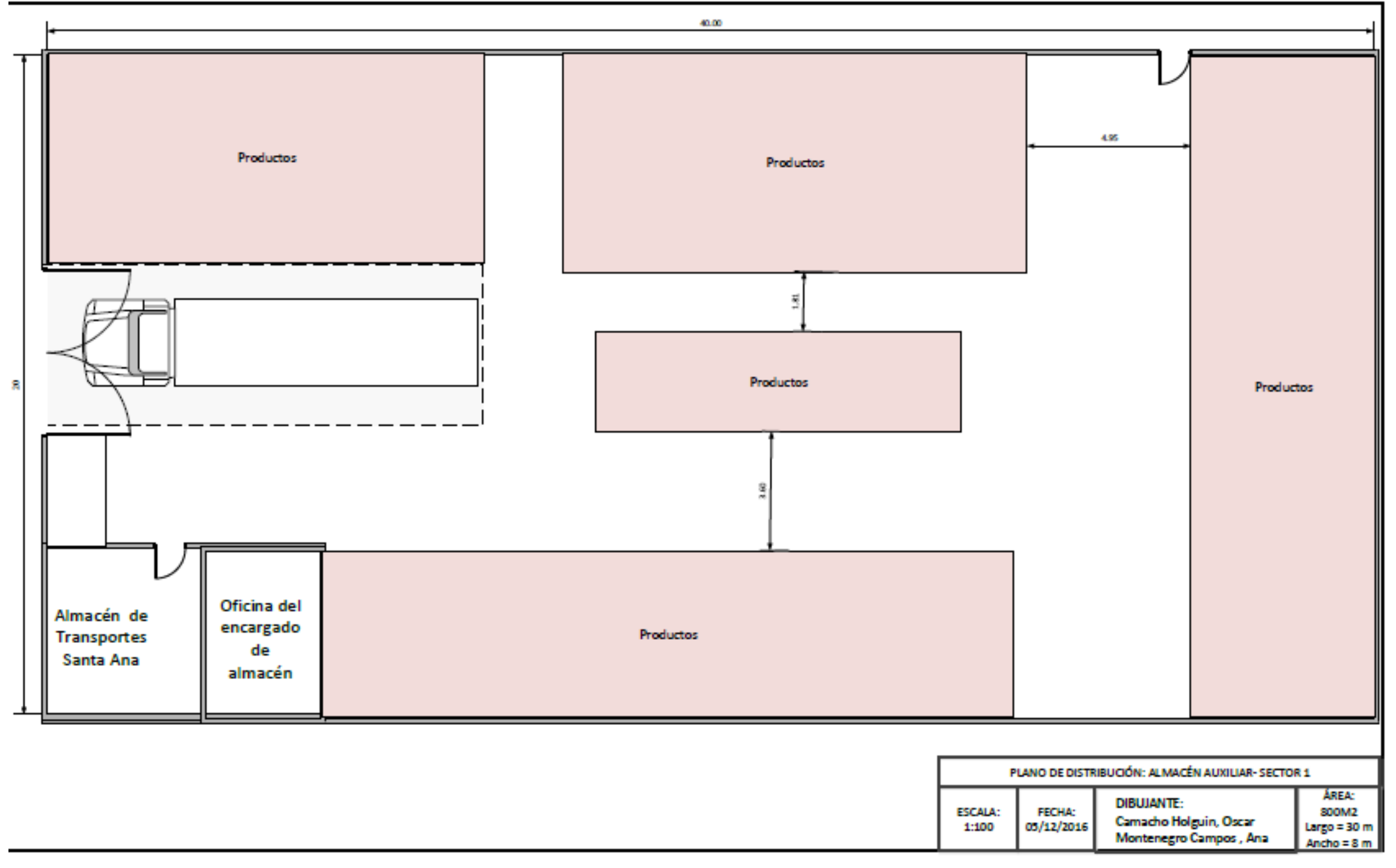

Labersiba propia 
Figura 5.12.

Plano de almacén auriliar - sector 2

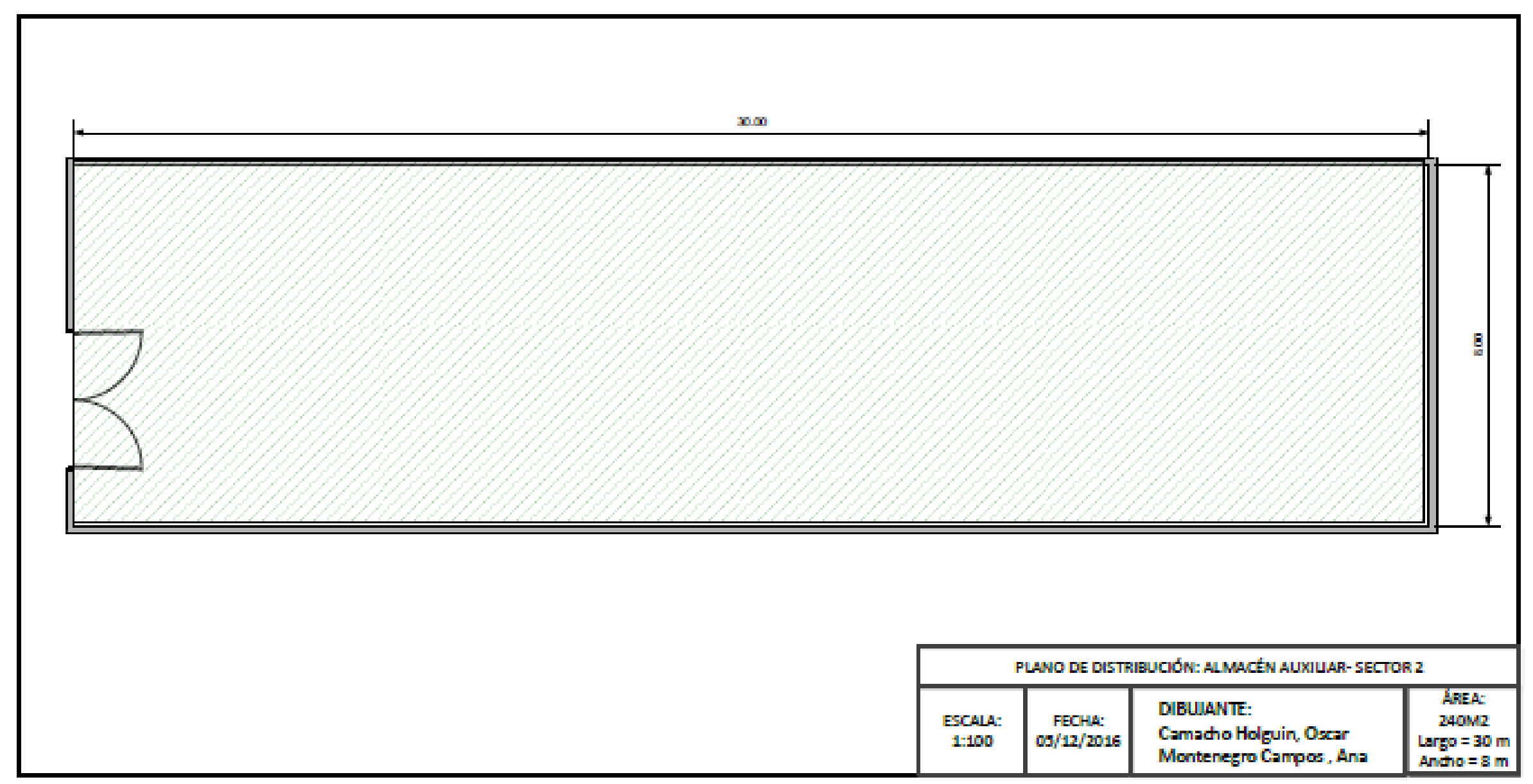

Elderscibn propis 
Figura 5. 13.

Plano de primer piso de almacén central mejorado

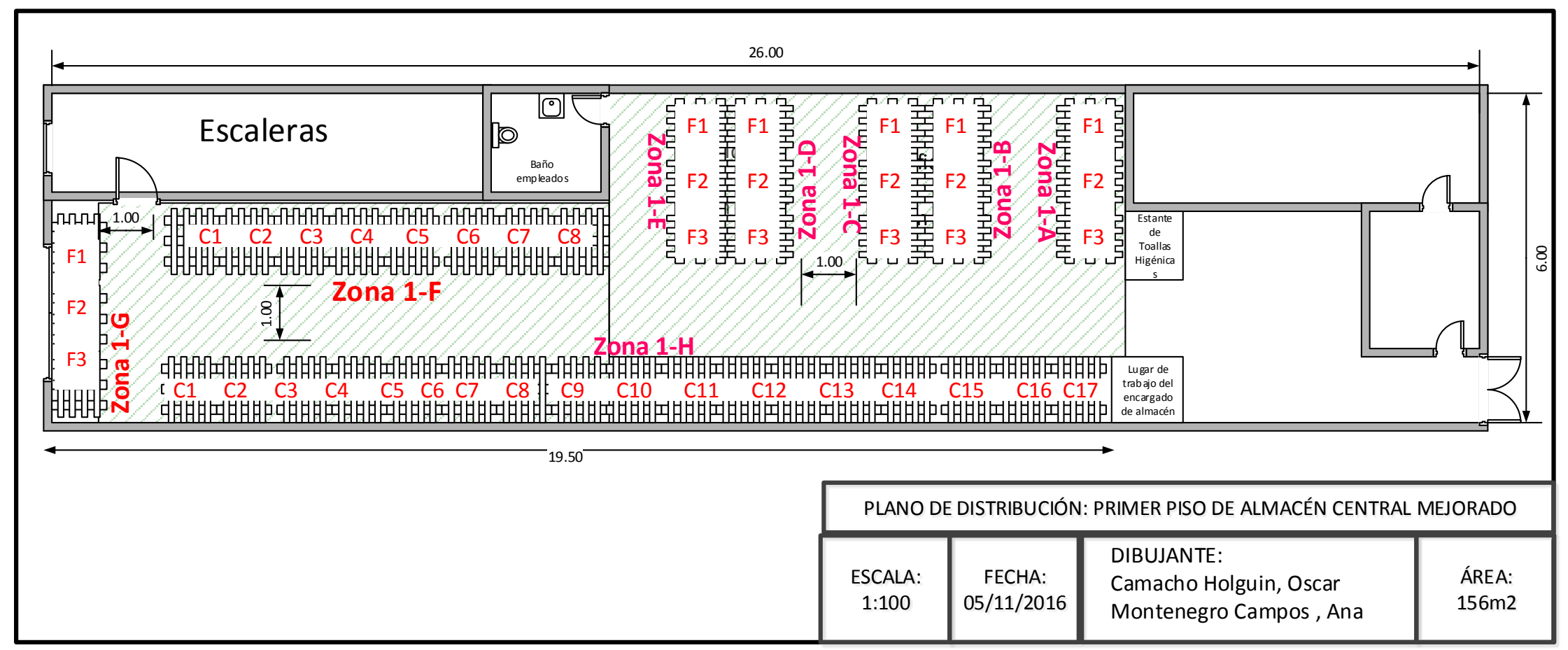

Elaboración propia 
Figura 5. 14.

Plano de mezzanines de almacén central mejorado

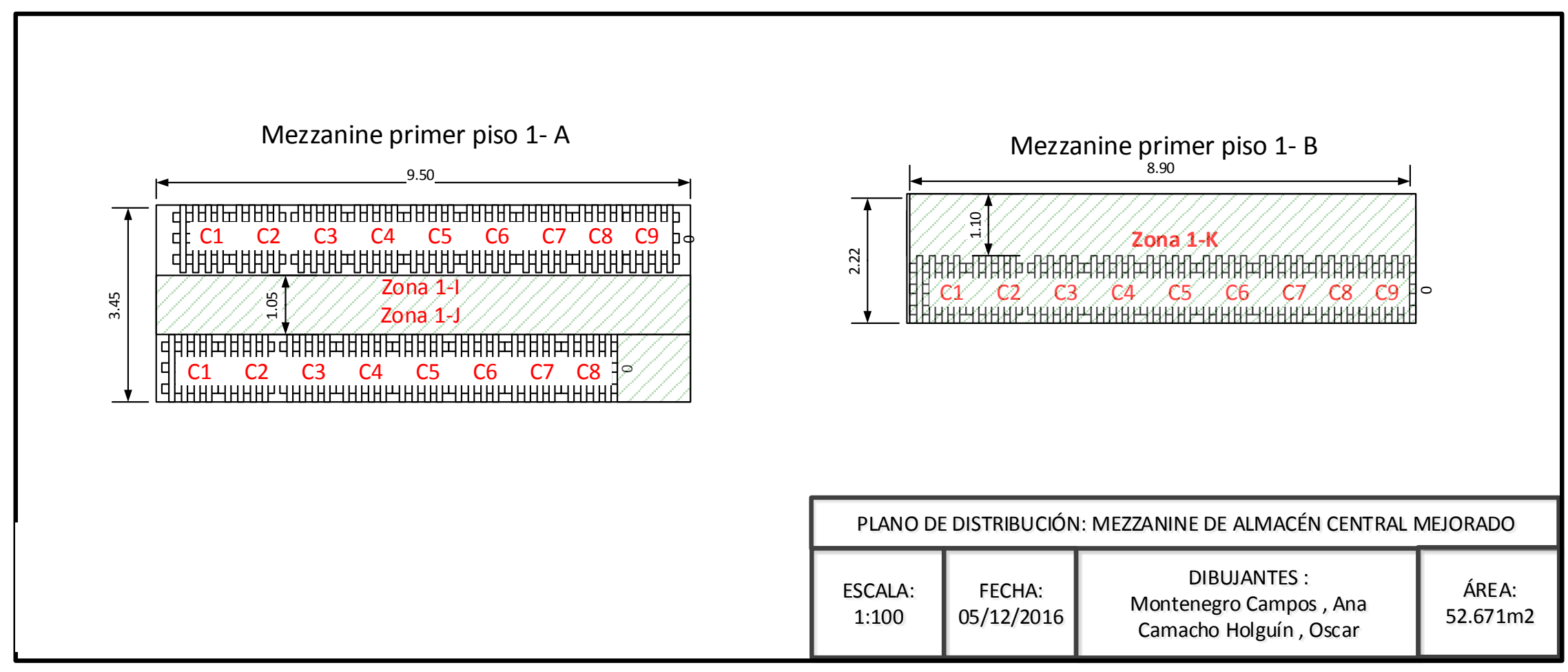

Elaboración propia 
Figura 5.15.

\section{Plano de segundo piso de almacén central mejorado}

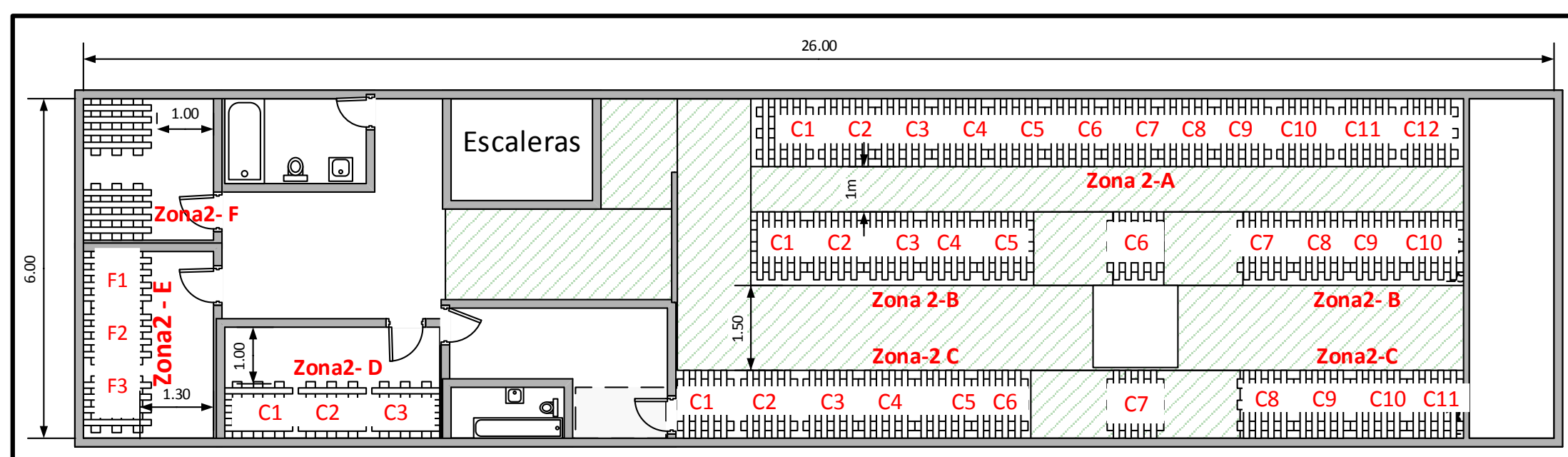

PLANO DE DISTRIBUCIÓN: SEGUNDO PISO DE ALMACÉN CENTRAL MEJORADO

\begin{tabular}{c|c|l|c}
\hline ESCALA: & FECHA: & DIBUJANTE: & ÁREA: \\
\hline $1: 100$ & $05 / 12 / 2016$ & $\begin{array}{l}\text { Camacho Holguin, Oscar } \\
\text { Montenegro Campos, Ana }\end{array}$ & $156 \mathrm{~m} 2$ \\
\hline
\end{tabular}

Elaboración propia 
Figura 5. 16.

Plano de tercer piso de almacén central mejorado

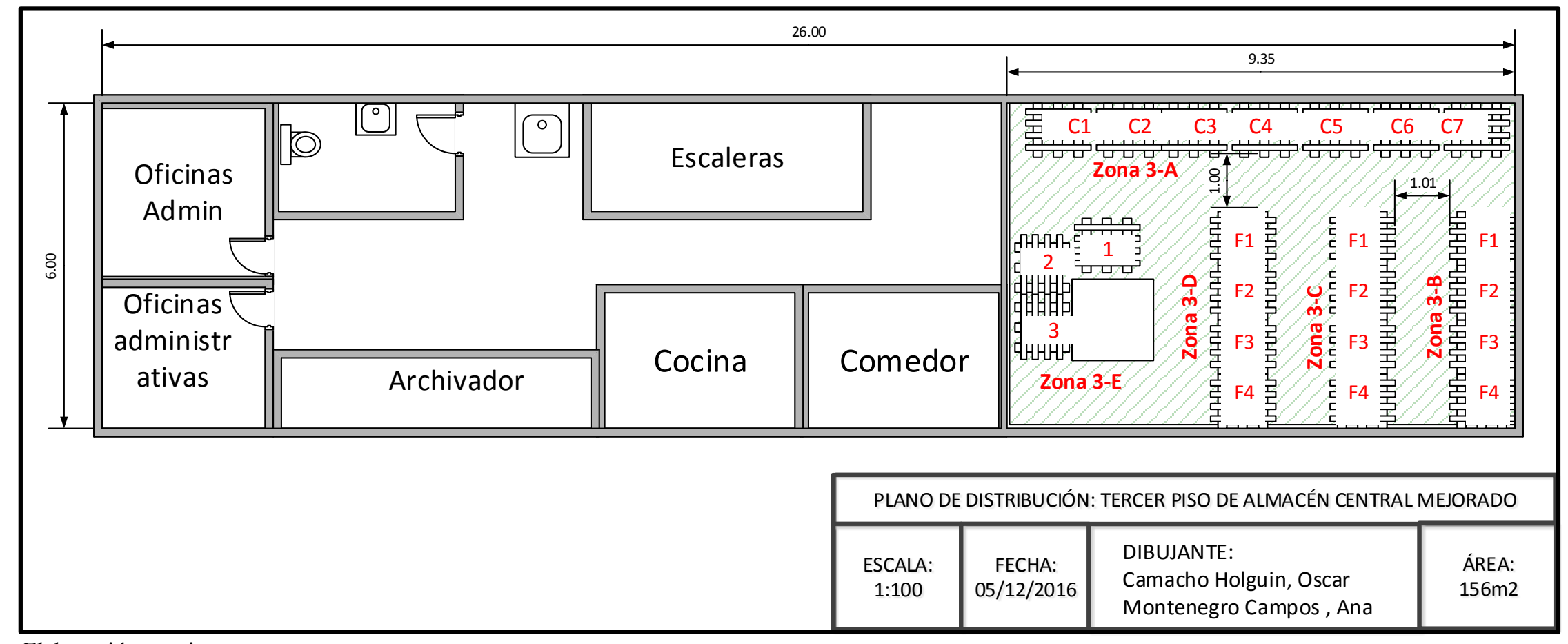

Elaboración propia 
Figura 5.17

Plano de almacén auriliar mejorado - sector 1

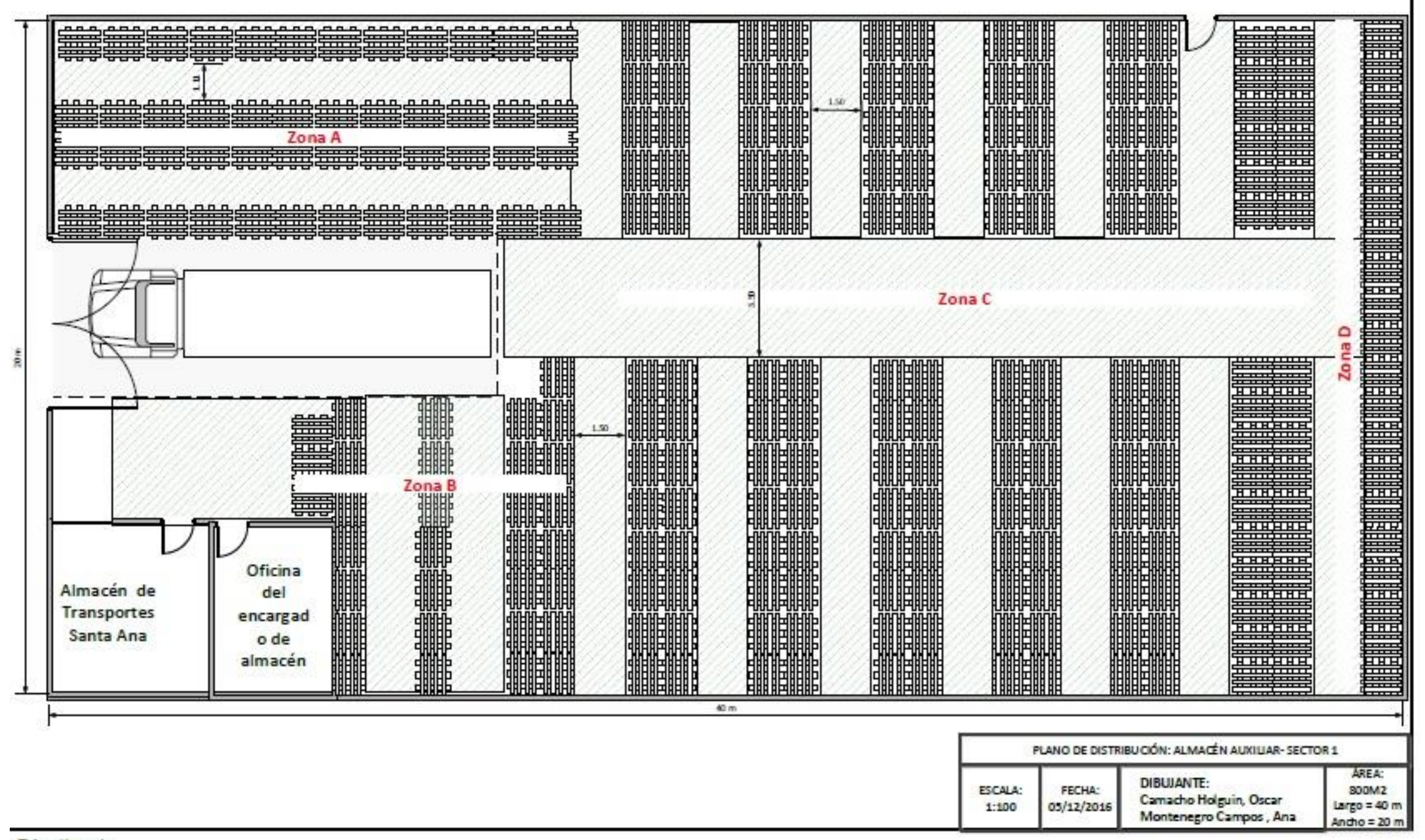


Figura 5.18.

Plano de almacén auriliar mejorado - sector 2

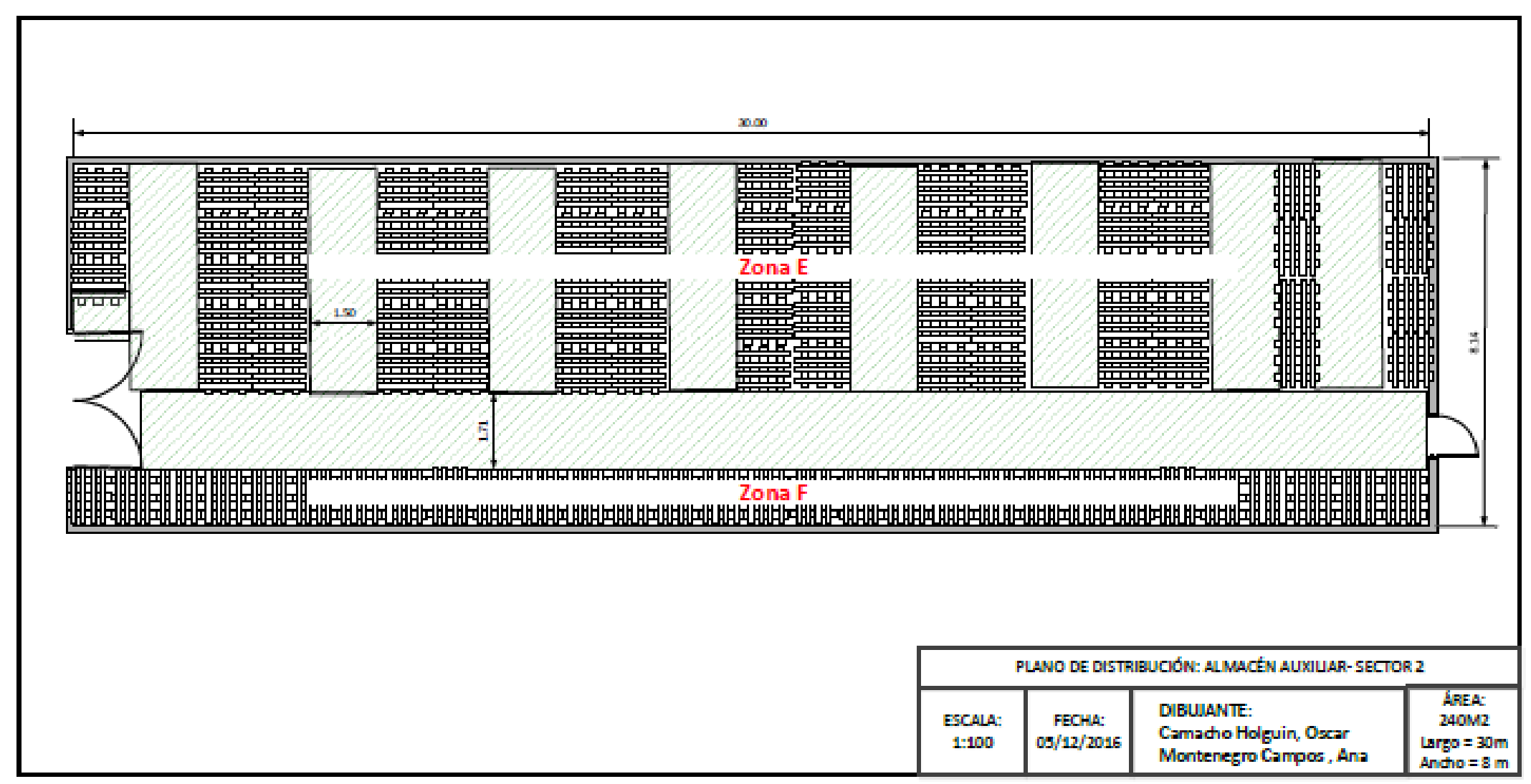

Elabonción propis 
Después de obtener el número de parihuelas por zonas y su distribución, como se muestra en las figuras 5.13. hasta 5.18., se procedió a organizar los productos según los conceptos mencionados anteriormente. Por otro lado, se determinó el número de productos por parihuela con el fin de determinar la capacidad del almacén por producto. Los criterios que se tomaron en cuenta fueron los mostrados en la tabla 5.17.

\section{Tabla 5. 10.}

\section{Criterios limitantes para la capacidad de parihuelas}

\begin{tabular}{|c|c|c|}
\hline Criterios & Dimensiones & $\begin{array}{c}\text { Unidad } \\
\text { de medida }\end{array}$ \\
\hline Altura Máxima & 1.65 & $\mathrm{M}$ \\
\hline Parihuela & 1.2 & $\mathrm{~m} 2$ \\
\hline Resistencia parihuela & 1000 & $\mathrm{Kg}$ \\
\hline
\end{tabular}

Elaboración propia

Después de haber aplicado estos criterios, se obtuvo los siguientes resultados de los productos que se pueden apilar por parihuela que se muestra en la tabla 5.18.

\section{Tabla 5. 11.}

\section{Número de productos por parihuela}

\begin{tabular}{|c|c|c|c|c|c|c|c|}
\hline $\begin{array}{c}\text { Línea de } \\
\text { productos }\end{array}$ & $\begin{array}{c}\text { Ancho } \\
(\mathbf{m})\end{array}$ & $\begin{array}{c}\text { Largo } \\
(\mathbf{m})\end{array}$ & $\begin{array}{c}\text { Alto } \\
(\mathbf{m})\end{array}$ & $\begin{array}{c}\text { Peso } \\
(\mathbf{k g})\end{array}$ & $\begin{array}{c}\text { Unidades } \\
\text { por nivel }\end{array}$ & $\begin{array}{c}\text { Número } \\
\text { de niveles }\end{array}$ & $\begin{array}{c}\text { Total por } \\
\text { parihuela }\end{array}$ \\
\hline Aceites & 0.3 & 0.4 & 0.35 & 20 & 10 & 4 & 40 \\
\hline Cafés & 0.15 & 0.2 & 0.25 & 2 & 40 & 6 & 240 \\
\hline Fideo & 0.3 & 0.4 & 0.2 & 10 & 10 & 8 & 80 \\
\hline Jabón & 0.3 & 0.4 & 0.3 & 10 & 10 & 5 & 50 \\
\hline Leche & 0.35 & 0.45 & 0.25 & 20 & 7 & 6 & 42 \\
\hline Harinas & 0.5 & 0.7 & 0.25 & 50 & 3 & 6 & 18 \\
\hline Pilas & 0.15 & 0.25 & 0.1 & 2.5 & 32 & 16 & 512 \\
\hline
\end{tabular}

Elaboración propia

Al tener los inventarios máximos, mostrados en la tabla 5.14, se distribuyó los productos según la capacidad de los almacenes asignando el mayor número de parihuelas al producto de mayor impacto en las ventas. Dicha distribución se muestra en el tabla 5.19. 
Tabla 5. 12.

\section{Capacidad por producto de cada almacén}

\begin{tabular}{|c|c|c|c|c|c|c|}
\hline Almacén & $\begin{array}{l}\text { Línea de } \\
\text { productos }\end{array}$ & $\begin{array}{l}\% \text { ventas } \\
\text { (und) }\end{array}$ & $\begin{array}{c}\mathrm{N}^{\circ} \\
\text { Parihuelas } \\
\text { asignadas } \\
\text { según \% } \\
\text { ventas }\end{array}$ & $\begin{array}{l}\mathrm{N}^{\circ} \text { pallets } \\
\text { necesarios }\end{array}$ & $\begin{array}{l}\text { Número de } \\
\text { cajas por } \\
\text { parihuela }\end{array}$ & $\begin{array}{c}\text { Unidades } \\
\text { totales }\end{array}$ \\
\hline \multirow{4}{*}{ Central } & Aceites & $62.3 \%$ & 83 & 83 & 40 & 3,320 \\
\hline & Fideos & $15.9 \%$ & 22 & 23 & 80 & 1,840 \\
\hline & Otros & $21.8 \%$ & 28 & & & \\
\hline & \multicolumn{2}{|c|}{ Total de parihuelas } & 133 & & & \\
\hline \multirow{4}{*}{ Auxiliar } & Aceites & $62.3 \%$ & 225 & 227 & 40 & 9,080 \\
\hline & Fideos & $15.9 \%$ & 58 & 34 & 80 & 2,720 \\
\hline & Otros & $21.8 \%$ & 77 & & & \\
\hline & \multicolumn{2}{|c|}{ Total de parihuelas } & 360 & & & \\
\hline
\end{tabular}

Elaboración propia

Como se puede ver se cuenta con la capacidad disponible para almacenar el inventario máximo mostrado en la tabla 5.14, por lo que para esta planificación no se tendrá problemas de capacidad.

Según la tabla 5.20, se observa que no se utilizará la totalidad de la capacidad del almacén auxiliar debido a que se compartirá con otra empresa; y además, se considera que el almacén central es usado en su totalidad. Sin embargo, esto no sucede debido a que este comparte $36 \mathrm{~m} 2$ con la otra empresa. Se necesitará adquirir en total 393 parihuelas y serán cambiadas cada dos años de acuerdo a su vida útil.

\section{Tabla 5. 20.}

\section{Capacidad de almacenes para PROASA}

\begin{tabular}{|c|c|c|}
\hline Almacén & Capacidad en parihuelas & $\%$ utilizado \\
\hline Central & 133 & $100 \%$ \\
\hline Auxiliar & 360 & $95 \%$ \\
\hline
\end{tabular}

Elaboración propia

Cabe mencionar que si bien la utilización del espacio de los almacenes es alto y puede suponer una dificultad de cara a un crecimiento, de ser necesario en un horizonte cercano se 
puede evaluar utilizar un almacenamiento en más niveles aumentando así la capacidad del almacén auxiliar. Este posee una altura de 7 metros a lo largo de todo el espacio donde se han colocado las parihuelas lo cual permitiría aumentar 2 niveles para colocar los productos duplicando la capacidad.

Por otro lado, se determinó la distribución, utilizando el criterio de análisis ABC mostrados en la tabla 5.21. y la figura 5.19. , por zonas de los productos dentro de cada almacén las cuales se muestran en la tabla 5.22. y 5.23.

Tabla 5. 13.

Análisis ABC de las líneas de productos

\begin{tabular}{|c|c|c|c|c|}
\hline Línea & Venta 2016 en S/. & \% venta & \%Acum & Clase \\
\hline Aceites & $10,558,510$ & $80.89 \%$ & $80.89 \%$ & $\mathrm{~A}$ \\
\hline Fideos & 765,135 & $5.28 \%$ & $86.17 \%$ & $\mathrm{~B}$ \\
\hline Jabones & 549,863 & $3.79 \%$ & $89.96 \%$ & $\mathrm{~B}$ \\
\hline Leches & 478,144 & $3.30 \%$ & $93.26 \%$ & $\mathrm{~B}$ \\
\hline Pilas & 287,947 & $1.99 \%$ & $95.25 \%$ & $\mathrm{C}$ \\
\hline Harina & 247,462 & $1.71 \%$ & $96.95 \%$ & $\mathrm{C}$ \\
\hline Cafés & 225,443 & $1.55 \%$ & $98.51 \%$ & $\mathrm{C}$ \\
\hline Otros & 216,478 & $1.49 \%$ & $100.00 \%$ & $\mathrm{C}$ \\
\hline TOTAL & $14,500,229$ & & & \\
\hline
\end{tabular}

Elaboración propia

\section{Figura 5. 19.}

\section{Gráfica del análisis ABC}

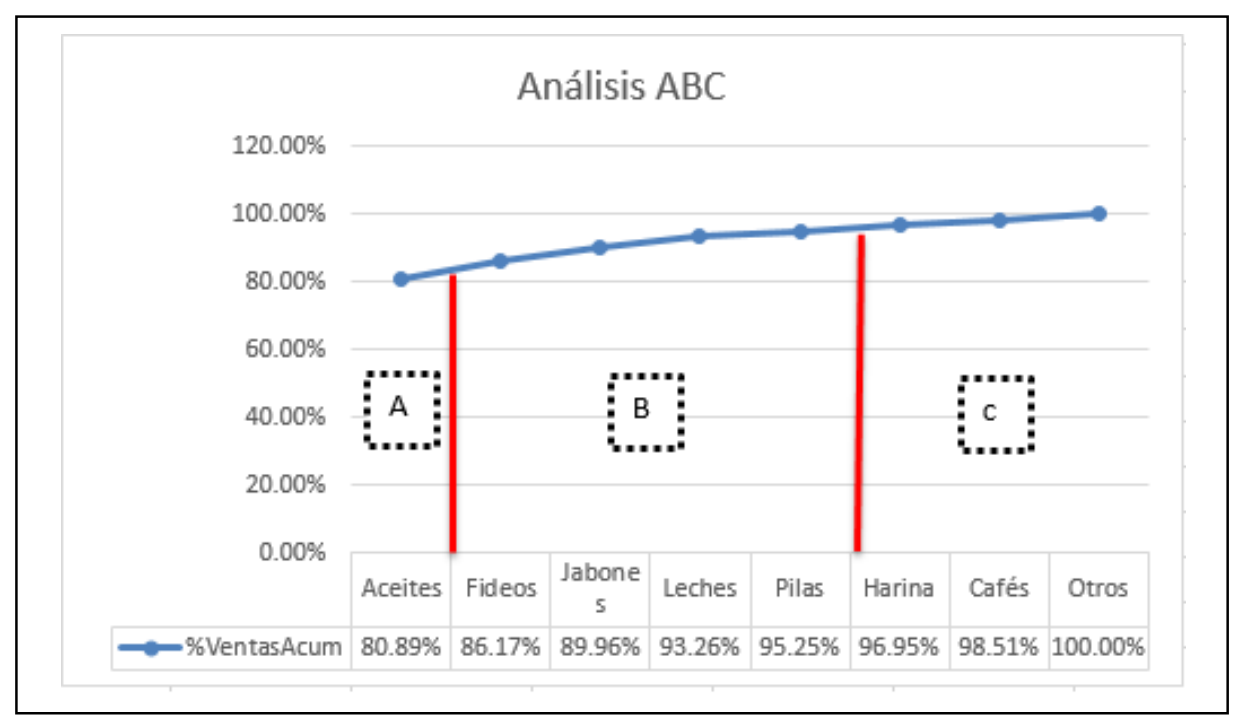

Elaboración propia 
Tabla 5.14.

Distribución interna de los productos en el almacén central

\begin{tabular}{|c|c|c|c|c|}
\hline & & \\
\hline & & $\begin{array}{l}\text { Línea de } \\
\text { productos }\end{array}$ & Aceite & Fideo \\
\hline Ubicación & Zona & $\begin{array}{c}\text { Capacidad } \\
\text { en } \\
\text { pallets }\end{array}$ & 83 & 23 \\
\hline \multirow{8}{*}{ Primer piso } & Zona 1-A & 3 & 3 & \\
\hline & Zona 1-B & 3 & 3 & \\
\hline & Zona 1-C & 3 & 3 & \\
\hline & Zona 1-D & 3 & 3 & \\
\hline & Zona 1-E & 3 & 3 & \\
\hline & Zona 1-f & 8 & 4 & \\
\hline & Zona $1-\mathrm{G}$ & 3 & 2 & \\
\hline & Zona $1-\mathrm{H}$ & 17 & 11 & 2 \\
\hline \multirow{2}{*}{$\begin{array}{c}\text { Mezzanine } \\
1-\mathrm{A}\end{array}$} & Zona 1-I & 9 & & 9 \\
\hline & Zona 1-J & 8 & 3 & 5 \\
\hline $\begin{array}{c}\text { Mezzanie 1- } \\
\text { B }\end{array}$ & Zona 1-K & 9 & & 7 \\
\hline \multirow{6}{*}{$\begin{array}{l}\text { Segundo } \\
\text { piso }\end{array}$} & Zona 2-A & 12 & 11 & \\
\hline & Zona 2-B & 10 & 10 & \\
\hline & Zona 2-C & 11 & 11 & \\
\hline & Zona 2-D & 3 & 3 & \\
\hline & Zona 2-E & 3 & 3 & \\
\hline & Zona 2-f & 3 & 3 & \\
\hline \multirow{5}{*}{ Tercer piso } & Zona 3-A & 7 & & \\
\hline & Zona 3-B & 4 & & \\
\hline & Zona 3-C & 4 & 4 & \\
\hline & Zona 3-D & 4 & 3 & \\
\hline & Zona 3-E & 3 & & \\
\hline
\end{tabular}

Elaboración propia 


\section{Tabla 5. 15.}

\section{Distribución interna de los productos en el almacén auxiliar}

\begin{tabular}{|c|l|l|c|c|}
\cline { 3 - 5 } \multicolumn{2}{c|}{} & $\begin{array}{l}\text { Línea de } \\
\text { productos }\end{array}$ & Aceite & Fideo \\
\hline \multirow{5}{*}{ Almacén } & Zona & $\begin{array}{c}\text { Capacidad en } \\
\text { Pallets }\end{array}$ & 227 & 34 \\
\hline \multirow{5}{*}{ Auxiliar } & Zona A & 48 & 48 & \\
\cline { 2 - 5 } & Zona B & 32 & 32 & \\
\cline { 2 - 5 } & Zona C & 172 & 147 & 25 \\
\cline { 2 - 5 } & Zona D & 20 & & 9 \\
\cline { 2 - 5 } & Zona E & 71 & & \\
\cline { 2 - 5 } & Zona F & 20 & & \\
\hline
\end{tabular}

Elaboración propia

Finalmente después de obtener la capacidad que se tiene en los almacenes por productos, se realizará la planeación diaria de pedidos básicamente la cual consta en la decisión de hacer los requerimientos entre almacenes o al proveedor de acuerdo a las existencias. Para ello, se empezará a utilizar una opción del software que ya se tiene en la cual se puede hacer el requerimiento de mercadería por día. Esto permitirá que el encargado de almacén auxiliar o el proveedor puedan recibir de inmediato el pedido y programar el despacho.

Por otro lado, al planear los pedidos que la empresa va a hacer por días, se reducen el número de viajes. Dichos pedidos serían transportados en camión de 6.5 toneladas que se propone comprar debido a que nos permitirá tener un número reducido de viajes en comparación con el actual, por tanto nos permitirá reducir estos costos. Por otro lado, es importante mencionar que no presentaría incovenientes al ingresar a la zona donde se encuentra el almacén principal; y además, se tuvo en cuenta el límite de presupuesto que la empresa ha establecido para la selección de este. Este camión reemplazaría a las motos. El precio de dicho es \$ 20 500. A continuación, el modelo del camión se muestra en la figura 5.20 . 
Figura 5. 20.

\section{Camión de 6.5 toneladas}

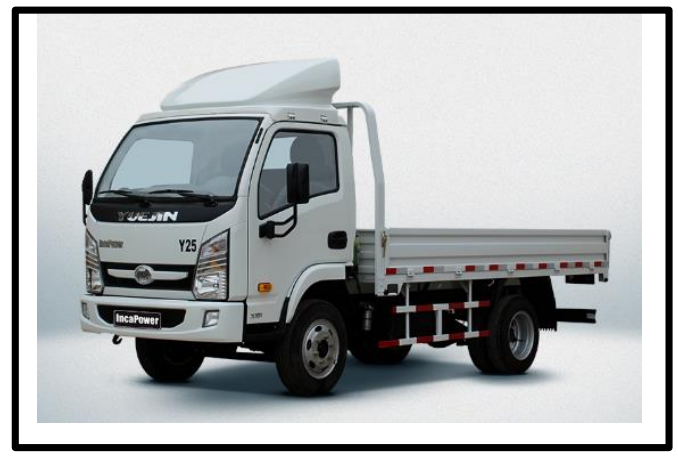

Fuente: Incapower(2017)

El camión tiene las siguientes características: $42.34 \mathrm{~m} 3$ de capacidad de volumen y 6,500 kg de capacidad de carga. Con estos datos se determinó, el número estimado de viajes que se realizarían por mes de acuerdo a los productos que se transportarían por mes. El procedimiento se muestra en las tablas 5.24 y 5.25. Es importante mencionar que los pedidos se realizarían al final del día; y además, de acuerdo si se ha llegado o no al stock de seguridad lo cual será indicado por el software.

Tabla 5. 16.

\section{Transporte mensual}

\begin{tabular}{|c|c|c|c|}
\hline Línea de productos & $\begin{array}{c}\text { Pedido máximo } \\
\text { (capacidad del } \\
\text { almacén central) }\end{array}$ & $\begin{array}{c}\text { Días que dura el } \\
\text { inventario }\end{array}$ & $\begin{array}{c}\text { Unidades a } \\
\text { trasladar por mes } \\
\text { (cajas) }\end{array}$ \\
\hline Aceites & 3320 & 4 & 24,120 \\
\hline Fideos & 1,680 & 8 & 6,988 \\
\hline Jabones & 400 & 16.3 & 734 \\
\hline Leches & 168 & 124.4 & 61 \\
\hline Harina & 18 & 4.3 & 380 \\
\hline Otros & 462 & 5 & 2,772 \\
\hline
\end{tabular}

Elaboración propia 


\section{Tabla 5.17.}

\section{Viajes del camión al mes}

\begin{tabular}{|c|c|c|c|c|c|c|c|}
\hline $\begin{array}{c}\text { Línea de } \\
\text { productos }\end{array}$ & $\begin{array}{c}\text { Volumen } \\
(\mathbf{m 3})\end{array}$ & $\begin{array}{c}\text { Unidades } \\
\text { según } \\
\text { volumen }\end{array}$ & $\begin{array}{c}\text { Peso } \\
\mathbf{( k g )}\end{array}$ & $\begin{array}{c}\text { Unidades } \\
\text { según el } \\
\text { peso }\end{array}$ & $\begin{array}{c}\text { Unidades } \\
\text { por viaje }\end{array}$ & $\begin{array}{c}\text { Unidades a } \\
\text { trasladar } \\
\text { por mes }\end{array}$ & $\begin{array}{c}\text { Número } \\
\text { de viajes } \\
\text { al mes }\end{array}$ \\
\hline Aceites & 0.042 & 1,008 & 15 & 433 & 433 & 24,120 & 56 \\
\hline Fideos & 0.024 & 1,764 & 8 & 813 & 813 & 6,988 & 9 \\
\hline Jabones & 0.036 & 1,176 & 10 & 650 & 650 & 734 & 1 \\
\hline Leches & 0.039 & 1,086 & 20 & 325 & 325 & 61 & 1 \\
\hline Harina & 0.088 & 481 & 50 & 130 & 130 & 380 & 3 \\
\hline Otros & 0.027 & 1,568 & 5 & 1,300 & 1,300 & 2,772 & 2 \\
\hline
\end{tabular}

Elaboración propia

En total, se realizarían 72 viajes al mes aproximadamente con el camión reduciéndose un $50 \%$ el número de viajes.

\section{Acondicionar correctamente la edificación}

En la solución propuesta anteriormente, se consideró que PROASA utilizaría el 100\% de capacidad del almacén central. Sin embargo, la empresa comparte el almacén con otra del mismo grupo la cual necesita alrededor de $36 \mathrm{~m} 2$. Por ello, se propone la compra de nuevos mezzanines que permitan tener un subnivel en el primer piso. El material de este sería de fierro como los que actualmente tiene la empresa. El precio por $36 \mathrm{~m} 2$ de mezzanine es de S/. 12000 soles.

Cabe recalcar que la distribución propuesta permite la instalación de estos debido a que se apilará a un solo nivel.

Esta propuesta permitirá que la empresa pueda tener el stock adecuado para atender a sus clientes y lograr el ahorro que se planea con estas propuestas.

A continuación, en la figura 5.21. se muestran los mezzanines propuestos. 
Figura 5. 21.

\section{Mezzanine propuesto}

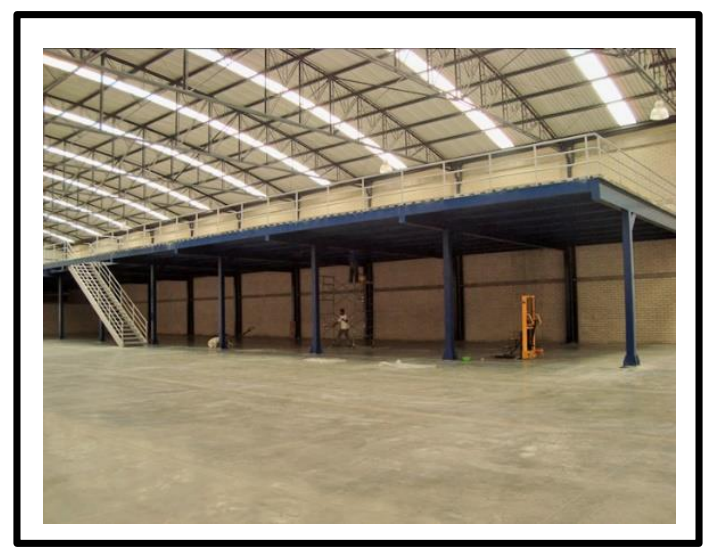

Fuente: ESTRUDUQUE (2016)

\section{- Gastos por daños, conservación o vencimiento de productos}

\section{Realizar plan de control de vencimiento de productos}

En esta sección, se planea contratar al desarrollador del software que actualmente utiliza la empresa con el fin de que realice las mejoras a la sección de almacén. Según el sistema de almacenaje FEFO, los productos que hayan ingresado con fechas de vencimiento más cercanas son los primeros que se deben ir asegurando de esta manera que algún producto pase su fecha de caducidad. Por otro lado, también nos dice que debemos agruparlo por líneas de producto. La agrupación de esto ya se explicó líneas arriba. Por lo tanto, se establece que las mejoras necesarias en el software son las siguientes:

- Crear códigos por cada producto

- Colocar el detalle de la mercadería que ingresa. Este detalle incluye código, lote y fecha de caducidad

- Asignar a la mercadería que ingresa una ubicación según los planos definidos líneas arriba.

- Asignar la mercadería que se debe despachar según la fecha de caducidad del producto. Deberá enviar un mensaje al almacén en el que se indique la zona donde se localiza. 
Gracias a estas, el encargado de almacén podrá manejar de una manera óptima el almacén debido a que le permitirá conocer dónde se encuentra cada producto y que no se malogre algún producto.

Esta mejora tendrá un costo de $\$ 6000$ debido a que se deberá actualizar el software de todas las computadoras; y además, el precio incluye los honorarios del ingeniero a cargo de los cambios que se realizarán.

\section{Control en la manipulación de productos}

En el capítulo 2, se mencionó que suelen presentarse productos rotos debido a que estos son lanzados desde los pisos superiores al primer piso. Por ello, se determina como solución para este problema la compra de un elevador hidráulico de carga debido a que la instalación de este requiere de modificaciones mínimas a la edificación y se aprovecharía el ducto que ya se tiene. Asimismo, no requiere en la parte superior ningún equipo ni cuarto de máquinas y el funcionamiento no produce excesivo ruido. La capacidad de carga estaría entre 100 a 500 $\mathrm{Kg}$. El voltaje sería de $220 \mathrm{~V}$ y $60 \mathrm{~Hz}$ de frecuencia. El costo de este sería de \$ 10500 dólares.Cabe recalcar que el ascensor será construido a la medida de la estructura; y además,

por un proveedor local. Por otro lado, es importante mencionar que gracias a esta compra, se estaría reduciendo el riesgo de futuros accidentes del personal lo cual podría provocar multas y problemas judiciales a la empresa. A continuación, se muestra una imagen del ascensor propuesto en la figura 5.22 . 


\section{Figura 5. 22.}

\section{Elevador hidráulico propuesto}

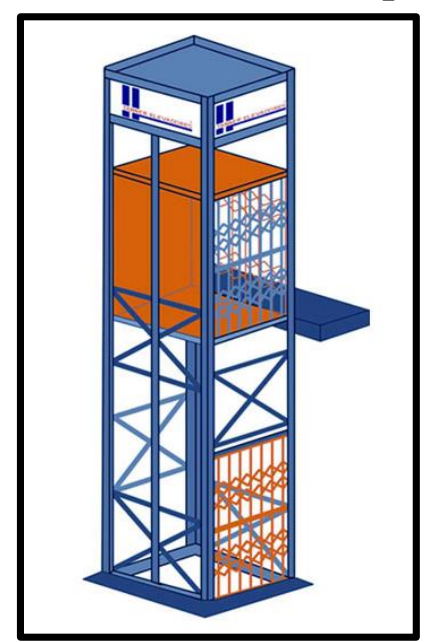

Fuente: Tanner Elevadores, (2016)

Como parte de esta propuesta, se ha decidido implementar un control más exhaustivo en la manipulación de productos, con énfasis en la carga y descarga de productos, que es en donde se producen los daños. Es por ello que se establecerían las siguientes medidas en la empresa, todo bajo supervisión y posibles penalidades a los trabajadores de no acatar las órdenes.

Para este caso, se trabajará en base a la ley de salud y seguridad laboral peruana, ley Na29783, y a las recomendaciones que da. Por ello, se tendrá en cuenta la carga máxima manual descrita en la figura 5.23. la cual indica que el trabajador puede soportar determinado peso según las zonas en donde manipula los productos. 
Figura 5. 23.

Máximo de carga manual

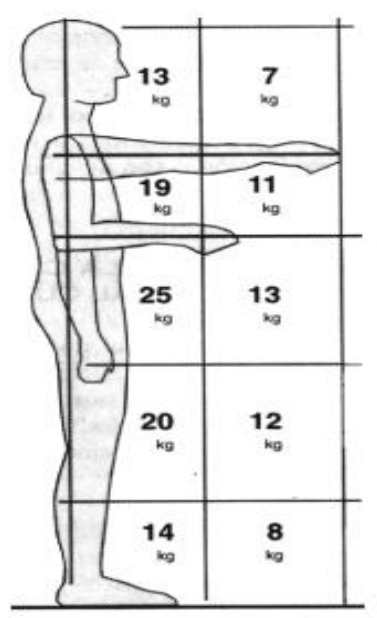

Fuente: Ley 29783 (2016)

Como se puede observar, habrá algunos productos que no se podrán llevar manualmente, por lo que se comprará carretillas manuales para la carga de estos productos y una escalera para trabajos altos. A continuación se detallan las medidas que tomará la empresa en la tabla 5.26. 
Tabla 5. 18.

Medidas para la manipulación de productos

\begin{tabular}{|c|c|c|}
\hline Actividad & Medidas & Imagen \\
\hline \multirow[t]{2}{*}{ Carga de productos } & $\begin{array}{l}\text { 1. Productos pesados cargarlos mediante las } \\
\text { carretillas manuales. (por encima de carga } \\
\text { permitida) }\end{array}$ & \\
\hline & $\begin{array}{l}\text { 2. Productos más livianos cargarlos } \\
\text { manualmente mediante las técnicas apropiadas } \\
\text { de carga. } \\
\text { Agacharse, coger la carga, levantarse y llevarla } \\
\text { pegada al cuerpo con el tronco erguido. }\end{array}$ & \\
\hline \multirow[t]{2}{*}{$\begin{array}{l}\text { Descarga de } \\
\text { productos }\end{array}$} & $\begin{array}{l}\text { 1. Si el producto está a una altura mayor a la } \\
\text { estatura del estibador, no realizar la descarga de } \\
\text { productos sólo, se debe contar con un compañero } \\
\text { que ayude en la labor. Usar la escalera para } \\
\text { retirar el producto. }\end{array}$ & \\
\hline & $\begin{array}{l}\text { 2. Usar los mismos criterios de la carga de } \\
\text { productos. }\end{array}$ & \\
\hline Entrega de productos & $\begin{array}{l}\text { 1. No lanzar los productos desde los mezzanines } \\
\text { o del segundo piso a los estibadores del cliente, } \\
\text { se debe bajar los productos al primer piso y } \\
\text { entregarlos. }\end{array}$ & \\
\hline
\end{tabular}

Elaboración propia

Con estas medidas, se evitarán todos los daños que actualmente sufren los productos.

\section{Ejecutar un plan de limpieza del almacén}

Para la mejor conservación de los productos, se necesita hacer una limpieza periódica de los espacios, para prevenir daños de productos por roedores, plagas, así como la suciedad y el polvo, entre otros.

A continuación, se detalla los controles que deberá realizar la empresa en la tabla 5.27: 


\section{Tabla 5. 19.}

\section{Mantenimiento a los almacenes}

\begin{tabular}{|c|c|c|}
\hline TIPO DE MANTENIMIENTO & DESCRIPCIÓN & FRECUENCIA \\
\hline $\begin{array}{l}\text { Fumigación de plagas } \\
\text { (gorgojos, hormigas y cucarachas) }\end{array}$ & $\begin{array}{l}\text { Con la contratación de un tercero } \\
\text {, se rociará por los distintos } \\
\text { ambientes del almacén el agente } \\
\text { que previene y elimina las plagas }\end{array}$ & Semestral \\
\hline Control de roedores & $\begin{array}{l}\text { Colocación de raticidas para } \\
\text { eliminar roedores. }\end{array}$ & Bimestral \\
\hline $\begin{array}{l}\text { Limpieza de los pasadizos de } \\
\text { tránsito del almacén }\end{array}$ & $\begin{array}{l}\text { Se barrerá, trapeará y limpiará el } \\
\text { ambiente. }\end{array}$ & Quincenal \\
\hline
\end{tabular}

Elaboración propia

Con estos mantenimientos periódicos, se eliminará las pérdidas de productos por daños o falta de mantenimiento.

La fumigación de plagas se realizarán los domingos, con la contratación de un tercero, para ello el encargado de almacén deberá colaborar; y por ello, se le compensará las horas extras trabajadas.

Por otro lado, el control de roedores y la limpieza se realizará al finalizar la jornada laboral, para lo cual el trabajador asignado del área de almacén realizará los mantenimientos fuera de la jornada de trabajo.

A continuación, se detallan los planes de mantenimiento por cada almacén a realizar en las figuras 5.24.; 5.25. y 5.26.: 
Figura 5. 24.

Plan de mantenimiento - fumigación de plagas

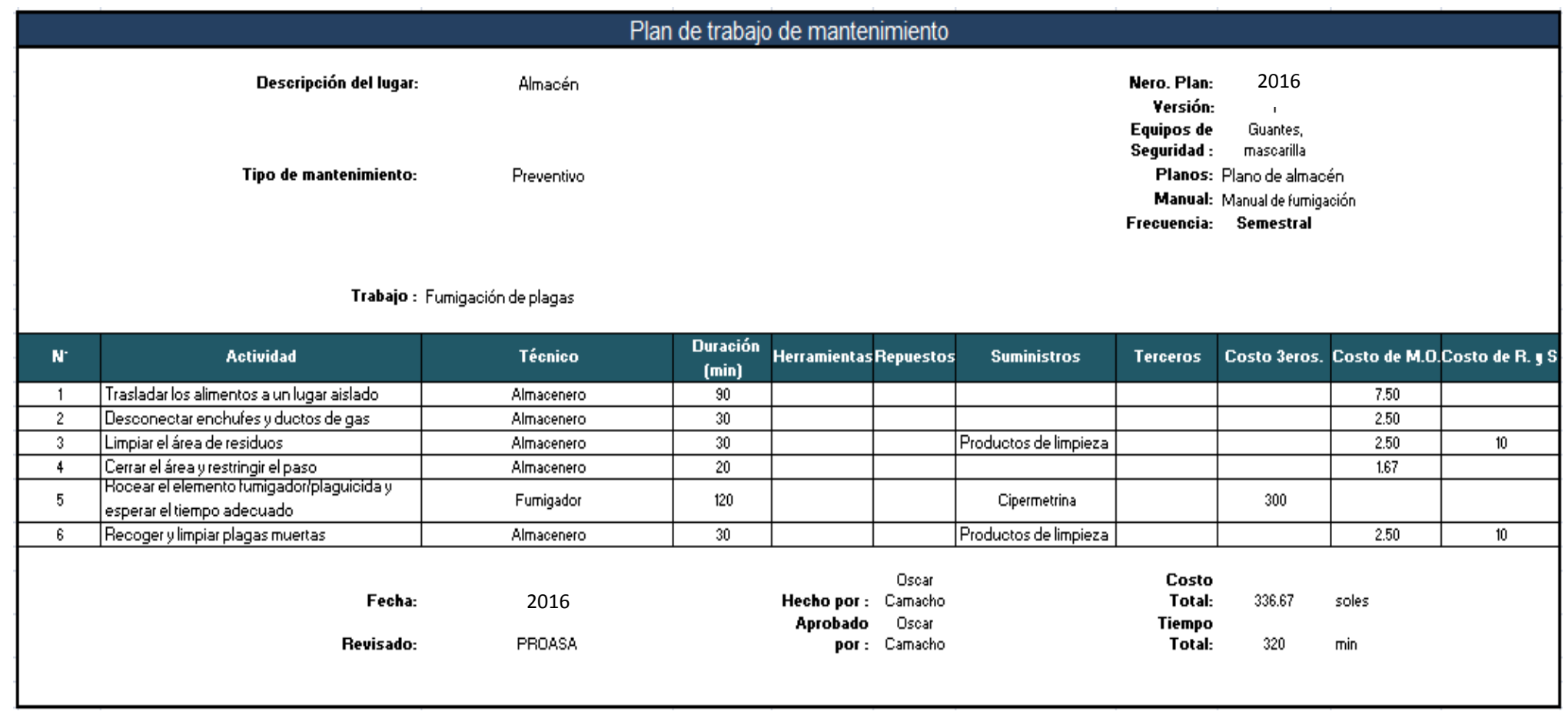

Elaboración propia 


\section{Figura 5. 25.}

Plan de mantenimiento - control de roedores

\begin{tabular}{|c|c|c|c|c|c|c|c|c|c|c|}
\hline \multicolumn{11}{|c|}{ Plan de trabajo de mantenimiento } \\
\hline & $\begin{array}{l}\text { Descripción del lugar: } \\
\text { Tipo de mantenimiento: }\end{array}$ & $\begin{array}{l}\text { Almacén } \\
\text { Preventivo }\end{array}$ & & & & & $\begin{array}{r}\text { Nero. Plan: } \\
\text { Yersión: } \\
\text { Equipos de } \\
\text { Seguridad : } \\
\text { Planos: } \\
\text { Manual: } \\
\text { Frecuencia: }\end{array}$ & $\begin{array}{c}2016 \\
\text { Guantes, } \\
\text { mascarilla } \\
\text { Plano de almace } \\
\text { Manual de fumiga } \\
\text { Bimestral }\end{array}$ & ación & \\
\hline $\mathbf{N}$ & Actividad & Téenico & $\begin{array}{c}\text { Duración } \\
\text { (min) }\end{array}$ & Herramientas & Repuestos & Suministros & Terceros & Costo 3eros. & Costo de M.O. & Costo de R. I s \\
\hline 1 & Limpiar las áreas de aplicación & Almacenero & 30 & & & & & & 2.50 & \\
\hline 2 & Colocar el raticida & Almacenero & 20 & & & Raticida & & & 1.67 & 25 \\
\hline 3 & Limpiar las plagas muertas & Almacenero & 20 & & & & & & 1.67 & \\
\hline & $\begin{array}{r}\text { Fecha: } \\
\text { Revisado: }\end{array}$ & $\begin{array}{r}2016 \\
\text { PROASA }\end{array}$ & & $\begin{array}{r}\text { Hecho por : } \\
\text { Aprobado } \\
\text { por : }\end{array}$ & $\begin{array}{c}\text { Oscar } \\
\text { Camacho } \\
\text { Oscar } \\
\text { Camacho }\end{array}$ & & $\begin{array}{c}\text { Costo } \\
\text { Total: } \\
\text { Tiempo } \\
\text { Total: }\end{array}$ & $\begin{array}{c}30.83 \\
70\end{array}$ & $\begin{array}{l}\text { soles } \\
\text { min }\end{array}$ & \\
\hline
\end{tabular}

Elaboración propia 
Figura 5. 26.

Plan de mantenimiento - limpieza general de almacén

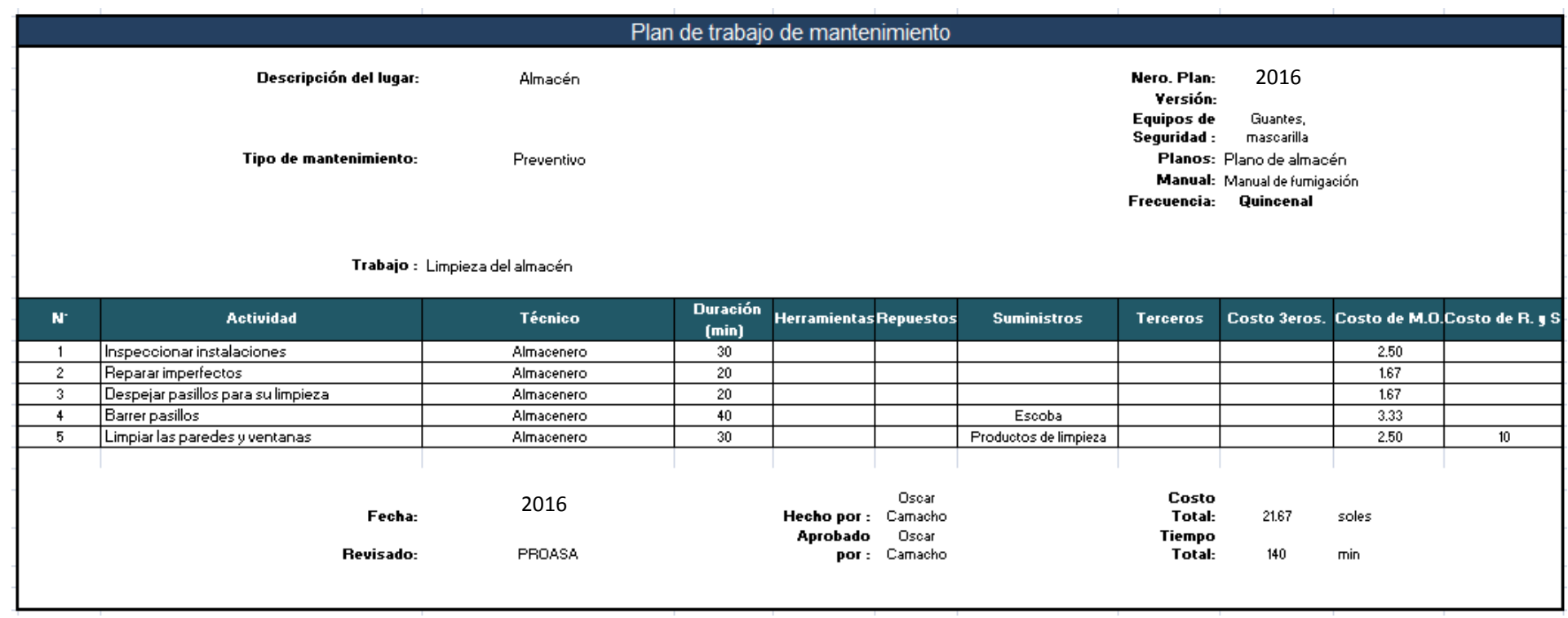

Elaboración propia 


\subsection{Planificación de la implementación de la solución}

\subsubsection{Evaluación de objetivos y metas}

- Ventas perdidas

Para calcular el indicador se debe considerar la recuperación de ventas descrita en la sección 5.1. que se obtendría por la aplicación de las soluciones propuestas. Todo se resume en la tabla 5.28.

\section{Tabla 5. 28.}

\section{Recuperación de ventas perdidas}

\begin{tabular}{|c|c|}
\hline Problema & $\begin{array}{c}\text { Recuperación } \\
\text { neta mensual } \\
(\mathrm{S} / .)\end{array}$ \\
\hline Falta de stock & 20,300 \\
\hline Precio alto & 955 \\
\hline $\begin{array}{c}\text { No se tiene el } \\
\text { producto en cartera }\end{array}$ & 0 \\
\hline $\begin{array}{r}\text { Total recuperado al } \\
\text { mes }\end{array}$ & 21,255 \\
\hline
\end{tabular}

Elaboración propia

Entonces, el nuevo monto será las ventas perdidas por mes calculadas en el capítulo 2 menos las ventas recuperadas al mes:

$$
\mathrm{S} / .23,490-\mathrm{S} / .21,255=\mathrm{S} / .2,235 / \text { mes }
$$

Como se puede observar, el monto de ventas perdidas se ha reducido a S/. 2,336 soles al mes debido a que las soluciones propuestas permitirán recuperar los clientes que antes no eran atendidos.

- Gastos por daños, conservación o vencimiento de productos

Al aplicar las soluciones propuestas, ya no se tendrán gastos por daños o vencimientos. Para este indicador, se considerará los gastos por la conservación derivada del plan de mantenimiento aplicado, el costo de la actualización del software y la compra del elevador de carga. 
El cálculo se puede observar en la tabla 5.29.

Tabla 5. 29.

Gastos para evitar daños, conservación o vencimiento de productos

\begin{tabular}{|c|c|c|c|}
\hline Plan de mantenimiento & Gasto unitario & Frecuencia & $\begin{array}{c}\text { Gasto anual (dos } \\
\text { almacenes) }\end{array}$ \\
\hline Actualización de software & $\$ 6,000 * 3.3=19,800$ & Único pago & 19,800 \\
\hline $\begin{array}{c}\text { Elevador hidráulico de } \\
\text { carga }\end{array}$ & $\$ 10,500 * 3.3=34,650$ & Único pago & 34,650 \\
\hline Fumigación de plagas & 336.67 & Semestral & $1,346.7$ \\
\hline Control de roedores & 30.83 & Bimestral & 369.96 \\
\hline Limpieza & 21.67 & Quincenal & $1,040.16$ \\
\hline & & Total & $60,506.82$ \\
\hline
\end{tabular}

Elaboración propia

- Gastos de transporte desde almacén auxiliar

Los nuevos gastos de transporte serían dados por el costo del camión al trasladar productos del almacén auxiliar al almacén central.

Consultando con el propietario, la tarifa se estableció en S/3.19 / km., con ello calculamos este indicador en la tabla 5.30.

Tabla 5.30.

Costo de viajes por transporte

\begin{tabular}{|c|c|c|c|}
\hline $\begin{array}{l}\text { Línea de } \\
\text { productos }\end{array}$ & $\begin{array}{l}\text { Número de } \\
\text { viajes al } \\
\text { mes }\end{array}$ & $\begin{array}{c}\text { Distancia } \\
\text { (km) }\end{array}$ & $\begin{array}{c}\begin{array}{c}\text { Costo total al } \\
\text { mes }\end{array} \\
(\mathrm{S} / .) \\
(\mathrm{S} / .3 .19 / \mathrm{Km})\end{array}$ \\
\hline Aceites & 56 & 6 & 1,072 \\
\hline Fideos & 9 & 6 & 172 \\
\hline Jabones & 1 & 6 & 19 \\
\hline Leches & 1 & 6 & 19 \\
\hline Harina & 3 & 6 & 57 \\
\hline Otros & 2 & 6 & 38 \\
\hline \multicolumn{3}{|c|}{ Total } & 1,378 \\
\hline
\end{tabular}

Elaboración propia 
Por lo tanto, el gasto anual en este transporte sería de S/. 16,537 soles. Asimismo, debemos agregar el costo de \$20 500 dólares por el nuevo camión. Se considerará el tipo de S/ 3.3 soles. Por ello, el monto equivalente en soles es S/ 67,650.

\subsubsection{Elaboración del presupuesto general requerido para la ejecución de la solución}

El presupuesto anual necesario se muestra en la tabla 5.31. 
Tabla 5. 20.

\section{Presupuesto anual requerido}

\begin{tabular}{|c|c|c|c|c|c|c|}
\hline Solución & Concepto & Tipo & Año 2016 & Año 2017 & Año 2018 & Año 2019 \\
\hline $\begin{array}{c}\text { Mejorar la } \\
\text { distribución de } \\
\text { los almacenes }\end{array}$ & 392 Parihuelas & Inversión & $17,640.00$ & & $17,640.00$ & \\
\hline $\begin{array}{l}\text { Control en el } \\
\text { vencimiento de } \\
\text { productos }\end{array}$ & $\begin{array}{l}\text { Programador y } \\
\text { Actualización de } \\
\text { software }\end{array}$ & Inversión & $19,800.00$ & & & \\
\hline $\begin{array}{l}\text { Control en la } \\
\text { manipulación de } \\
\text { productos }\end{array}$ & $\begin{array}{l}\text { Instalación de } \\
\text { elevador }\end{array}$ & Inversión & $34,650.00$ & & & \\
\hline $\begin{array}{l}\text { Acondicionar la } \\
\text { edificación }\end{array}$ & $\begin{array}{l}\text { Instalar } 40 \mathrm{~m} 2 \text { de } \\
\text { mezzanines }\end{array}$ & Inversión & 12,000 & & & \\
\hline $\begin{array}{l}\text { Disminuir viajes } \\
\text { entre almacenes }\end{array}$ & $\begin{array}{c}1 \text { camión de } 6.5 \\
\text { toneladas }\end{array}$ & Inversión & $67,650.00$ & & & \\
\hline $\begin{array}{l}\text { Control en la } \\
\text { manipulación de } \\
\text { productos }\end{array}$ & $\begin{array}{l}3 \text { carretillas } \\
\text { manuales }\end{array}$ & Inversión & 240.00 & & & \\
\hline $\begin{array}{l}\text { Control en la } \\
\text { manipulación de } \\
\text { productos }\end{array}$ & 1 escalera & Inversión & 200.00 & & & \\
\hline Plan de limpieza & $\begin{array}{l}2 \text { barredoras } \\
\text { mecánicas }\end{array}$ & Inversión & 400.00 & & & \\
\hline Plan de limpieza & $\begin{array}{l}\text { Servicio de } \\
\text { fumigación }\end{array}$ & Operativo & & $1,346.7$ & $1,346.7$ & $1,346.7$ \\
\hline Plan de limpieza & $\begin{array}{c}\text { Desinfectante, } \\
\text { Trapos }\end{array}$ & Operativo & & 1040.16 & 1040.16 & 1040.16 \\
\hline Plan de limpieza & Raticida & Operativo & & 369.96 & 369.96 & 369.96 \\
\hline Plan de limpieza & $\begin{array}{c}\text { Horas extra - } \\
\text { trabajadores }\end{array}$ & Operativo & & $1,074.86$ & $1,074.86$ & $1,074.86$ \\
\hline \multicolumn{3}{|c|}{ Total } & 151,140 & $3,831.68$ & $24,306.86$ & $3,831.68$ \\
\hline
\end{tabular}

Elaboración propia 
Tabla 5. 21.

\section{Cronograma de implementación}

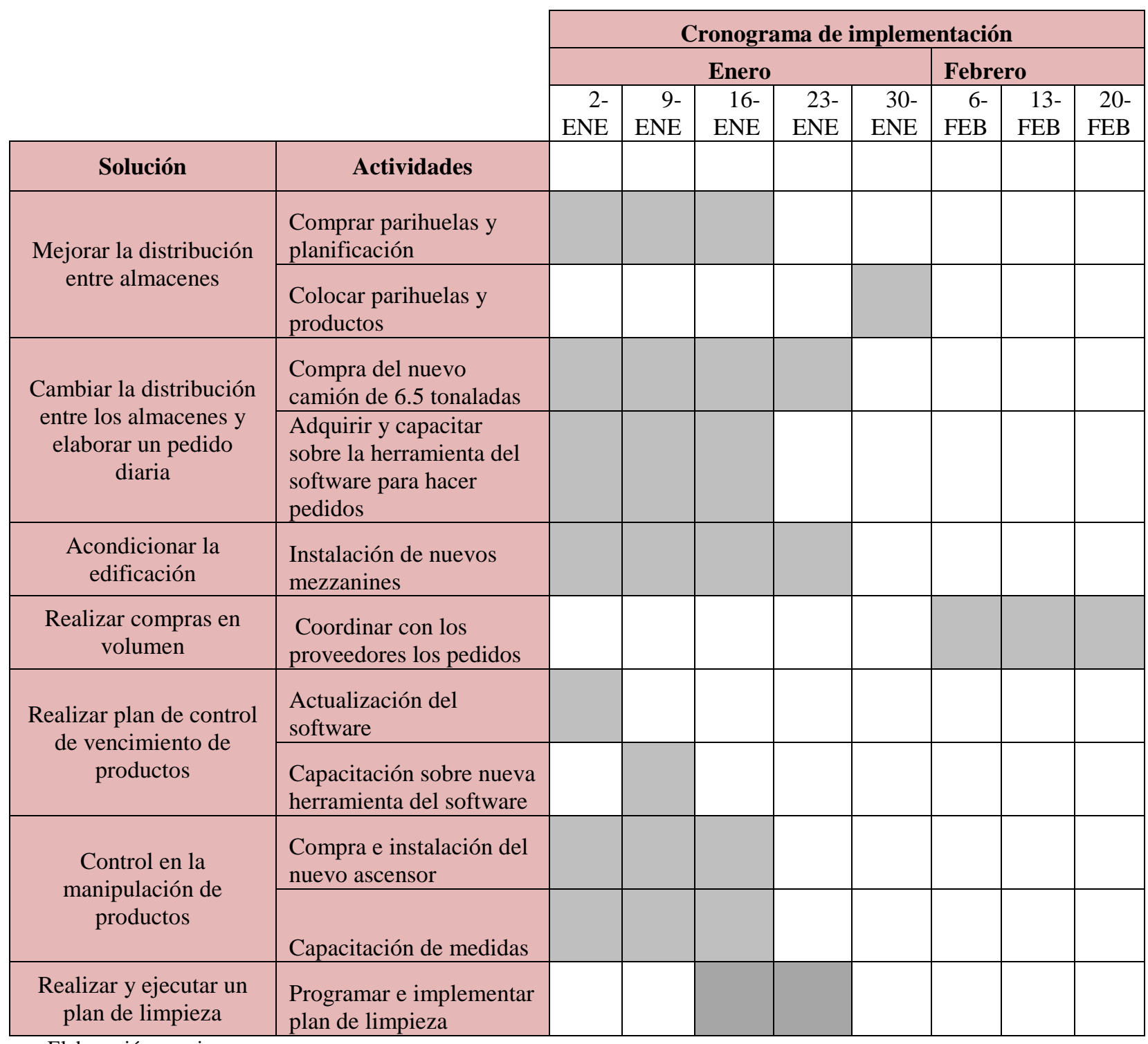

Elaboración propia

En la tabla 5.32., se aprecia que todo puede ser implementado para inicios del 2017. 


\title{
CAPÍTULO VI: EVALUACIÓN DE LA PROPUESTA Y BENEFICIOS SOCIALES
}

\author{
6.1.Determinación de escenarios que afectarían la solución \\ Para este punto manejaremos tres escenarios para cada alternativa de solución: una optimista, \\ una pesimista y uno esperado, en el cual nos basaremos para la evaluación tanto cualitativa \\ como cuantitativa.
}

A continuación se presentan en la tabla 6.1.los tres escenarios para cada solución. 
Tabla 6. 1.

\section{Escenarios de las soluciones propuestas}

\begin{tabular}{|c|c|c|c|c|}
\hline \multirow[b]{2}{*}{ Indicador } & \multirow[b]{2}{*}{ Solución } & \multicolumn{3}{|c|}{ Escenarios } \\
\hline & & Optimista & Esperado & Pesimista \\
\hline \multirow{3}{*}{$\begin{array}{l}\text { Ventas } \\
\text { perdidas }\end{array}$} & $\begin{array}{l}\text { Mejorar la } \\
\text { distribución entre } \\
\text { almacenes }\end{array}$ & $\begin{array}{c}\text { Los dos almacenes se } \\
\text { utilizarían al } 100 \% \text { para la } \\
\text { empresa }\end{array}$ & $\begin{array}{l}\text { La estructura de ambos } \\
\text { almacenes se mantiene } \\
\text { como hasta ahora }\end{array}$ & $\begin{array}{c}\text { La empresa tendría que } \\
\text { compartir mayor porcentaje } \\
\text { de espacio de los almacenes } \\
\text { con las otras empresas }\end{array}$ \\
\hline & $\begin{array}{l}\text { Realizar compras en } \\
\text { mayor volumen }\end{array}$ & $\begin{array}{l}\text { La empresa tendrá mayor } \\
\text { capacidad para almacenar } \\
\text { productos. El menor precio } \\
\text { atrae más clientes. }\end{array}$ & $\begin{array}{l}\text { Se utiliza al máximo la } \\
\text { capacidad de los } \\
\text { almacenes }\end{array}$ & $\begin{array}{l}\text { La empresa tendría que } \\
\text { compartir mayor porcentaje } \\
\text { de espacio de los almacenes } \\
\text { con las otras empresas. Se } \\
\text { recuperan menos ventas. }\end{array}$ \\
\hline & $\begin{array}{l}\text { Ampliar la cartera } \\
\text { con productos } \\
\text { demandados }\end{array}$ & $\begin{array}{l}\text { Proveedores de productos } \\
\text { demandados no incluidos } \\
\text { en la cartera de productos } \\
\text { de la empresa ofrecerían } \\
\text { mayor seguridad y } \\
\text { beneficios }\end{array}$ & $\begin{array}{c}\text { Proveedores de } \\
\text { productos demandados } \\
\text { no incluidos en la } \\
\text { cartera de productos de } \\
\text { la empresa no ofrecen } \\
\text { seguridad y bajos } \\
\text { beneficios }\end{array}$ & $\begin{array}{c}\text { No existe posibles productos } \\
\text { para incluir en la cartera de } \\
\text { productos }\end{array}$ \\
\hline \multirow{3}{*}{$\begin{array}{c}\text { Gastos por } \\
\text { daños, } \\
\text { conserva-ción } \\
\text { o vencimien- } \\
\text { to de } \\
\text { productos }\end{array}$} & $\begin{array}{l}\text { Realizar plan de } \\
\text { control de } \\
\text { vencimiento de } \\
\text { productos }\end{array}$ & $\begin{array}{l}\text { Se tendría un software más } \\
\text { sofisticado que el actual } \\
\text { para manejar el almacén }\end{array}$ & $\begin{array}{c}\text { Se actualiza el software } \\
\text { actual con las mejoras } \\
\text { necesarias }\end{array}$ & $\begin{array}{c}\text { No se podrá actualizar el } \\
\text { software }\end{array}$ \\
\hline & $\begin{array}{l}\text { Control de la } \\
\text { manipulación de } \\
\text { productos }\end{array}$ & $\begin{array}{c}\text { Se propone mejoras en las } \\
\text { prácticas de manipulación } \\
\text { de productos. }\end{array}$ & $\begin{array}{l}\text { Se cumpliría con lo } \\
\text { establecido en las } \\
\text { capacitaciones }\end{array}$ & $\begin{array}{c}\text { No se tome en cuenta lo } \\
\text { establecido en las } \\
\text { capacitaciones. }\end{array}$ \\
\hline & $\begin{array}{l}\text { Ejecutar un plan de } \\
\text { limpieza del } \\
\text { almacenes }\end{array}$ & $\begin{array}{l}\text { Menor requerimiento de } \\
\text { mantenimiento }\end{array}$ & $\begin{array}{l}\text { Seguir los planes de } \\
\text { mantenimiento }\end{array}$ & $\begin{array}{c}\text { Tener que aumentar la } \\
\text { frecuencia de mantenimiento } \\
\text { por plagas. }\end{array}$ \\
\hline \multirow{2}{*}{$\begin{array}{l}\text { Gastos por } \\
\text { transporte } \\
\text { desde } \\
\text { almacén } \\
\text { auxiliar }\end{array}$} & $\begin{array}{c}\text { Cambiar la } \\
\text { distribución en los } \\
\text { almacenes y elaborar } \\
\text { un plan de pedidos }\end{array}$ & $\begin{array}{l}\text { La cantidad de pedidos se } \\
\text { cumple en su totalidad. El } \\
\text { costo de transporte de } \\
\text { reduce. }\end{array}$ & $\begin{array}{l}\text { La cantidad de pedidos } \\
\text { al mes se asemeja a lo } \\
\text { proyectado }\end{array}$ & $\begin{array}{l}\text { La cantidad a distribuir } \\
\text { aumenta y el costo de } \\
\text { transporte aumenta. }\end{array}$ \\
\hline & $\begin{array}{c}\text { Acondicionar la } \\
\text { edificación para tener } \\
\text { nuevos espacios }\end{array}$ & $\begin{array}{c}\text { Posibilidad de aprovechar } \\
\text { el nuevo espacio para la } \\
\text { empresa }\end{array}$ & $\begin{array}{l}\text { La empresa comparte el } \\
\text { almacén según lo } \\
\text { señalado }\end{array}$ & $\begin{array}{l}\text { No se podrá instalar los } \\
\text { mezzanines }\end{array}$ \\
\hline
\end{tabular}

Elaboración propia 


\subsection{Evaluación económica financiera de la solución}

En el análisis económico y financiero se analizarán los beneficios que obtiene la empresa al aplicar las soluciones. Se considera un COK de 15\% y un periodo de evaluación de 3 años. Por el nivel de inversión, el dueño considera que no es necesario financiarse por deuda, debido a que la empresa es capaz de generar esos recursos en menos de un mes. Por lo tanto, el análisis financiero es equivalente al económico. A continuación, en la tabla 6.2., se presenta la evaluación económica y en la tabla 6.3. los indicadores de la evaluación:

Tabla 6. 2.

Análisis económico de la propuesta

\begin{tabular}{|c|c|c|c|c|c|}
\hline |Indicador & Concepto & 2016 & 2017 & 2018 & 2019 \\
\hline Ventas Perdidas & Ingreso neto por ventas recuperadas & & 255,060 & 256,335 & 257,617 \\
\hline \multicolumn{6}{|c|}{ Costos } \\
\hline \multirow{5}{*}{$\begin{array}{l}\text { Gastos por daños, } \\
\text { conservación o } \\
\text { vencimiento de } \\
\text { productos }\end{array}$} & Fumigación & & $-1,347$ & $-1,347$ & $-1,347$ \\
\hline & Raticidas & & -370 & -370 & -370 \\
\hline & Productos de Limpieza & & $-1,040$ & $-1,040$ & $-1,040$ \\
\hline & Horas extra - trabajadores & & $-1,075$ & $-1,075$ & $-1,075$ \\
\hline & Gastos anteriores no incurridos & & 4,488 & 4,488 & 4,488 \\
\hline \multirow{2}{*}{$\begin{array}{l}\text { Gastos por } \\
\text { transporte desde } \\
\text { almacén auxiliar }\end{array}$} & Nuevos gastos de transporte & & $-17,341$ & $-17,999$ & $-18,554$ \\
\hline & Gastos anteriores no incurridos & & 39,639 & 41,141 & 42,411 \\
\hline Depreciación & Depreciación & & $-26,988$ & $-26,988$ & $-26,988$ \\
\hline \multicolumn{2}{|c|}{ Utilidad Agregada antes de Impuestos } & & 259,957 & 270,808 & 279,644 \\
\hline \multicolumn{2}{|l|}{ Impuesto a la Renta } & & 77,987 & 81,242 & 83,893 \\
\hline \multicolumn{2}{|c|}{ Utilidad Agregada después de Impuestos } & & 181,970 & 189,565 & 195,751 \\
\hline \multirow{8}{*}{ Inversión } & Parihuelas & $-17,640$ & & $-17,640$ & \\
\hline & Software & $-19,800$ & & & \\
\hline & Carretillas & -240 & & & \\
\hline & Escalera & -200 & & & \\
\hline & Barredora & -400 & & & \\
\hline & Elevador & $-34,650$ & & & \\
\hline & Camión 6.5 toneladas & $-67,650$ & & & \\
\hline & Instalación de mezzanines & $-12,000$ & & & \\
\hline Depreciación & Depreciación & & 26,988 & 26,988 & 26,988 \\
\hline \multicolumn{2}{|c|}{ Utilidad Agregada después de Impuestos } & $-152,580$ & 208,958 & 198,913 & 222,739 \\
\hline
\end{tabular}

Elaboración propia

*Los gastos anteriores no incurridos se encuentran descritos en el capítulo 2. 


\section{Tabla 6. 3.}

\section{Indicadores de evaluación económica}

\begin{tabular}{|c|c|}
\hline VAN & 297,170 \\
\hline TIR & $117 \%$ \\
\hline PR & 0.76 \\
\hline
\end{tabular}

Elaboración propia

Se trabajó los escenarios optimista y pesimista, teniendo los siguientes resultados mostrados

en la tabla 6.4 y 6.5. Como se puede apreciar incluso en el escenario pesimista se tiene un retorno de inversión.

\section{Tabla 6. 4.}

\section{Descripción escenarios optimista y pesimista}

\begin{tabular}{|c|c|c|}
\cline { 2 - 3 } \multicolumn{1}{c|}{} & Escenario Optimista & Escenario Pesimista \\
\hline Ventas Perdidas & $\begin{array}{c}\text { Se recupera todas las ventas } \\
\text { perdidas. }\end{array}$ & $\begin{array}{c}\text { Se recupera el 60\% de las ventas } \\
\text { perdidas. (Clientes asiduos) }\end{array}$ \\
\hline Gastos de conservación & $\begin{array}{c}\text { El buen control de plagas reduce a } \\
\text { la mitad la frecuencia de limpieza. }\end{array}$ & $\begin{array}{c}\text { Se requiere el doble de inversión } \\
\text { de limpieza y mantenimiento. }\end{array}$ \\
\hline Gastos por transporte & Se reduce el costo por km a S/3 & $\begin{array}{c}\text { Se incrementa el costo por km a } \\
\text { S/4 }\end{array}$ \\
\hline
\end{tabular}

Elaboración propia

\section{Tabla 6. 5.}

\section{Resultados económicos de los escenarios}

\begin{tabular}{|c|c|c|c|}
\cline { 2 - 4 } \multicolumn{1}{c|}{} & $\begin{array}{c}\text { Escenario } \\
\text { Optimista }\end{array}$ & $\begin{array}{c}\text { Escenario } \\
\text { Esperado }\end{array}$ & $\begin{array}{c}\text { Escenario } \\
\text { Pesimista }\end{array}$ \\
\hline VAN & 377,145 & 297,170 & 135,068 \\
\hline TIR & $142 \%$ & $117 \%$ & $64 \%$ \\
\hline PR & 0.64 & 0.76 & 1.16 \\
\hline
\end{tabular}

Elaboración propia 


\subsection{Análisis del impacto social y ambiental de la solución}

\subsubsection{Impacto social}

Las soluciones que se han planteado en el trabajo tienen impacto social que serán analizados por cada indicador en el que se desarrollaron propuestas.

- $\quad$ Costo de oportunidad por Ventas perdidas

Con la mejor distribución del almacén se logrará mejoras importantes en cuanto a la comodidad del cliente, debido a que contará con un espacio establecido de atención, además al contar con pasadizos y seguir las recomendaciones de ley, se mejora la seguridad del local y se disminuye los tiempos de atención, todo esto mejora la calidad de servicio de la empresa.

Al comprar en volúmenes, se ofrecerán productos a precios más bajos y competitivos, lo que hará que más público pueda acceder a ellos y a la vez, obtengan un ahorro en la canasta básica, por lo que se impulsa el bienestar social.

- Gastos por daños, conservación o vencimiento de productos

Al controlar el vencimiento de productos, ya no se entregarán productos caducados a los clientes, por lo que se mejorará el servicio a los mismos ya que no tendrán la incomodidad de regresar a la tienda para devolver los productos expirados. Además, no se desperdician recursos, ya que se consumen los productos antes de que se venzan.

Cuando se trasladen y manipulen los productos adecuadamente, se beneficiará al cliente al entregarle lo que requiere en perfectas condiciones y estado. No genera incomodidad y contribuye a la satisfacción del usuario.

Por otro lado, al controlar las plagas, se mejorará los aspectos de salubridad, con lo que se eliminarán las posibilidades que le cliente contraiga enfermedades.

- Gastos de transporte desde almacén auxiliar

Al elaborar un plan de pedidos, se puede proveer lo que el cliente necesitará, por lo que se les puede atender mejor y aumentar el nivel de servicio de la empresa.

\subsubsection{Impacto ambiental}

Con el fin de determinar el impacto ambiental de las propuestas, se procedió a identificar los medios físicos, biológicos y socioeconómicos que podrían ser afectados debido a estas. Para 
ello, se utilizó el método de lista de chequeo; y además, se filtró a los de mayor probabilidad con el fin de priorizar los más importantes. Los factores son los siguientes:

- $\quad$ Medio físico natural

1. Medio inerte

- $\quad$ Aire : Emisión de CO2 por camiones

- $\quad$ Suelo : Disminución de residuos por productos vencidos

- $\quad$ Agua : Limpieza de almacenes haciendo uso de agua

2. Medio biótico

- $\quad$ Flora: Requerimiento de madera para la producción de parihuelas. Requerimiento mayor de productos comestibles.

- $\quad$ Fauna : Eliminación de plagas

Identificados los factores y haciendo uso de la matriz de Leopold, se determinó el impacto de estos el cual se muestra en la tabla 6.6.

Tabla 6. 6.

Matriz de Leopold

\begin{tabular}{|c|c|c|c|c|c|c|}
\hline $\begin{array}{l}\text { Acciones/ } \\
\text { Factores }\end{array}$ & Aire & Suelo & Agua & Flora & Fauna & EVALUCIÓN \\
\hline Emisión de $\mathrm{CO} 2$ por camiones & & & & & & \\
\hline $\begin{array}{l}\text { Disminución de residuos por } \\
\text { productos vencidos }\end{array}$ & & & & & & \\
\hline $\begin{array}{c}\text { Limpieza de almacenes haciendo } \\
\text { uso de agua. }\end{array}$ & & & & & & \\
\hline $\begin{array}{l}\text { Requerimiento de madera para } \\
\text { la producción de parihuelas }\end{array}$ & & -4 & & & & 22 \\
\hline $\begin{array}{l}\text { Requerimiento de mayor } \\
\text { productos comestibles }\end{array}$ & & & & 5 & & 21 \\
\hline Eliminación de plagas & & & & & & \\
\hline EVALUACIÓN & & & & & & \\
\hline
\end{tabular}

Elaboración propia 
Según la tabla, se observa que el factor de mayor impacto es el de requerimiento de madera para la producción de parihuelas ya que se necesitará un gran número de parihuelas que producirá que la empresa productora de estas requiera mayor cantidad de madera. Por ello, es que se considera importante este impacto en la flora.

Asimismo, se puede identificar el factor con menor impacto el cual es el de eliminación de plagas ya que la cantidad y la frecuencia con la que esta se haga efectiva serán leves. Por ello, no se considera importante.

En la figura 6.1. se observa que el proyecto genera un impacto ambiental leve el cual se irá monitoreando a lo largo del mismo.

\section{Figura 6. 1.}

Magnitud e impacto ambiental del proyecto

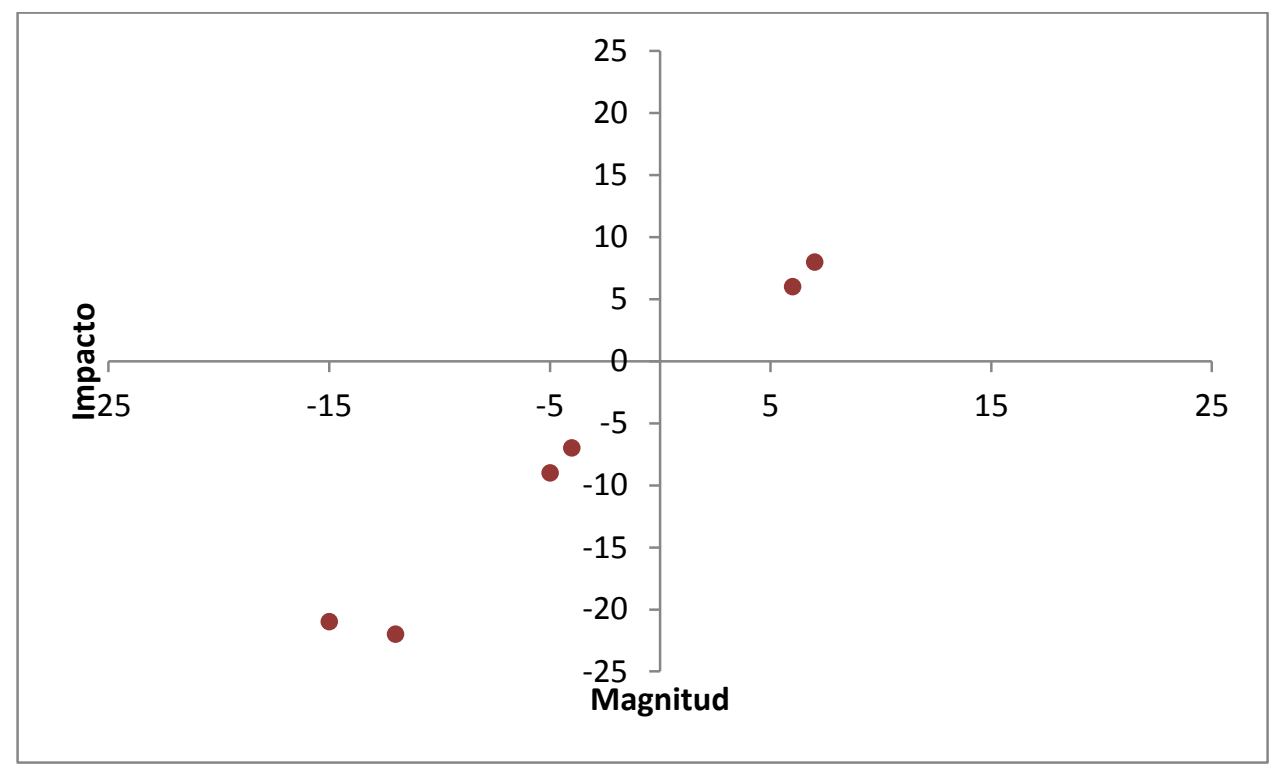

Elaboración propia 


\section{CONCLUSIONES}

- Actualmente, la empresa se encuentra desarrollando ciertos problemas que le impiden percibir S/.312, 288 al año. Estos se han dado por diversos factores que son generados debido a la falta de manejo apropiado de la empresa por parte de los dueños de la empresa.

- Entre las principales limitantes importantes para desarrollar las soluciones, fue la infraestructura inadecuada de los almacenes ya que cuenta con paredes y elementos innecesarios que dificultan la buena distribución de los productos en parihuela.

- $\quad$ PROASA posee dos almacenes cercanos los cuales poseen un área importante y están separados por una distancia corta. Por tanto, esto permitió que se establezcan mejoras para aumentar la cantidad de compra de pedidos y que el número de viajes de abastecimiento sean menores.

- La empresa debe aprovechar las herramientas nuevas que ofrecen el proveedor del software actual con el fin de que pueda mejorar el manejo de sus almacenes.

- $\quad$ Actualmente PROASA no cumple con las medidas de seguridad establecidas por las normas. Sin embargo, según lo establecido en las propuestas, la empresa podrá cubrir los requisitos de estas sin problema.

- Las soluciones propuestas requieren de una inversión que se recuperará en menos de 1 año; y además, permitirán a la empresa aumentar sus ganancias y mejorar el servicio de abastecimiento de productos a sus clientes logrando aumentar el nivel de servicios que ofrecen

- La inversión que se requiere está dentro del límite establecido por la gerencia y traen un ingreso marginal importante.

- Finalmente, se considera que la empresa tiene un gran potencial para crecer debido a la cartera de productos que posee y a la confianza que genera en sus clientes ; sin embargo, debe seguir mejorando continuamente con el fin de mejorar sus operaciones. 


\section{RECOMENDACIONES}

- Se debe actualizar los conocimientos de las personas claves de la compañía en términos de gestión y competitividad empresarial.

- Se debe disponer la ubicación de productos en almacenes de la forma más conveniente posible, aprovechando el máximo espacio disponible y regirse de acuerdo a la ley vigente.

- Crear sinergias tanto en empresas del mismo grupo como con proveedores y clientes.

- Implementar las soluciones propuestas, medir su desempeño en la reducción de costos

e implantar un modelo de mejora continua que permita perfeccionar las medidas implantadas.

- Realizar un diagnóstico estratégico para aprovechar oportunidades y mitigar amenazas. Del mismo modo, medir si la empresa va por el camino deseado propuesto en sus objetivos. 


\section{REFERENCIAS}

Alibaba (2016). Carretillas manuales de acero inoxidable. Recuperado de http://spanish.alibaba.com/p-detail/carretillas-manuales-de-acero-inoxidable300002639953.html

Chopra, S. (2013). Administración de la cadena de suministro: Estrategia, planeación y operación. México D.F.: Pearson Educacion.

Instituto Peruano de Economía. (2016). Índice de competitividad regional de Lambayeque 2016. Recuperado de http://www.ipe.org.pe/sites/default/files/u3/incore_2016__lambayeque.pdf

IncaPower. (2016). Modelos de camiones IncaPower. Recuperado de http://www.incapower.com.pe/p/camiones/f68-br-6-5-ton

Mercado libre. (2016). Escalera de madera de 3 pasos y base, herramientas para Industrias y Oficinas. Recuperado de http://articulo.mercadolibre.com.pe/MPE-412009949escalera-de-madera-de-3-pasos-y-base-herramientas-_JM

Estruduque Ltda. (2016). Mezanine. Recuperado de https://www.estruduque.com/productos/mezanine

Tamer Elevadores. (2016). Elevador hidráulico. Recuperado de https://www.tamerelevadores.com/diseños/elevadorhidráulico

Ministerio de trabajo. (2016). Ley 29783 “ Ley de seguridad y salud en el trabajo. Recuperado de https://www.mtc.gob.pe/nosotros/seguridadysalud/documentos/Ley\%20N\%C2\%B0 $\% 2029783 \% 20$ Ley\%20de\%20Seguridad\%20y\%20salud\%20en\%20el\%20Trabajo.p df

Consorcios Santa Ana (2017). Proveedores de Abarrotes Santa Ana SRL. Recuperado de: www.consorciosantaana.com

Proveedores de Abarrotes Santa Ana. (2016). Registro de Ventas. Superintendencia Nacional de aduanas y de Administración Tributaria.

Proveedores de Abarrotes Santa Ana. (2016). Registro de Compras.Superintendencia Nacional de aduanas y de Administración Tributaria. 


\section{BIBLIOGRAFÍA}

Alfaro Salked, D. (2015). Mejora en el Sistema de almacenamiento y despacho de arroz de la empresa Costeño Alimentos S.A.C. (tesis para optar por el título de ingeniero industrial). Universidad de Lima.

Gordillo-Cerruti, R. (2016). Mejora en el proceso de elaboración y gestión e los pronósticos de demanda en una empresa dedicada a la venta de productos de belleza. (tesis para optar por el título de ingeniero industrial). Universidad de Lima.

Krajewski, Lee (2013). Administración de operaciones: procesos y cadenas de suministro. México: Pearson Educación.

Mora, G. L. A. (2012). Gestión logística integral: las mejores practices en la cadena de abastecimiento. Bogotá: Ecoe Ediciones.

Morales Valerio, F. (2015). Mejoras a la gestión del proceso de abastecimiento de insumos clínicos para el hospital San José. (tesis para optar por rl título de ingeniero civil industrial). Universidad de Chile.

Reyes Maquín, G. (2015). Mejora en la distribución de productos a nivel local de una empresa manufacturera de aceituna y sus derivados (tesis para optar por el título de ingeniero industrial). Universidad Católica del Perú. 


\section{ANEXOS}


ANEXO 1: Fotografías de almacén principal

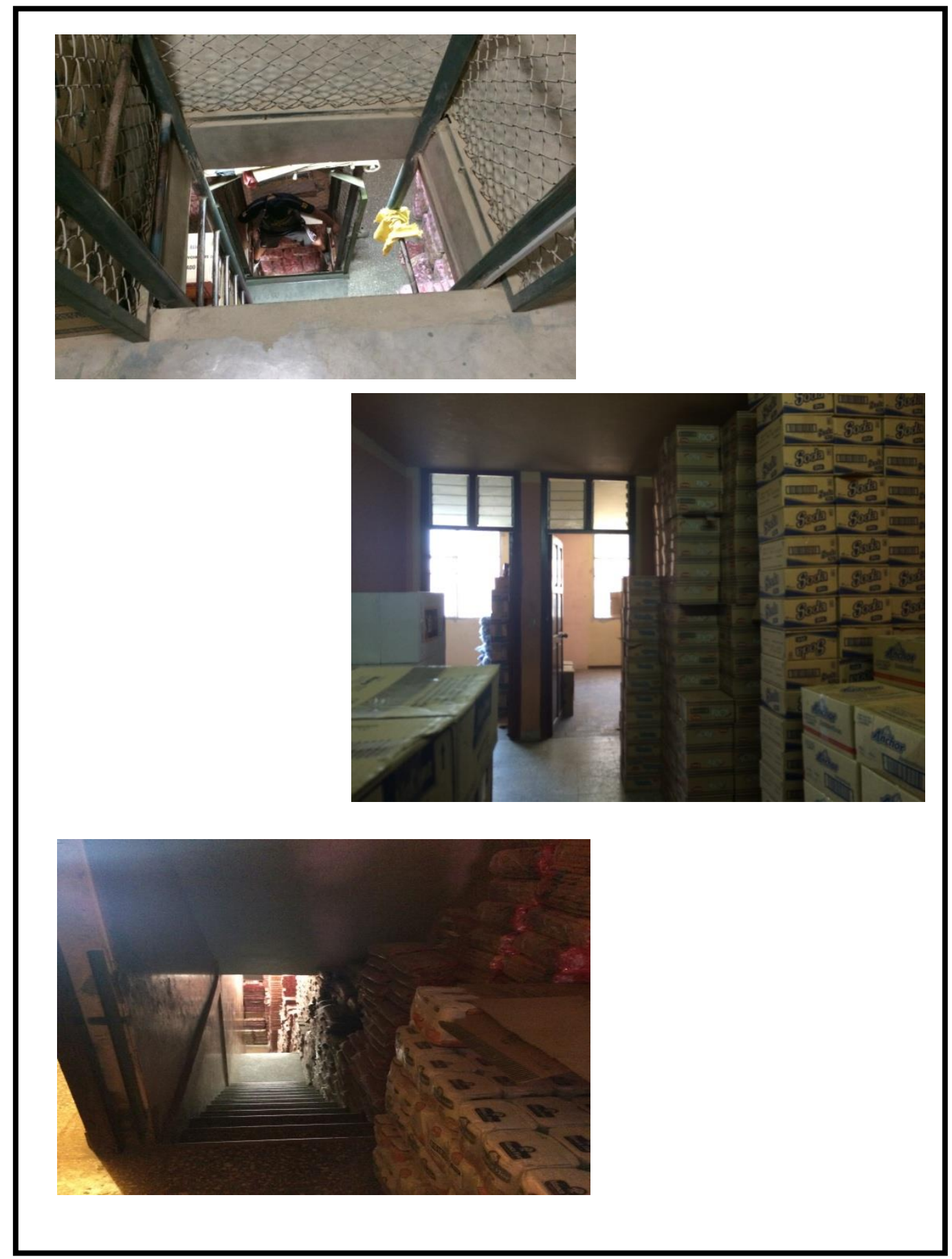

Elaboración propia 


\section{ANEXO 2: Fotografías de almacén auxiliar}

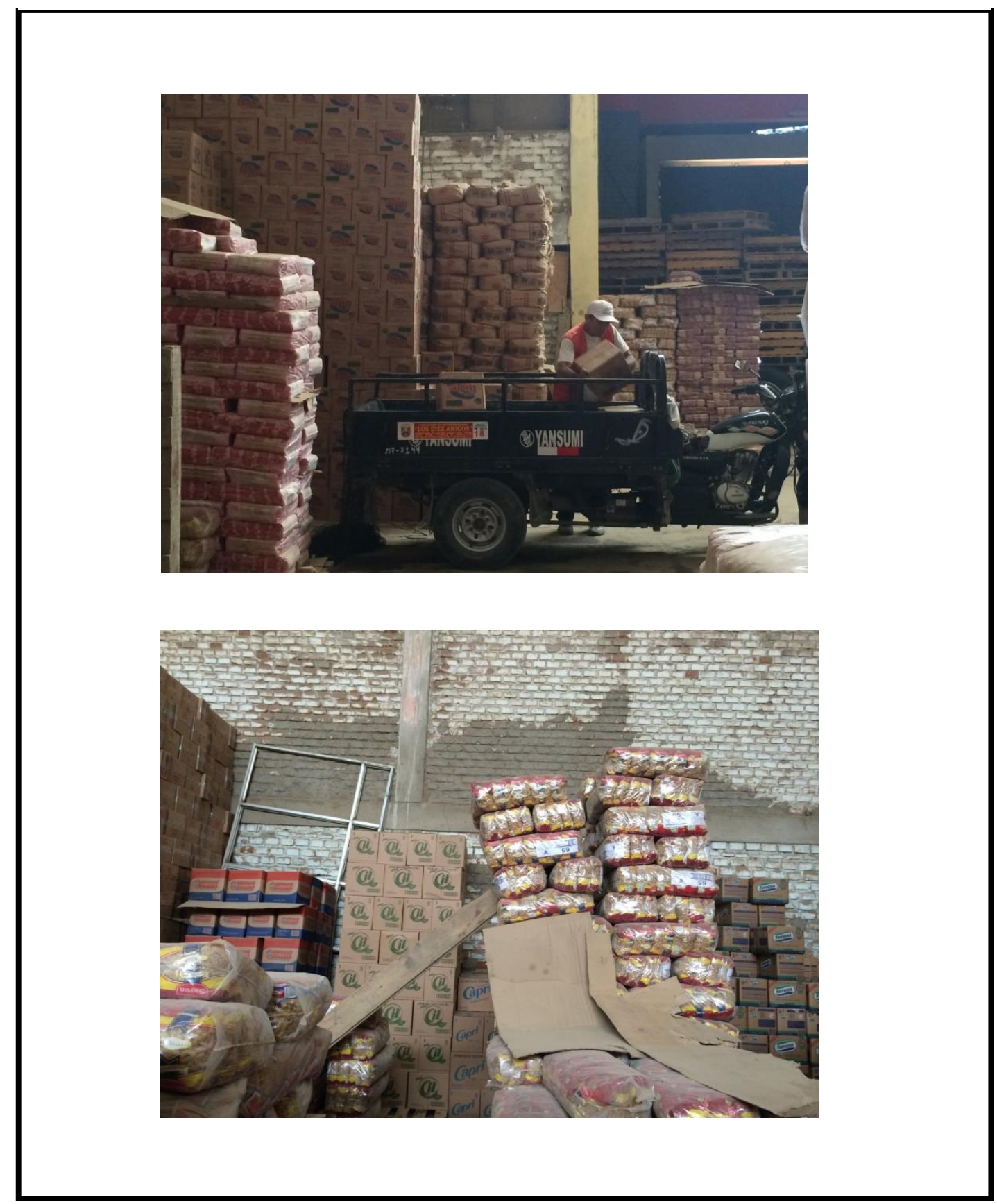

Elaboración propia 


\section{ANEXO 3: Entrevista al encargado de almacén central}

A continuación, se presenta la entrevista al encargado del almacén central de la empresa Proveedores de Abarrotes Santa Ana S.R.L. con el fin de recopilar información en relación a prácticas en almacenes, medición de indicadores, principales problemáticas que la empresa debe enfrentar y las soluciones que se aplican a estas.

El encargado del almacén se llama César Augusto Monja quien viene trabajando durando 7 años en la empresa. Actualmente, se encarga de la recepción y entrega de los productos de consumo masivo que la empresa posee.

\section{Según su experiencia, ¿Cuáles son los problemas frecuentes que encuentra en la gestión del almacén? \\ "Durante mi gestión como encargado, el mayor problema que encuentro es la desorganización que hay en el almacén"}

\section{¿Cuáles cree usted que son las causas principales de estos problemas hallados?}

"La empresa suele pedir gran cantidad de productos cuando no se posee el espacio necesario lo cual provoca que tengamos que ubicarlo en diversos espacios y no en una ubicación exacta.

Por otro lado, debido a que no siempre se compra los mismos productos y las mismas cantidades no se puede establecer una ubicación para cada producto.

Hace falta una planificación por parte del dueño cuando realiza los pedidos”

\section{¿Cómo solucionó o piensa solucionar el problema que ha descrito?}

"Se trata de recibir la cantidad correcta para almacenar en un mismo espacio. La mercadería restante se envía al otro almacén.

Para el otro problema, se busca poner ubicaciones que puedan ser designados a varios productos." 
En cuanto a la gestión del almacén, ¿Cuáles son los indicadores que la empresa posee para medirla? ¿Cada cuánto se miden estos indicadores?

"No se tienen indicadores pero se realiza un conteo del inventario para ver las diferencias que se tiene con el sistema. Esto se realiza mayormente cada 6 meses. Digo mayormente porque es difícil en algunas oportunidades cumplir con esto debido a que se tiene que cerrar tienda para realizarlo y eso significa un día perdido de ventas"

La empresa nos comentó que posee un software que permite obtener manejar las áreas de esta, como el almacén, ¿Cómo le ayuda a usted esta herramienta? ¿Conoce bien las bondades de esta?

"Sólo me ayuda a saber cuánta cantidad de cada producto se poseo actualmente. Sólo me enseñaron eso para que al final del día pueda hacer un conteo rápido de algunos productos en los que tengo dudas si se realizó una entrega correcta al cliente. Por supuesto, también para hacer el inventario que les comenté”.

En nuestras visitas a la empresa, hemos podido apreciar que no se tiene un cuidado especial a los productos. Por ejemplo, hemos visto que se lanzan los productos desde los pisos superiores. ¿Por qué se realiza de esta manera?

"Muy buena pregunta. Existen varios motivos. Entre ellos, tenemos a que debido al gran flujo de clientes que se tiene, se debe despachar lo más pronto a cada cliente para poder atender al siguiente. Por eso, es que los lanzamos desde los pisos superios para evitar la demora que llevarías bajarlo por las escaleras. Además, la empresa no permite que los estibadores de los clientes suban a los pisos superiores por lo que demoraría más entregar el producto al cliente ya que sólo se cuenta con un ayudante en cada piso superior."

Por otro lado, quisiéramos saber \& Por qué se apila los productos a una altura excesiva? "Debido a que no se cuenta con mucho espacio para almacenar las grandes cantidades de pedidos, debemos apilarlo de esa manera “

Finalmente quisiéramos saber si actualmente cuenta con un plan de limpieza y un control del vencimiento de los productos. 
"No se cuenta que ninguno de los dos. Pero si se barre el pasadizo principal todos los miércoles"

Después de haber realizado la entrevista, se puede reconocer los problemas que se tiene actualmente en el almacén central los cuales serán descritos en la tesis. 


\section{ANEXO 4: Entrevista a la encargada de ventas}

A continuación, se presenta la entrevista a la encargada de ventas de la empresa Proveedores de Abarrotes Santa Ana S.R.L. con el fin de recopilar información en relación a las causas de las ventas que se pierden a la semana y cuánto es el ticket promedio de compra.

El nombre de nuestra entrevistada es Jovanny Sosa quien tiene más de 12 años trabajando en la empresa. Se encarga de atender a los clientes, registrar su pedido y entregarlos al encargado de cobranza.

Según su experiencia, ¿la empresa logra satisfacer todos los requerimientos de productos de los clientes? ¿Cuáles son los principales motivos?

"No. Hay veces que el cliente viene por un número determinado de producto que si se tiene en cartera pero como no se tiene la cantidad que busca, se va a buscar en otras empresas vecinas. Otra causa sería que no se cuenta con el producto solicitado. Y otra sería que tenemos alguna diferencia de precio mayor que nuestra competencia. Esta diferenca puede ser hasta de 0.5 céntimos, pero aún así el cliente se retira. Nuestros clientes le toman bastante importancia al precio ya que de esto depende cuánta ganancia tendrán en sus negocios. Otras causas podrían ser que el cliente se encontraba apurado y no se le pudo atender a tiempo o que no se le dé el descuento que espera."

¿ Cuántas personas creen que se dejen de atender a las semana? ¿Podría ponerle un porcentaje de ocurrencia a cada causa mencionada?

“Aproximadamente deben ser unas 40 personas en total por ventanilla. Los porcentajes serían 50\%, 20\%, 25\% y 5\% respectivamente. A las últimas causas que mencioné no son muy frecuentes."

De ese número de personas, ¿podría clasificarlos por tipos de clientes? ¿cuánto es que compran en soles estos grupos según su clasificación?

"Nuestros clientes se pueden clasificar en dos grupos : minoristas y mayoristas. Los minoristas vendrían a hacer las bodegas, restaurants y panaderías. Los mayoristas son los 
mayoristas de los pueblos cercanos en los que no se encuentran distribuidores que los puedan abastecer.Según mi experiencia, los minoristas suelen realizer compras alrededor de S/.500 soles y los mayoristas, de S/.5000 soles."

Según las causas que nos señaló, ¿ cuáles son las causas que podría atribuirle a cada grupo de clientes?

"Definitivamente la primera causa sería para los clientes mayoristas. Como ellos compran grandes cantidades, siempre buscan qu una sola empresa tenga todo su pedido para que no se estén movilizando mucho. Las demás causas las atribuyo a los clientes minoristas debido a que vienen por pocas cosas enctonces siempre buscan precio bajos y productos poco demandantes o que no conviene que la empresa lo venda."

\section{¿Por qué no le atribuye a los mayoristas la causa de diferencia de precios con la competencia?}

"No se la atribuyo a ellos debido a que como ellos son clientes importantes a la empresa se le hace el descuento que ellos desean. Y además, son clientes que buscan factura para sustentar sus compras y poder trasladar su mercadería. Muchas veces el descuento que les dan, se lo dan sin factura en otras empresas.Por ello, es que nos prefieren. Nosotros tal vez. no le demos el descuento que ellos deseen exactamente, pero le damos la factura con el descuento acordado"

Finalmente, según lo observado en nuestras visitas, hemos podido observar que si se les hace falta productos hacen pedidos al otro almacén transportándolos en motos cargueras. ¿Cuántas veces al día realizan al día estos viajes? ¿Cuánto es el costo de estos?

"Aproximadamente realizamos alrededor 5 a 7 viajes al día.El precio de cada viaje es de S/ 15 soles."

Gracias a esta entrevista, se puede reconocer las causas de la fuga de clientes y el número de viajes que se realiza lo cual nos ayudará a realizar los cálculos del monto en soles que la empresa está dejando de percibir. 